Por que usar bancos de dados orientados a objetos?

\author{
Yen Chin Shen
}

DISSERTAÇÃO APRESENTADA

$\mathrm{AO}$

INSTITUTO DE MATEMÁTICA E ESTATÍSTICA

DA

UNIVERSIDADE DE SÃO PAULO

PARA

OBTENÇÃO DO TÍTULO DE MESTRE

EM

CIÊNCIAS

Área de Concentração: Ciência da Computação

Orientador: Professor Dr. Valdemar W. Setzer

São Paulo, julho de 2006 


\section{Por que usar bancos de dados orientados a objetos?}

Este exemplar corresponde à redação final da dissertação devidamente corrigida e defendida por Yen Chin Shen e aprovada pela Comissão Julgadora.

São Paulo, 23 de junho de 2006

Banca Examinadora:

Prof. Dr. Waldemar W. Setzer (orientador) - IME/USP

Prof. Dr. João Eduardo Ferreira - IME/USP

Profa. Dra. Cláudia B. Medeiros - UNICAMP 


\section{DEDICATÓRIA}

Dedico este trabalho de dissertação à minha terra natal, Taiwan, a ilha em que vivi meus anos de aprendizagem até minha formatura. As imagens da infância, a vida na ilha, nunca saíram de minha memória.

Taiwan tem 23 milhões de habitantes, em uma área equivalente a 1/8 da área do Estado de São Paulo, com um PIB aproximadamente metade do brasileiro. Tem seu governo constituído pelo governante eleito democraticamente pelo seu próprio povo. Mas hoje esse país está ameaçado de perder sua soberania, sua liberdade e a sua democracia. Uma das propostas da ONU é manter a paz e a justiça internacionais, mas a minha terra está tão injustiçada que nem a ONU reconhece-a como um país e não a aceita como membro. Conseqüentemente, ela ficou desamparada.

A poderosa China instalou mais de 800 mísseis na fronteira apontando para a ilha e ameaça tomar o seu poder. O mundo está calado por temor ou por interesse comercial com a China; Taiwan tornou-se um órfão internacional.

Escrevo esta pequena mensagem a fim rogar aos leitores que, se um dia essa última injustiça vier a acontecer, façam um gesto de solidariedade para com a minha pobre pátria.

Yen Chin Shen 


\section{AGRADECIMENTO}

É preciso ter muita paciência para orientar um aluno de mestrado com 53 anos de idade e dificuldade em língua portuguesa. O professor Valdemar, um profissional muito competente, paciente e atencioso, passou muitos dias e noites me orientando, explicando e corrigindo erros, até que eu conseguisse finalizar este trabalho. Ele merece meu maior respeito e agradecimento.

Meus pais sempre me incentivaram a estudar, e eu sentia a vontade deles de ver um filho conquistar títulos para honrar a família. É uma pena que eles não estejam viva para ver isso acontecer. Mas a vontade deles transformou-se numa força incansável dentro de mim, que me empurrou para estudar cada vez mais. Portanto, meu segundo agradecimento é para meus pais.

Agradeço a Deus que me deu saúde e condições de poder continuar estudando. No primeiro ano de estudos, sentia tanta dificuldade que até pensava em desistir, mas o sorriso confiante da minha esposa sempre me dava forças para voltar à sala de aula nos dias seguintes. A vontade de querer ser um exemplo para os meus quatro filhos também foi um grande estímulo.

Há mais pessoas que me deram ajuda, tais como o professor Siang, meu primeiro orientador, professores que me deram aulas, colegas de classe que me ajudaram ao esclarecer minhas dúvidas, tantos outros que apesar de não terem sido citados nesta carta, têm minha profunda gratidão.

Muito obrigado.

Yen Chin Shen 


\section{Introdução}

\subsection{Histórico}

A tecnologia de programação com orientação a objetos $(\mathrm{OO})$ está cada dia mais popular. Hoje, muitas indústrias de software estão desenvolvendo projetos usando linguagens orientadas a objetos (LOOs). Na engenharia de software, as LOOs favorecem o desenvolvimento de projetos de grande porte porque facilitam o trabalho em equipe [MCC 04]. Os usos de heranças de classes, de práticas adequadas de polimorfismo, reaproveitamento dos códigos-fonte, encapsulamento das implementações das classes e métodos, facilitam muito a vida dos programadores, não só para quem desenvolve, mas também para quem lê o programa com a finalidade de dar-lhe manutenção. Com isso, obtém-se maior eficiência no desenvolvimento, nos testes e nas manutenções futuras.

Isso quanto às linguagens de programação, tais como $\mathrm{C}++$, Java, SmallTalk e VB.NET. Na área de Bancos de Dados também surgiu o Banco de Dados Orientado a Objetos (BDOO), mas não foi tão aceito como as LOOs. Hoje, os Bancos de Dados Relacionais (BDRs) ou Bancos de Dados Objeto-Relacionais (BDORs, uma extensão do modelo relacional de dados para abarcar algumas das características da orientação a objetos) ainda ocupam a maior parte do mercado, sendo que muitos gerenciadores da segunda categoria são utilizados como puramente relacionais devido à falta de informação sobre as vantagens da OO.

Como os BDRs surgiram na década de 70 e as LOOs na década de 80, foi natural adaptar os BDRs existentes às LOOs. As classes são declaradas no ambiente de LOO e os dados são armazenados nas tabelas de um BDR. Se no ambiente de processamento necessitar-se um objeto qualquer já existente, o procedimento deve ser o seguinte:

- Instanciar um objeto vazio da classe do objeto desejado;

- Extrair os dados desse objeto do BDR com SQL;

- Atribuir os dados ao objeto vazio;

Depois de usar e atualizar esse objeto, é necessário salvá-lo no BDR:

- Salvar os atributos do objeto na tabela do BDR item por item com SQL;

- Se houver junções de tabelas será necessário repetir o procedimento anterior em cada tabela;

- Destruir o objeto. 
Esses processos são necessários porque é preciso armazenar o objeto na forma de uma tabela do BDR. Uma colocação feita pela escritora e comentarista industrial americana Esther Dyson, citada em [KIR 03] é:

Usar tabelas para armazenar objetos é como dirigir seu carro para casa e desmontá-lo na garagem. Ele pode ser montado novamente na manhã seguinte, mas pergunta-se eventualmente se essa é a forma mais eficiente de estacionar um carro.

Obviamente, aqui está havendo uma comparação indevida, pois um carro é algo físico e, portanto, montá-lo e desmontá-lo exige muitas ações físicas trabalhosas e demoradas. Uma tabela relacional é algo virtual, podendo-se fazer uma única vez um programa para inserir nela os dados e um outro para obtê-los, de modo que não haverá mais trabalho para isso - o trabalho é do computador executando esses programas sempre que necessário. De qualquer modo, a metáfora é pertinente, pois mostra muito bem uma diferença essencial de visão entre o modelo relacional e o orientado a objetos.

No Modelo Relacional Normalizado (MRN), que foi criado na década de 70, cada célula de uma tabela pode armazenar um só dado elementar, para facilitar a organização de dados [COD 70, 79]. Então, para armazenar os dados de um certo livro que tem 2 autores e 3 assuntos, por exemplo, ter-se-á que representá-lo em 3 tabelas (Livros, Autores e Assuntos) com 2 chaves estrangeiras e um total de 6 tuplas [SET 05]. Se o BD permitisse dados multivalorados [SET 05], uma tabela seria suficiente para armazenar todos os dados dos livros, sem a necessidade de chaves estrangeiras e operações de junção. A complicação não advém somente da operação de junção de tabelas, mas também de uma estrutura de dados mais complexa. Afinal de contas, é muito mais fácil ver os dados numa só tabela (ou objeto) do que em três, além de que, ao se examinar um livro no mundo real, ele não é picado em várias partes!

Até a década de 70, as linguagens de programação trabalhavam com os tipos de dados primitivos, ou seja: integer, string, date, float, char - a menos da linguagem COBOL que admitia variáveis compostas mas não a declaração de tipos, como apareceu em ALGOL 68 e em Pascal. Baseado na teoria dos tipos de dados abstratos (Abstract Data Types), em que um tipo era definido matematicamente por meio da definição do seu 
conjunto de valores e das operações matemáticas de manipulação desses valores, surgiu também a idéia de introduzir essa noção nas linguagens de programação. Com isso, criou-se a noção de classe, englobando os tipos (ou classes) dos dados e os métodos que os processam. Por exemplo, um carro pode ser representado por um objeto; ele pode ter um motor que também é um objeto. Por sua vez, o motor contém 4 pistões, virabrequim, anéis, carcaça, parafusos etc. que também são objetos.

Em um BDR, para se obter os dados de uma pessoa e seu cônjuge ou dependentes, é preciso fazer junções de tabelas. Para a composição de materiais de um carro é necessário formar a estrutura de um material fazendo-se sucessivas junções, percorrendo a árvore de composição. Modelar os dados em forma de objeto fornece uma visão mais simples do que em tuplas de tabelas, auxiliando o desenvolvimento de sistemas, como será mostrado neste trabalho.

\subsection{Objetivos}

Os BDOOs foram criados para armazenar os dados na forma de objetos, declarando-se classes com "tipo persistente" (ao contrário das LOOs, nas quais ao fim do processamento de um programa os valores de todas suas variáveis eram perdidos). Com um simples comando o objeto é salvo, como um carro que se estaciona em garagem sem desmontá-lo. Além disso, os BDOOs permitem a representação de dados complexos, como os compostos e multivalorados, eliminados por Codd do modelo relacional "normalizado", que foi o usado em quase todos os gerenciadores de BDR (GBDR) [COD 70].

O objetivo deste trabalho é demonstrar as vantagens de se empregar BDOOs do ponto de vista de desenvolvimento, isto é, não entraremos em considerações de eficiência de processamento. Mostraremos que a visão dos dados pode ser global, e mostraremos como modelar e implementar um BDOO usando dados compostos e multivalorados. Para isso, desenvolvemos um catálogo de estruturas com objetos, derivadas das estruturas do modelo conceitual de entidades e relacionamentos. Veremos que o uso das classes da $\mathrm{OO}$ pode levar à eliminação das chaves estrangeiras e das junções de tabelas. Com isso, fica bem mais fácil visualizar e manipular estruturalmente os dados, mantendo-os mais próximos do mundo real. Os códigos ficam bem mais documentados e facilita o 
desenvolvimento de software de grande porte, ou seja, facilita o desenvolvimento em equipe.

\subsection{Metodologia}

É importante salientar que este trabalho reflete nossa experiência na implementação de uma grande aplicação (ver cap. 5), um sistema administrativo comercial (isto é, foi instalado em empresas e está funcionando), contendo cadastros (clientes, vendedores, produtos, fornecedores), emissão de pedidos de vendas, notas fiscais, controle de estoques, comissões de venda, pedidos de compras, despacho e recebimento de material. Começamos o desenvolvimento a partir da confecção de um MER (Modelo de Entidades e Relacionamentos) e fomos introduzindo novas representações gráficas do modelo OO. Para esse sistema foram feitas implementações no gerenciador de BDOO (GBDOO) Caché empregando como LOOs Caché Objectscript, Java e CSP (Caché Server Page). Durante essas implementações, a fim de acelerar o desenvolvimento e melhorar a documentação, desenvolvemos padrões de métodos e uma nomenclatura de classes, objetos e outros elementos, aqui apresentados.

Salientamos também que este trabalho deriva de nossa experiência de mais de 15 anos em desenvolvimento, implantação e manutenção de sistemas com linguagens estruturadas e BDRs, tais como MySQL 4.0, 5.0, Access 2000, SQL Server 2000 e Oracle 7.0. As comparações apresentadas neste trabalho são baseadas nessas experiências de desenvolvimento, bem como em estudos e testes dos BDORs PostgreSQL 8.0 e Oracle 8.0 e dos GBDOOs FastObjects e GemStone 3.0.

\subsection{Abreviaturas e notações}

Usaremos as seguintes abreviaturas:

$\begin{array}{ll}\text { BD } & \text { Banco de Dados } \\ \text { BDR } & \text { Banco de Dados Relacional } \\ \text { BDOO } & \text { Banco de Dados Orientado a Objetos } \\ \text { BDOR } & \text { Banco de Dados Objeto-Relacional } \\ \text { GBD } & \text { Gerenciador de Bancos de Dados } \\ \text { GBDOO } & \text { Gerenciador de Bancos de Dados Orientados a Objetos }\end{array}$


GBDOR Gerenciador de Bancos de Dados Objeto-Relacionais

GBDR Gerenciador de Bancos de Dados Relacionais

LOO Linguagem Orientada a Objetos

MER Modelo de Entidades e Relacionamentos

OO Orientado a Objetos ou Orientação a Objetos

As seguintes notações serão empregadas nos programas aqui apresentados:

- Nomes de classes (da OO): sempre iniciados com a letra $\mathrm{C}$ como, por exemplo, CVendedor.

- Nomes de objetos: sempre iniciados com a letra O como, por exemplo, OVendedor, indicando um objeto da classe CVendedor.

- Nomes de atributos de tabelas e de objetos: sempre iniciadas com letra maiúscula, as restantes em minúscula como, por exemplo, Vendedor (cf. [SET 05]).

- Nomes de atributos chaves estrangeiras de tabelas do modelo relacional: sempre iniciadas com CE_como, por exemplo, CE_Cliente_Id.

- Nomes de variáveis de programa, dentro de comandos em SQL ou OQL (Ver P.9): precedidas por \%, como por exemplo \%Oid.

- Nomes de variáveis de programas: sempre iniciadas com letra minúscula como, por exemplo, nomeDoVendedor.

\subsection{Organização}

Este trabalho está organizado como se segue.

No cap. 2 levantamos 6 características gerais dos BDOOs que são essenciais para poder implementá-los com a com a proposta que apresentaremos neste trabalho.

No cap. 3 introduzimos, por meio de exemplos, uma notação gráfica para representar os casos de atributos que são objetos e mostramos implementações de estruturas do MER em um BDOO, comparando-as com as implementações em BDRs.

No cap. 4 fazemos uma abstração dos exemplos, apresentando um catálogo de esquemas abstratos de implementações do BDOO a partir do MER.

No cap. 5 mostramos um sistema administrativo comercial desenvolvido por nós em BDOO Caché aplicando os esquemas aqui descritos. 
No cap. 6 estendemos o trabalho de Sérgio Linares [LIN 05], estabelecendo um método de análise de requisitos de software para BDOO, partindo de um MER e de protótipos de telas e relatórios.

No cap. 7 apresentamos as conclusões deste trabalho e rebatemos críticas sobre os BDOOs feita no livro de Ramakrishnan [RAG 02], para mostrar que vale a pena usar esse tipo de BD.

Na bibliografia, colocamos vários textos que não foram citados neste trabalho, mas que foram consultados durante esta pesquisa. 


\section{Características necessárias dos BDOOs}

Existem vários GBDOOs no mercado. Neste trabalho não vamos nos concentrar em BDORs, dedicando-nos a uma comparação entre os modelos de BDRs e BDOOs. Para isso, empregaremos as seguintes características dos GBDOOs, essenciais para modelar os dados numa forma totalmente orientada a objetos como propomos neste trabalho.

Característica 1: Armazenagem dos dados na forma de objetos. As classes devem poder ser declaradas como persistentes, e seus objetos geralmente são salvos no repositório com um só comando tipo save. Não importa como o GBDOO organiza os objetos internamente; o salvamento de um objeto independe da complexidade de sua estrutura. Em comparação, os BDR e BDOR salvam os dados armazenando-os como se formassem um conjunto.

Característica 2: Todos os objetos armazenados em um BD devem ter um Identificador de Objeto (Object Identitifier, Oid), gerado automaticamente pelo gerenciador com valores únicos. Os objetos podem ser obtidos pelo valor de seu identificador e são apresentados na forma de um objeto (e não um conjunto de dados, como no GBDR ou GBDOR). O processo de montar um objeto a partir de um conjunto de dados fica para o gerenciador.

Característica 3: Deve ser permitido declarar as classes com atributos do tipo de classes declaradas anteriormente, ou seja, permitir que o próprio programador crie suas estruturas de dados, o que não é possível nos BDR normalizados. Esse uso de objetos complexos foi uma das maiores motivações para a introdução dos BDOO. Se o BDR fosse não-normalizado, a motivação teria que ser outra, usando as características da $\mathrm{OO}$, como encapsulamento, por exemplo [SET 05].

Característica 4: Objetos devem poder receber outros objetos como parte de seus dados. Um objeto armazenado em um BDOO repassa o Oid para o objeto solicitante como referência. Os objetos podem compartilhar os dados de um objeto armazenado. (Esta característica é explicada na fig. 1 junto com a característica 5. Ver as explicações depois dessa figura.)

Característica 5: Resolução de Objetos. Um objeto deve poder ser resumido pelo seu Oid, isto é, por meio desse identificador obtêm-se todos os dados do objeto. Quando 
um usuário precisa de dados de um objeto que contém outros objetos, estes são colocados à disposição automaticamente. Isso é chamado, no GBDOO FastObjects, de Resolução de Objetos (Object Resolution). A vantagem disso é que um objeto pode conter muitos objetos dentro dele, mas estes só são trazidos para memória RAM quando isso é solicitado. Este processo é chamado em FastObjects e no Caché de Lazy Loading.

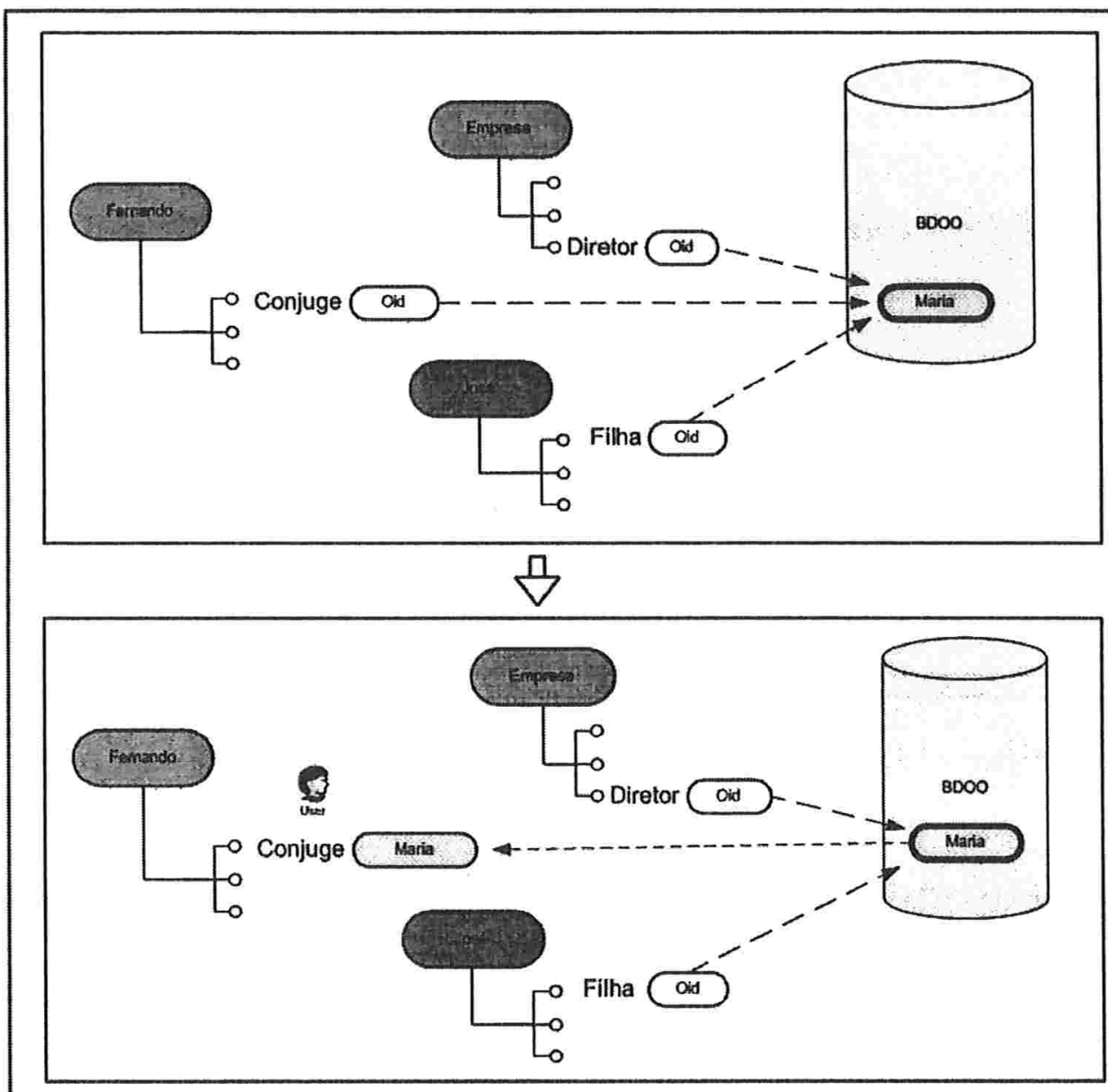

Fig.1 Compartilharmento de dados entre os objetos e Resoluçăo de Objetos

$\mathrm{Na}$ fig. 1 exemplificamos as características 4 e 5 . O objeto Fernando tem o objeto Maria representando os dados de seu cônjuge; o objeto José tem o objeto Maria representando os dados de sua filha, e o objeto Empresa tem o objeto Maria representando os dados da diretora da empresa; note-se que Maria é o mesmo objeto em todos os casos. Um GBDOO armazena o objeto Maria no seu repositório. Os 3 outros objetos só têm o Oid do objeto Maria como referência nos atributos correspondentes. 
Quando o usuário solicita os dados do cônjuge do objeto Fernando, o gerenciador repassa-lhe uma cópia do objeto Maria. Houve assim uma resolução de objetos. Para o usuário é como se um objeto contivesse efetivamente o outro. Note-se que em um BDR, em lugar dos Oids ter-se-ia a chave da tupla dos dados de Maria. Exibindo-se a tupla de Fernando, apareceria a chave de Maria. No caso do BDOO, exibindo-se o objeto Fernando, todo o objeto Maria fica disponível - é como se a junção das duas tuplas tivesse sido sempre executada; no caso, o objeto Maria poderia ainda conter outros objetos, que estariam também disponíveis ao se exibir os dados de Fernando.

Um exemplo de resolução de objetos é a maneira como o MS Word insere figuras em um texto. Pode-se observar que, ao se passar para uma página com uma figura, esta leva algum tempo para aparecer; isso significa que a figura não está dentro da página, havendo nesta apenas uma referência (ponteiro) àquela.

Característica 6: Um GBDOO deve ter uma Object Query Language (OQL), que é uma linguagem para manipular os objetos armazenados no BDOO. Foi proposto pela organização Object Data Management Group (ODMG) um padrão de OQL (que recebeu esse mesmo nome), baseada em SQL [KIR 03, FON 05]. Como cada BDOO tem sua forma de armazenar e gerenciar os objetos, é difícil fazer uma padronização de uma linguagem de manipulação, de modo que os GBDOOs não seguiram estritamente a proposta do ODMG. No entanto, todas essas linguagens são semelhantes à SQL e são eficientes nas manipulações dos objetos, tais como obtê-los, armazená-los, alterá-los, navegando com e nos objetos. 


\section{Modelagem em BDOOs}

Pelas as características acima apresentadas, percebe-se que o modelo de um BDOO é muito diferente de um BDR ou de um BDOR. Portanto, é natural que haja muitas diferenças na modelagem dos dados e na sua implementação. É inadequado avaliar o modelo de BDOO sob o ponto de vista dos padrões do BDR ou do BDOR. Se a modelagem for feita no padrão de um BDR normalizado, teremos um caso análogo à metáfora apresentada acima de chegarmos cada dia em casa, e desmontarmos o carro para guardar as peças em prateleiras em algum cômodo. Essa avaliação, transpondo os paradigmas de um tipo de modelo para outro pode trazer problemas equivocados. Usando a nossa metáfora, isso equivaleria a mudarmos para uma nova casa com garagem sem prateleiras, não sabendo então o que fazer com o carro, começando por criticar a falta de prateleiras.

Para introduzir nossa proposta de modelagem e representação gráfica, vejamos alguns exemplo do MER e suas modelagens em um BDR e um BDOO. Neste capitulo mostramos também como é feita uma busca de um objeto em um BDOO. No próximo capitulo mostramos, de maneira abstrata e geral, vários casos de estruturas do modelo conceitual de Entidades e Relacionamentos (MER), e como elas seriam implementadas em um BDR e como podem ser implementadas em um BDOO.

\subsection{Busca de um objeto}

Na busca de uma tupla de um BDR ou de um BDOR com SQL é utilizado o comando select, que retorna um conjunto de dados (tuplas).

Em um BDOO também pode-se trabalhar do mesmo jeito da SQL de um BDR, mas seria mais coerente e eficiente buscar os dados em forma de objetos. É como buscar um carro em sua totalidade e não um conjunto de peças. A forma de busca de um objeto geralmente é feita usando-se seu Oid. A busca de um objeto pelo seu Oid é muito eficiente, com custo de tempo de T(1), ou seja, constante [KIR 03, FON 05, COR 01].

Por exemplo, numa pseudo-linguagem semelhante à OQL do GBDOO Caché a busca de um objeto OCarro poderia ser feita com (para maior clareza, denotaremos as funções embutidas na linguagem como se fossem palavras reservadas, isto é, em negrito): 
OCarro $=$ Class (CCarro). OpenId (\%oid);

OCarro é um objeto instanciado pertencente à classe CCarro. OpenId é uma função que faz a invocação de um objeto, cujo Oid é o valor da variável oid. A notação \%oid será usada neste trabalho para indicar, em um comando em SQL ou OQL, que se trata de uma variável do programa, externa a esse comando.

É necessário ter-se o valor do Oid de OCarro para poder fazer esta invocação. Se ele não for conhecido, seria necessário usar um comando em SQL (que é imersa na OQL) para achar o Oid, por exemplo:

select Oid from CCarro where placa = "CzD9999"

Seguindo-se uma invocação de OCarro pelo Oid obtido.

Uma alternativa mais eficiente é declarar o próprio Oid como um atributo-chave do objeto OCarro. Portanto, nos exemplos de BDOO a seguir, a busca de um objeto sempre envolve um Oid, a fim de facilitá-la.

\subsection{Relacionamento 1:N}

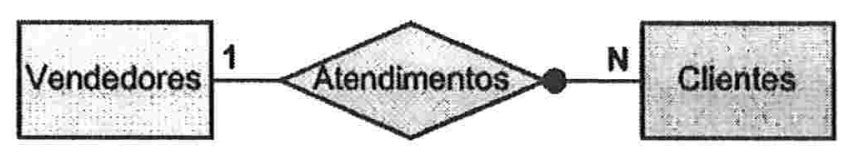

Fig. 3.2-1 Relacionamento 1:N

$\mathrm{Na}$ fig. 3.2-1 temos um exemplo de um relacionamento 1:N entre Clientes e Vendedores. Cada cliente é atendido somente por um vendedor e um vendedor pode atender um número qualquer de clientes. A bolinha indica que o relacionamento Atendimentos é total em Clientes, isto é, não há cliente cadastrado sem que se tenha um vendedor atribuído a ele. A implementação em um BDR é demonstrada na fig. 3.2-2 (usando a notação de [SET 05] ) 


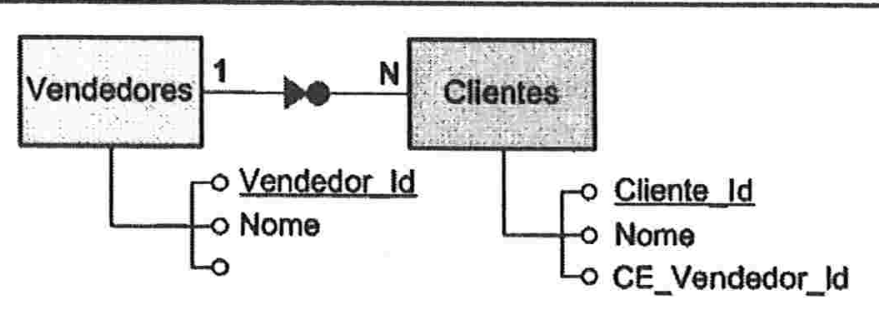

Fig. 3.2-2 Implementação de relacionamento 1:N em um BDR

Para implementar a ligação lógica 1:N, é colocada uma chave estrangeira CE_Vendedor_Id na tabela do lado $\mathbf{N}$ (Clientes) indicando a chave do vendedor que faz o atendimento. A totalidade da ligação lógica da fig. 3.2-2 é implementada por uma declaração de integridade referencial. Para obter dados completos de um cliente do BDR, suponhamos que o valor de seu identificador tenha sido atribuído a uma variável cid do programa. É preciso fazer a junção das tabelas Clientes e Vendedores usando a chave estrangeira da primeira. O comando em SQL para esta consulta seria:

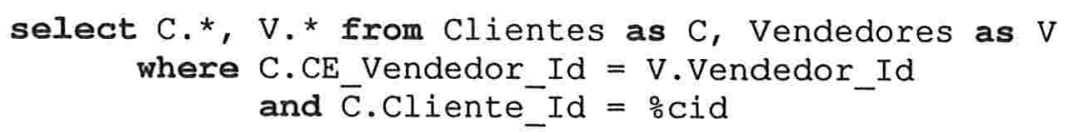

A implementação em um BDOO é completamente diferente; uma possibilidade é mostrada na fig. 3.2-3. Os retângulos CCliente e CVendedor são classes persistentes. Usaremos um retângulo arredondado como OVendedor para indicar a instanciação de um objeto, no caso, da classe CVendedor. Uma classe é essencialmente um tipo de dados (mais os métodos), portanto expressamos seu nome no singular (em outras palavras, a classe em si não é um conjunto, ao contrário dos nomes de tabelas no BDR [SET 05]). Indicamos um atributo que é uma chave sublinhando seu nome (como Oid).

A classe CCliente tem um atributo Vendedor, da classe CVendedor. O valor assumido por esse atributo é um objeto OVendedor. Devido à totalidade do relacionamento Atendimentos da fig. 3.2-1, o atributo Vendedor de CCliente é declarado como obrigatório (por exemplo, no GBDOO Caché isto é feito com a cláusula required). 


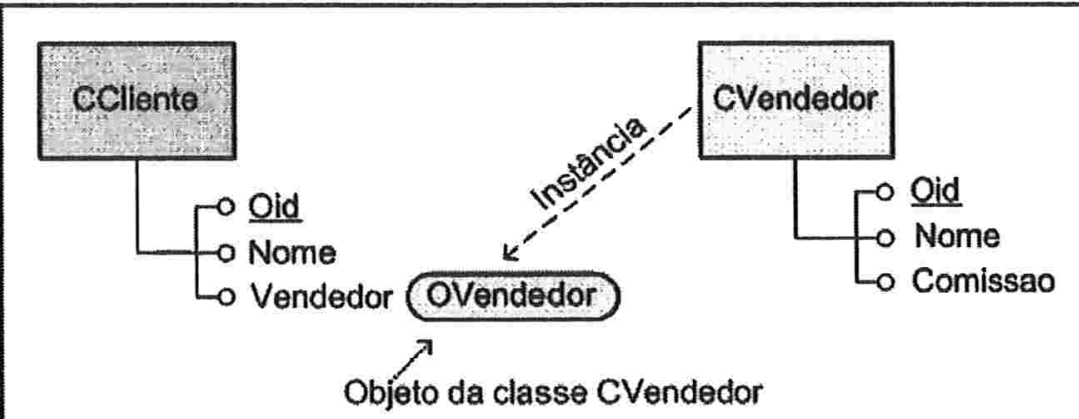

Fig. 3.2-3 Implementação em um BDOO

As declarações das estruturas do exemplo da fig. 3.2-3 poderiam ser as seguintes, em uma pseudo-linguagem baseada em OQL:

Declaração das classes CCliente e CVendedor:

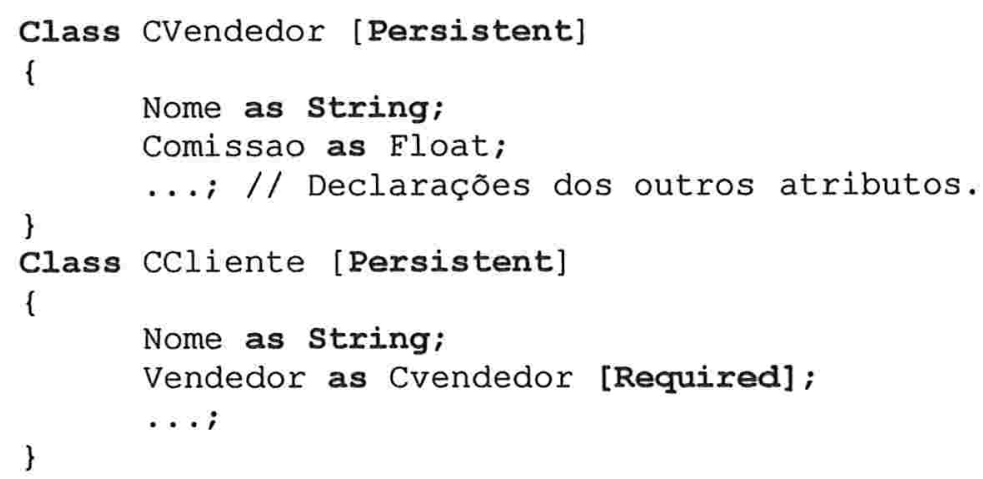

Note-se que não foi preciso declarar os atributos Oid, pois supomos que sejam gerados pelo sistema, como é em geral o caso dos GBDOOs.

Método de inclusão de um novo cliente:

\{

// Comandos para estabelecer a conexão com o BD:

-..;

// Instanciação de um objeto ocliente, da classe cCliente: oCliente = new CCliente;

/* Invocação de um objeto ovendedor armazenado no repositório do BDOO, cujo valor de oid foi atribuído a \%vid; nesta operação, o objeto OVendedor funciona como uma cópia do objeto que invocamos: * / OVendedor $=$ Class $($ CVendedor $)$. OpenId $(\%$ vid $)$;

// Atribuição do objeto ovendedor para o atributo Vendedor de oCliente ocliente. Vendedor = OVendedor;

// As operações acima foram sintetizadas na fig. 3.2-3. 


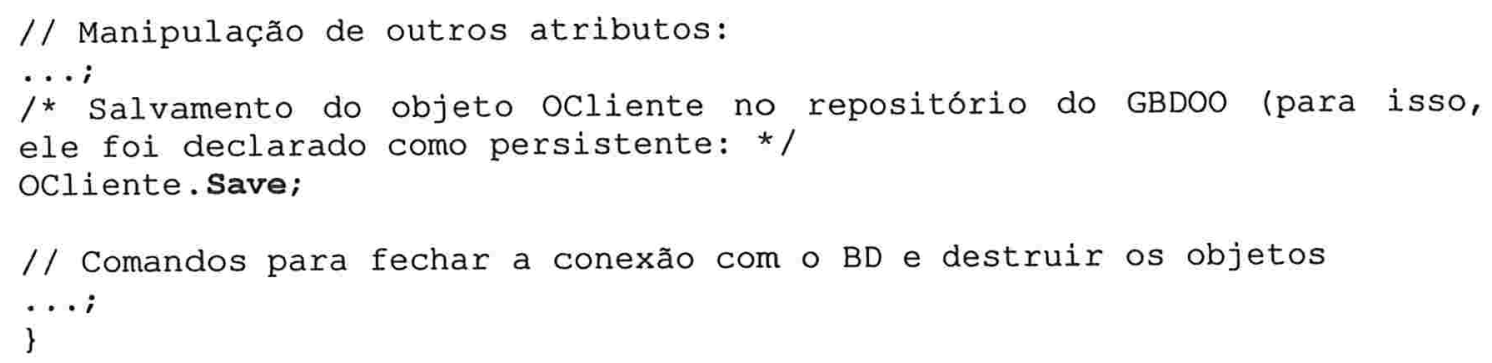

Seguem comandos em OQL para se obter o nome do vendedor que atende o cliente cujo Oid foi atribuído à variável \%cid. Existem pelo menos três formas para fazer essa consulta.

Forma 1: Invocar o objeto OCliente usando o valor de \%cid.

OCliente $=$ Class (CCliente) . OpenId (\%cid);

/* nomeDovendedor é uma variável local do programa, que receberá o nome procurado: * /

nomeDoVendedor $=$ ocliente. Vendedor. Nome;

Forma 2: Usar OQL em forma de SQL obtendo o valor de um atributo.

select Vendedor. Nome from CCliente where Oid = \%cid;

Com isso, obtém-se o nome do único vendedor com esse identificador Oid. Mas, em SQL, o resultado de um comando select é um conjunto de dados; portanto, os GBDOOs têm em geral uma classe especial, que contém esse tipo de resultado. Por exemplo, no GBDOO Caché essa classe é a Resultset; no FastObjects é a classe result-set, no GemStone é a classe result, todos semelhantes ao resultset da Java ou dataReader da VB.NET.

Note-se que CCliente é o nome de uma classe; quando um nome de uma classe é usado dentro de um comando em SQL, os GBDOOs tratam esse nome como se fosse o nome de uma tabela do modelo relacional; cada objeto da classe faz o papel de uma tupla dessa tabela, e vice-versa. Portanto, tudo se passa como se a cada tupla fosse associado um Oid. Continuemos o programa.

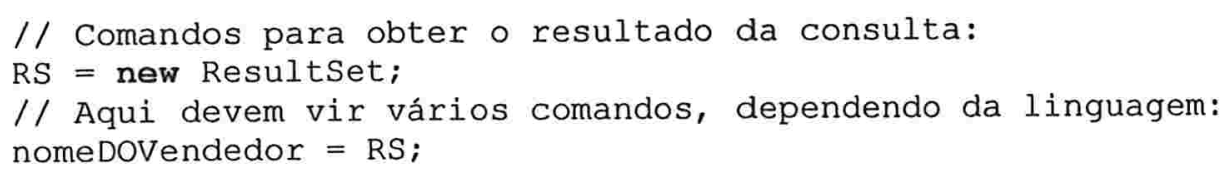


/* RS é um conjunto de dados; aqui deve vir um loop para obter o primeiro campo de dados */

Forma 3: Usar OQL em forma de SQL obtendo-se o Oid de uma tupla.

select Vendedor from CCliente where Oid $=$ \%cid;

Nesse caso o resultado será um (único) Oid, e não um objeto OVendedor, como no caso anterior. Para obter nome do vendedor é necessário fazer mais uma invocação pelo seu Oid. Mas antes disso é preciso usar, no caso do Caché, Resultset para obter o resultado da consulta. Continuando o programa:

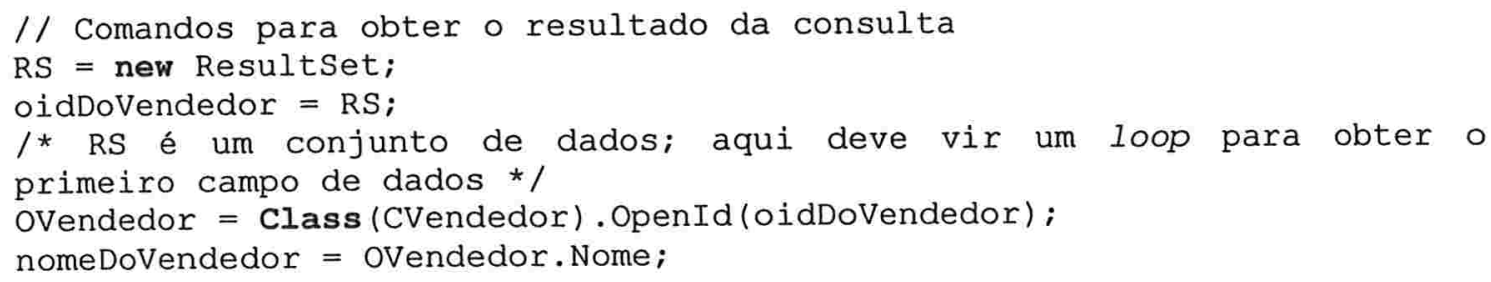

Evidentemente, a forma 1 é a mais simples e a que mais usamos nas nossas aplicações usando BDOO; assim, permanecemos nos conceitos da OO. É como entrarmos no carro e dirigimo-lo para sair da garagem sem precisar fazer a sua montagem prévia.

Uma consulta em OQL como "listar os clientes que o vendedor João atende", na implementação da fig. 3.2-3 poderia ficar:

select * from CCliente where Vendedor.Nome = "João"

Esse comando resulta numa varredura de todos os objetos da classe CCliente e custa $\mathrm{T}(\mathrm{n})$. Os resultados são recebidos como um conjunto de objetos da classe ResultSet.

Vejamos a ligação entre CCliente e CVendedor da fig. 3.2-3, na qual Vendedor é um atributo de CCliente. Criamos uma representação dessa ligação na fig. 3.2-4, onde o atributo Vendedor fica dentro do objeto OCliente e demonstrando uma visão bem mais estrutural. Essa representação gráfica, com a expansão de um atributo que é uma classe, será denominada de visão estrutural. Com esta visão, a implementação de um BDOO fica mais fácil e, certamente, bem mais documentada. Veremos isso mais adiante em detalhe. 


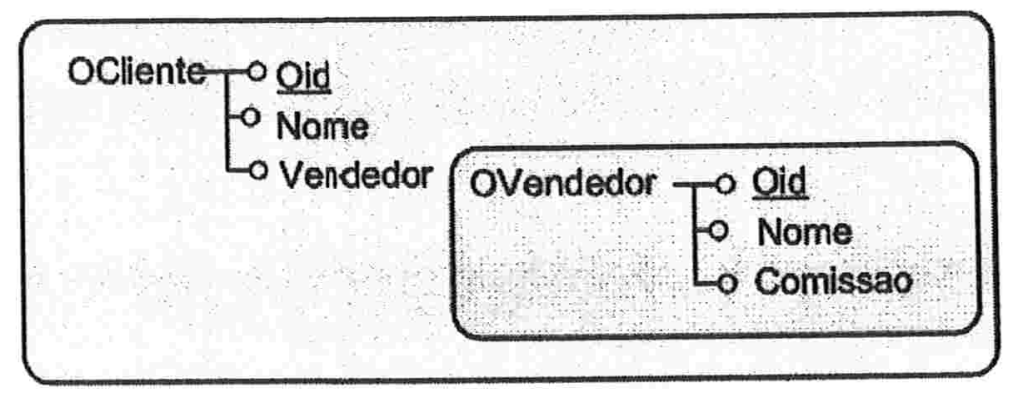

Fig. 3.2.4 Visão Estrutural da Fig. 3.2.3

Em um BDOO, geralmente há várias opções de implementação (como, aliás, é o caso de implementação de relacionamentos em um modelo relacional não-normalizado [SET 05]). No caso da fig. 3.2-3, uma segunda implementação seria colocar na classe CVendedor um atributo Clientes da classe CCliente como demonstrado na. fig. 3.2-5.

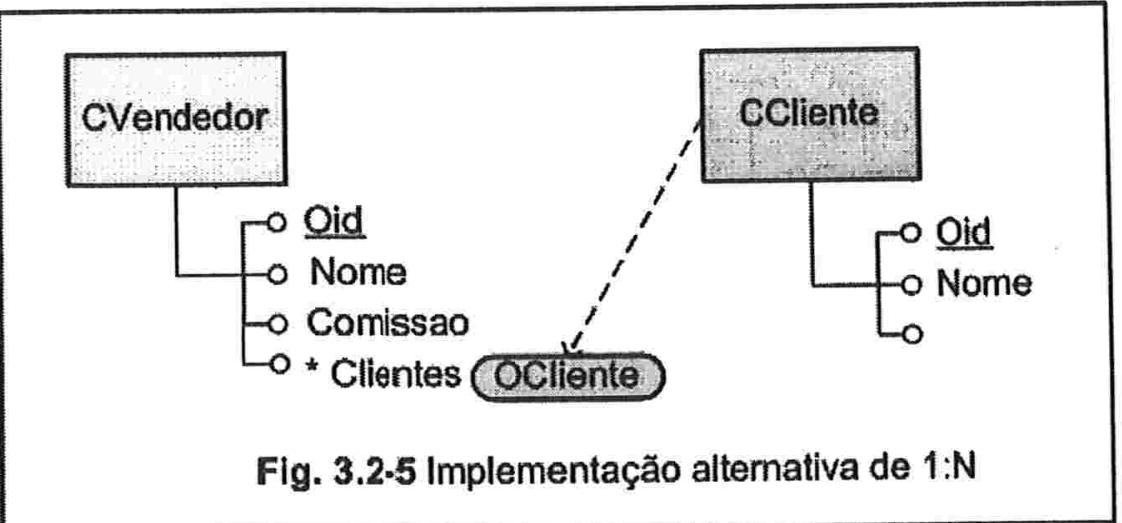

Como um vendedor pode ter vários clientes (ligação 1:N), o valor desse atributo seria um conjunto de objetos OCliente (um conjunto funciona como um atributo multivalorado, que é representado geralmente por um asterisco [SET 05], como fizemos na fig. 3.2-5).

Denominaremos aqui de coleção um atributo que é um conjunto, seguindo o padrão das LOOs SmallTalk, Java e Caché (de collection).

A visão estrutural da fig. 3.2-5 é demonstrada na fig. 3.2-6. 


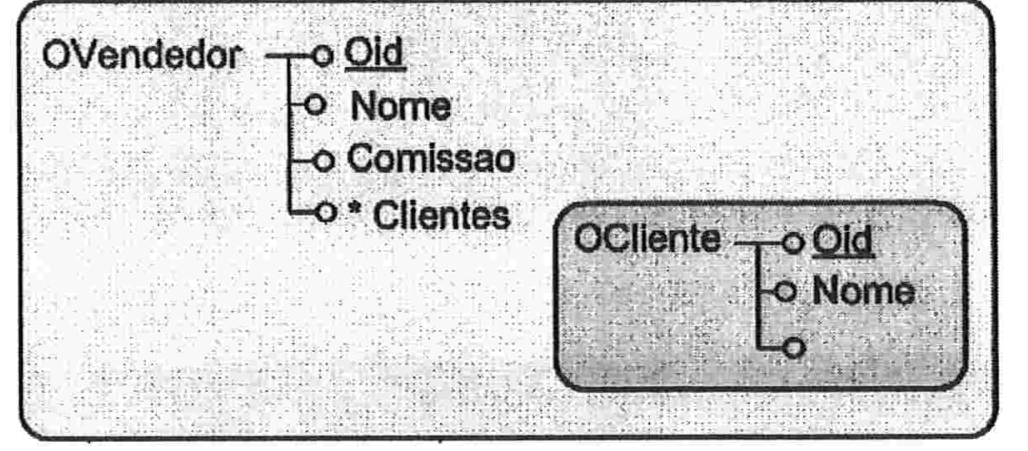

Fig. 3.2-6 Visão Estrutural da Fig. 3.2-5

Em Caché, uma coleção é declarada como um array ou uma lista (list). Por exemplo, no caso da fig. 3.2-5 teríamos:

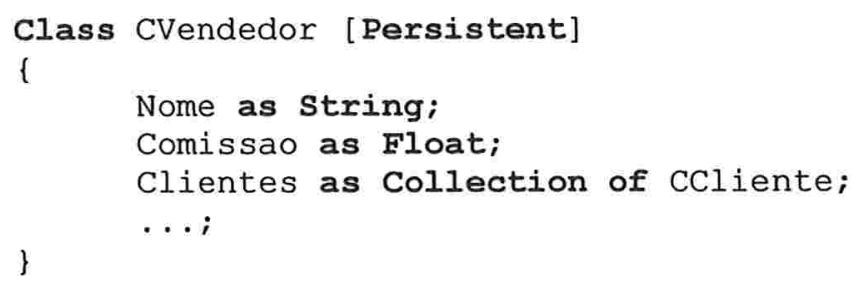

Usando as declarações de CCliente e CVendedor vistas (V. fig. 3.2-3), a implementação da consulta "listar os clientes que o vendedor João atende" fica bem mais simples (supomos que o Oid do vendedor foi atribuído a \%vid):

OVendedor $=$ Class (CVendedor). OpenId (\%vid);

O objeto OVendedor contém os dados do próprio João; para listar os nomes dos seus clientes é só percorrer a coleção:

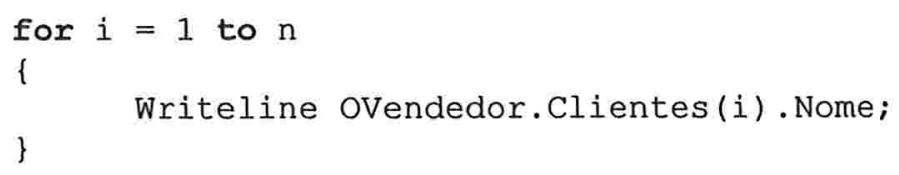

Note-se que, seguimos nesses comandos o padrão do OQL Caché: infelizmente uma coleção não é tratada como conjunto, e seria uma variável indexada. Se fosse tratada como conjunto, não seria necessário usar um índice (i), testar se chegou ao último elemento (n). Para obter um próximo elemento da coleção, bastaria usar Next OVendedor.Clientes. 
Nas figuras de visões estruturais vemos que um objeto pode conter outros. Denominaremos o objeto mais externo de objeto raiz. Quando um objeto raiz é invocado, todos os objetos dele descendentes (isto é, nele contidos, nos vários níveis de encaixamento) também ficam disponíveis (conforme a resolução de objetos). Isso é muito útil na programação, porque elimina muitas operações de acesso ao BD. Mais adiante, veremos objetos que contêm vários descendentes. Com uma simples invocação, todos os dados desses objetos e seus descendentes ficam disponíveis.

$\mathrm{Na}$ alternativa na fig. 3.2-4, o objeto raiz é OCliente e favorece uma consulta de dados a partir de um certo cliente, obtendo-se também os dados do vendedor que o atende. Mas na fig. 3.2-6, onde o objeto OVendedor é o objeto raiz, uma consulta "listar os clientes atendidos por um certo vendedor" fica bem mais eficiente. Assim, a estrutura depende qual tipo de consulta é mais freqüente no sistema. O programador deve escolher uma das opções.

Se as duas consultas fossem da mesma freqüência e fosse necessário ter consultas eficientes nos dois sentidos, poderíamos implementar uma terceira alternativa, colocando um atributo classe nas duas classes que implementam os conjuntos de entidades do MER, como demonstrado na fig. 3.2-7.

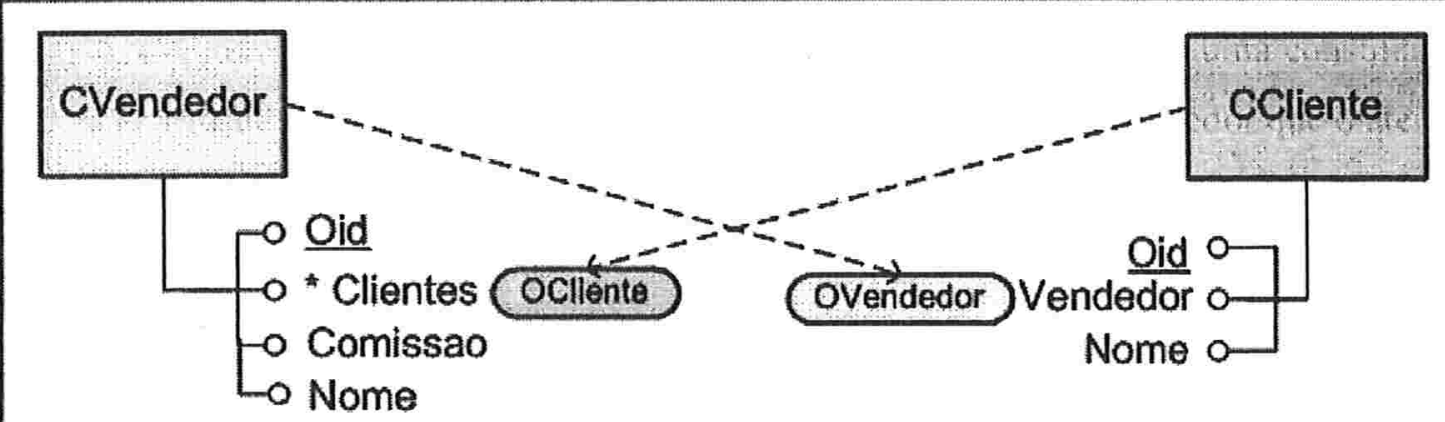

Fig. 3.2-7: Outra implementação alternativa de 1:N

Note-se que na fig. 3.2-7 há uma redundância: um par relacionando um certo vendedor a um certo cliente é representado tanto com um valor de Clientes no objeto de CVendedor, como um objeto vendedor do objeto CCliente correspondentes àqueles cliente e vendedor. Nos BDOOs, não consideramos esse tipo de redundância muito grave; pois pode-se aproveitar o encapsulamento da $\mathrm{OO}$ e ativar apenas a inserção de um dos 
dois pares, por exemplo em Clientes do objeto de CVendedor. O sistema ativaria sempre um outro método inserindo automaticamente o outro par em CCliente. O mesmo deveria ser feito em eliminações e alterações de pares da ligação.

Nesse caso, temos duas visões estruturais, mostradas nas figs. 3.2-8 e 9.
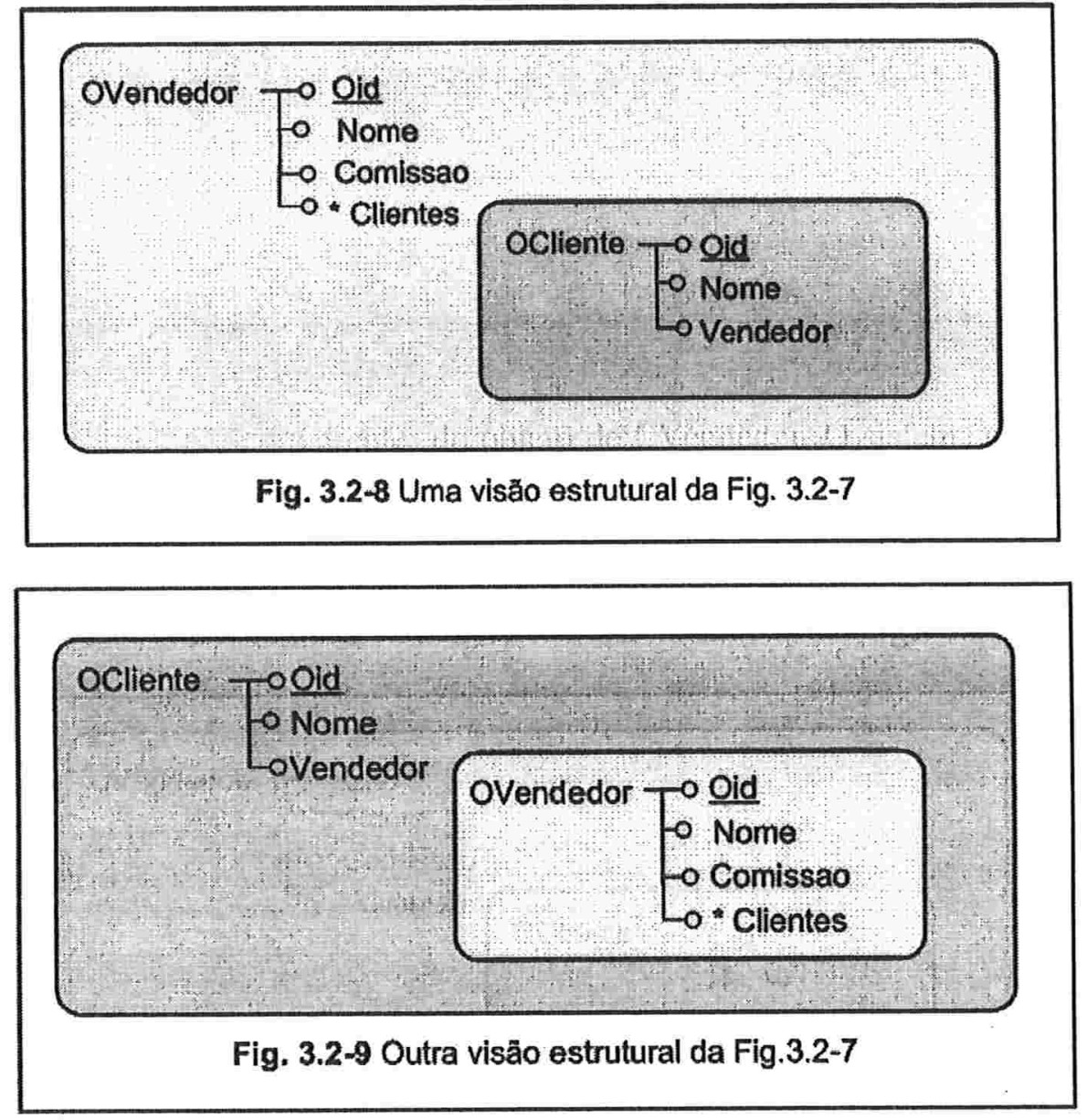

Na fig. 3.2-8, OVendedor é o objeto raiz, contendo uma coleção de objetos OCliente. Já na fig. 3.2-9, OCliente é que é o objeto raiz, contendo um objeto OVendedor. Neste caso pode-se usar uma consulta empregando uma ou outra visão estrutural, invocando um objeto OCliente ou OVendedor, dependendo da necessidade do sistema.

Nesta terceira alternativa as declarações das classes ficam:

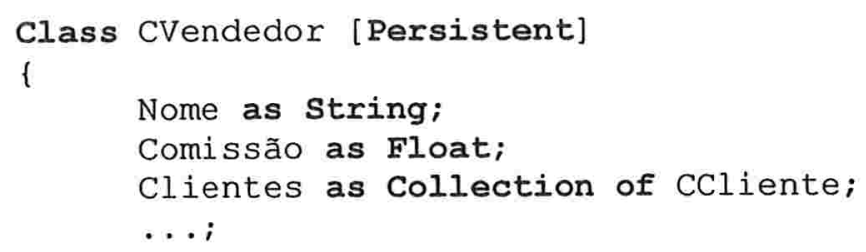




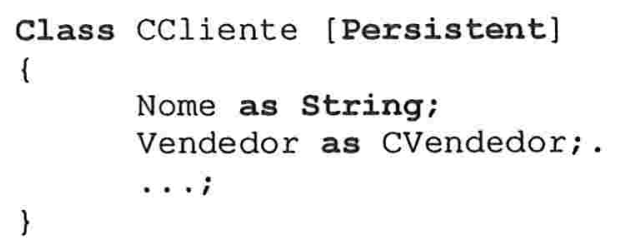

Como, ao se declarar o tipo do atributo Clientes em CVendedor, a classe CCliente ainda não foi declarada, um compilador, se for de um só passo, pode não aceitá-la; o mesmo se passa com ambientes de desenvolvimento, como o Studio do Caché e semelhantes, no qual só se pode escolher um tipo de um atributo se esse tipo já estiver previamente inserido em uma lista de tipos disponíveis (que envolve as classes já declaradas). No caso, ao se declarar CVendedor, CCliente ainda não foi inserido nessa lista. Portanto, é necessário declarar a classe CCliente com uma classe vazia, sem atributos, antes de declarar a classe CVendedor; posteriormente, no caso do Studio do Caché, basta adicionarem-se os atributos de CCliente e seus tipos.

\subsection{Relacionamento $\mathrm{N}: \mathrm{N}$ com atributo no relacionamento}

Na fig. 3.3-1 mostramos um relacionamento entre Pedidos e Produtos, onde o pedido pode ter vários produtos e um produto pode estar em vários pedidos. O losango do relacionamento tem atributos Preço e Quantidade porque estes valores são negociados com o cliente.

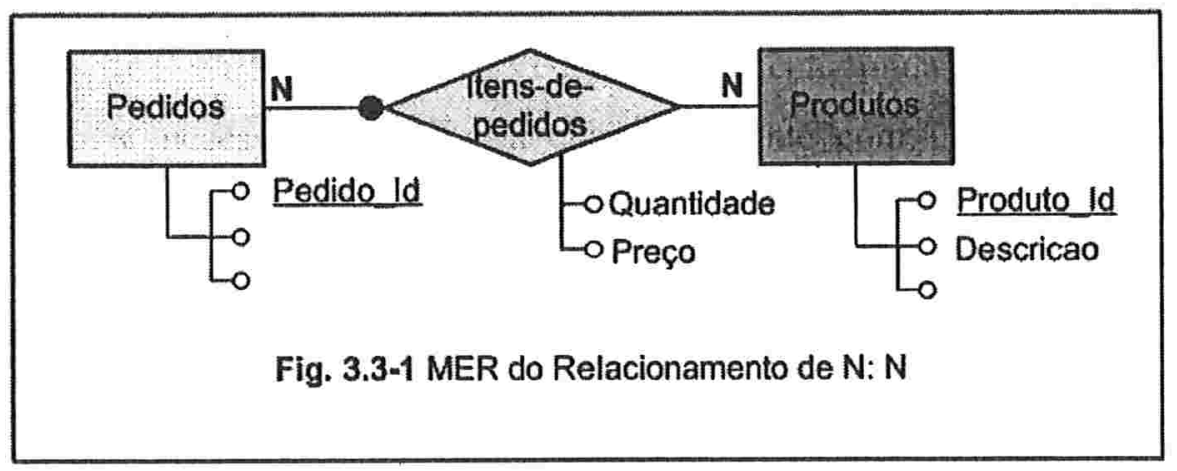

A implementação em um BDR está na fig. 3.3-2, usando a notação gráfica de [SET 05] - o hexágono é usado para mostrar claramente que essa tabela é auxiliar, introduzida apenas para implementar um relacionamento. Foram colocadas nessa tabela auxiliar duas chaves estrangeiras, CE_Pedido_Id que se refere a Pedido_Id e 
CE_Produto_Id que se refere a Produto_Id, podendo-se com isso fazer a junção das três tabelas. Note-se que na tabela auxiliar foram colocados os atributos do relacionamento.

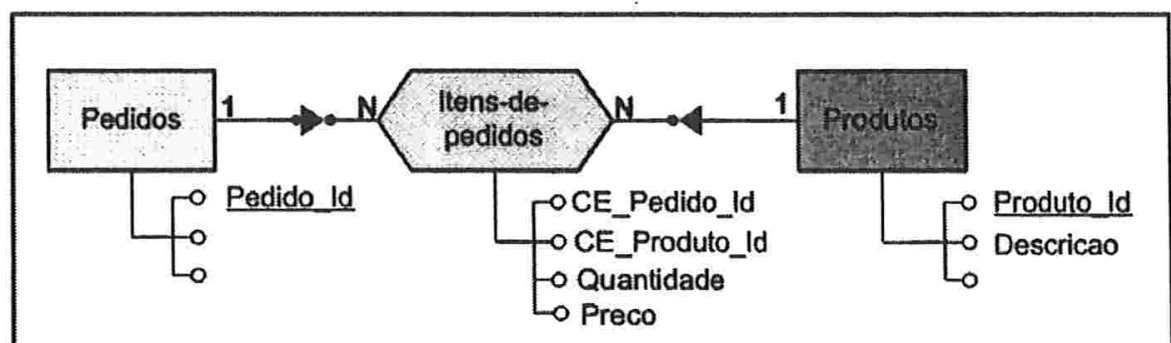

Fig. 3.3-2 Implementação em BDR

$\mathrm{Na}$ linguagem SQL, para consultar um pedido pode-se dar o seguinte comando (supomos que a variável \%pe_id contenha o número do pedido desejado):

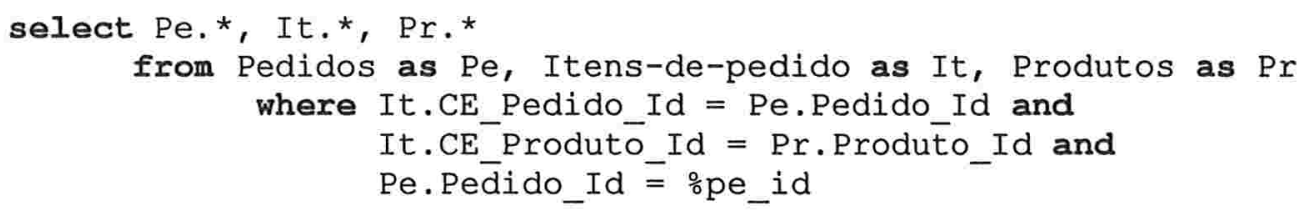

Uma possível implementação em BDOO é mostrada na fig. 3.3-3. Criamos uma classe auxiliar CItem-de-Pedido com os atributos do relacionamento, contendo o atributo Produto da classe CProduto. Criamos, também, na classe CPedido o atributo Itens-dePedido como uma coleção de objetos da classe CItem-de-Pedido. A junção dos três objetos é automática: ao se invocar o objeto de um pedido, toda a coleção de Itens-dePedido, e cada elemento da mesma com seu’ determinado produto ficará disponível ao usuário.

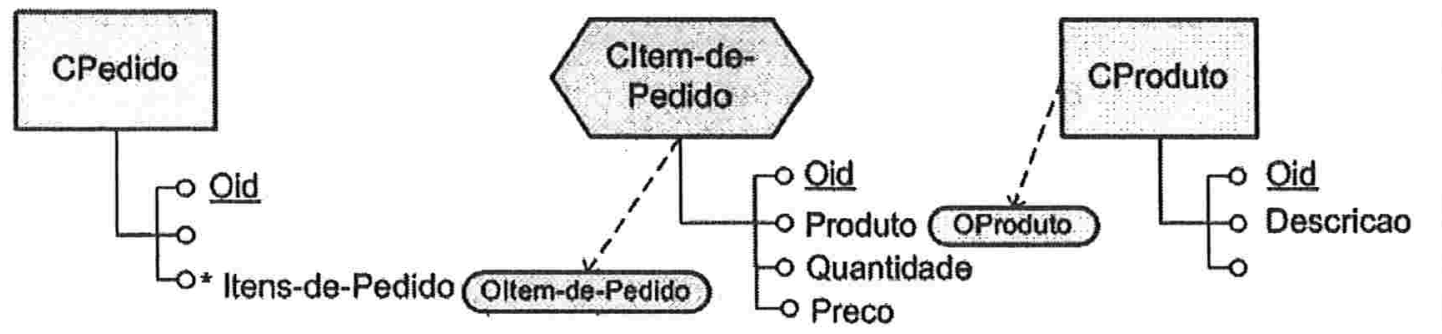

Fig. 3.3-3 Implementação em BDOO 
Geralmente os BDOOs permitem declarar um atributo composto. Na fig. 3.3-4 mostramos como se pode, com isso, fazer uma outra implementação do relacionamento. $\mathrm{O}$ atributo composto multivalorado Itens-de-Pedido implementa cada par do relacionamento, indicando, para cada objeto de CPedido, os objetos de CProduto relacionados com ele. Note-se que Quantidade e Preco são os atributos do relacionamento.

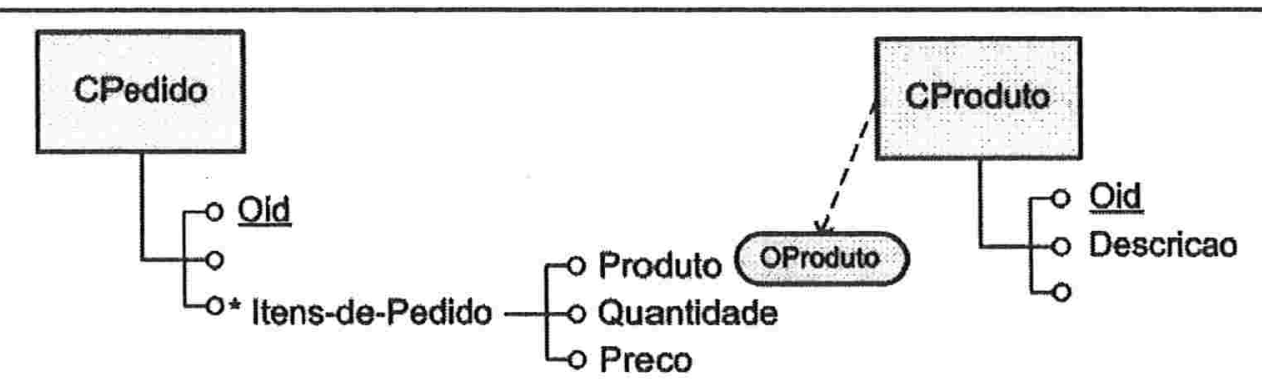

Fig. 3.3-4 Implementação em BDOO

No GBDOO Caché os atributos compostos devem ser implementados como classes separadas, do tipo SerialObject. A declaração da classe CItem-de-Pedido seria, nele:

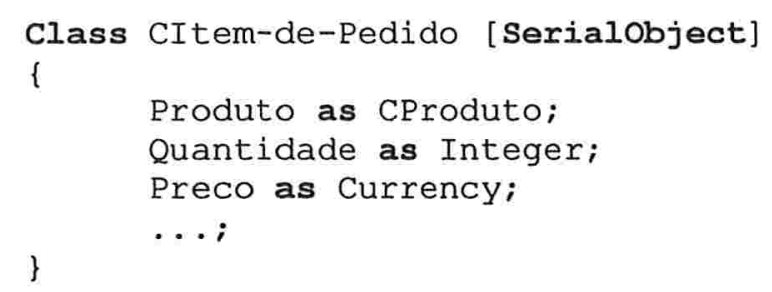

Portanto, em Caché, a implementação da fig. 3.3-4 é equivalente à da fig. 3.3-3. Como neste trabalho o estudo de caso foi implementado em Caché, a solução da fig. 3.33 é a que será usada, por ser mais explícita.

As ligações da fig.3.3-3 ficam mais claras na visão estrutural da fig. 3.3-5. 


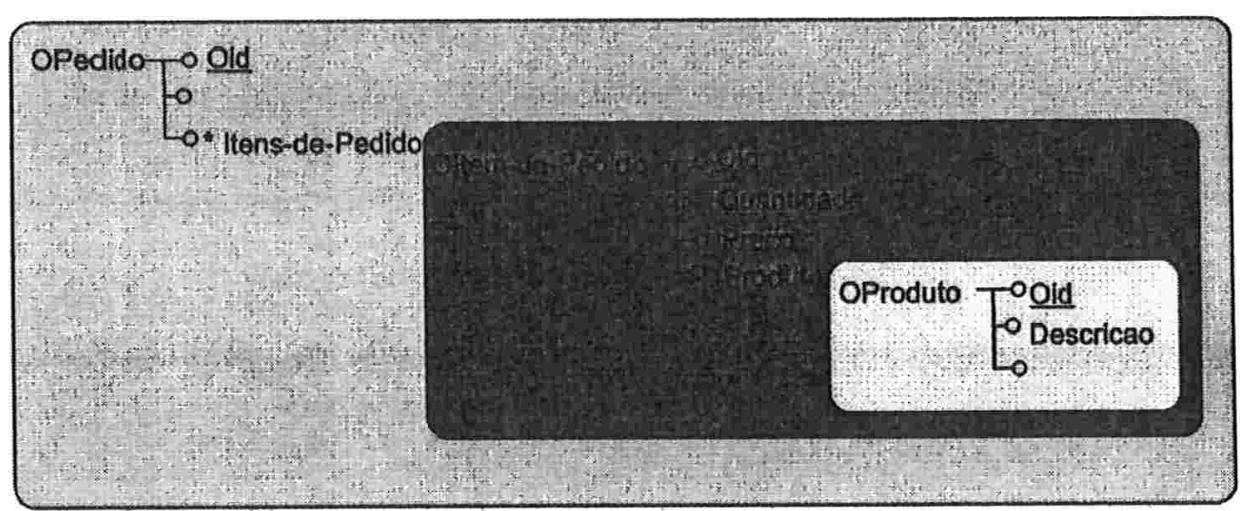

Fig. 3.3-5 Uma visåo Estrutural para a Fig. 3.3-3

Para a busca de um pedido cujo Oid é \%pe_id devemos fazer:

OPedido $=$ class $($ CPedido). OpenId (ope_id);

Na busca de uma lista de pedidos que contenham um certo produto, cujo Oid é \%pr_id fazemos:

select Oid from CPedido where Itens-de-Pedido.Produto.Oid=\%pr_id;

RS = new ResultSet; // Este comando já declara RS

// Comandos para obter o resultado da consulta:

for $i=1$ to ultimoItemRS

\{

pedidoOid $=$ RS (i);

OPedido = Class (CVendedor). OpenId (pedidoOid);

// Seguem-se comandos para a exibição de opedido na tela

\}

Note-se que a busca dos produtos dentro de um certo pedido é muito eficiente, sendo custo de tempo T(1) para cada item de pedido; além disso, sabemos que cada pedido contém sempre muito poucos itens. Por outro lado, a busca dos pedidos que contêm um certo produto é da ordem de $\mathrm{T}(n)$, no número de pedidos existentes no $\mathrm{BD}$. Isso é devido ao fato de que, para um certo produto é necessário varrer linearmente os objetos da classe CItem-de-Pedido, até localizar-se um de seus elementos que contém o produto desejado; em seguida, é necessário varrer os objetos de CPedido até localizar o Itens-de-Pedido com o Oid do item localizado. Consideramos, para a implementação da fig. 3.3-3, que há muito menos buscas de pedidos dado um certo produto, do que os produtos de um certo pedido. Na seção 4.1 mostramos uma solução genérica em que há 
eficiência na busca a partir de elementos de qualquer uma das duas classes provenientes dos conjuntos de entidades.

$\mathrm{Na}$ verdade, um pedido sempre tem dados de um cliente. O MER completo referente aos pedidos é mostrado na fig. 3.3-6. Um cliente pode ter vários pedidos e cada pedido refere-se somente a um cliente.

A implementação desse modelo em um BDR é mostrada na fig. 3.3-7. Na tabela Pedidos é colocada uma chave estrangeira CE_Cliente_Id para poder-se fazer a junção com a tabela Clientes.

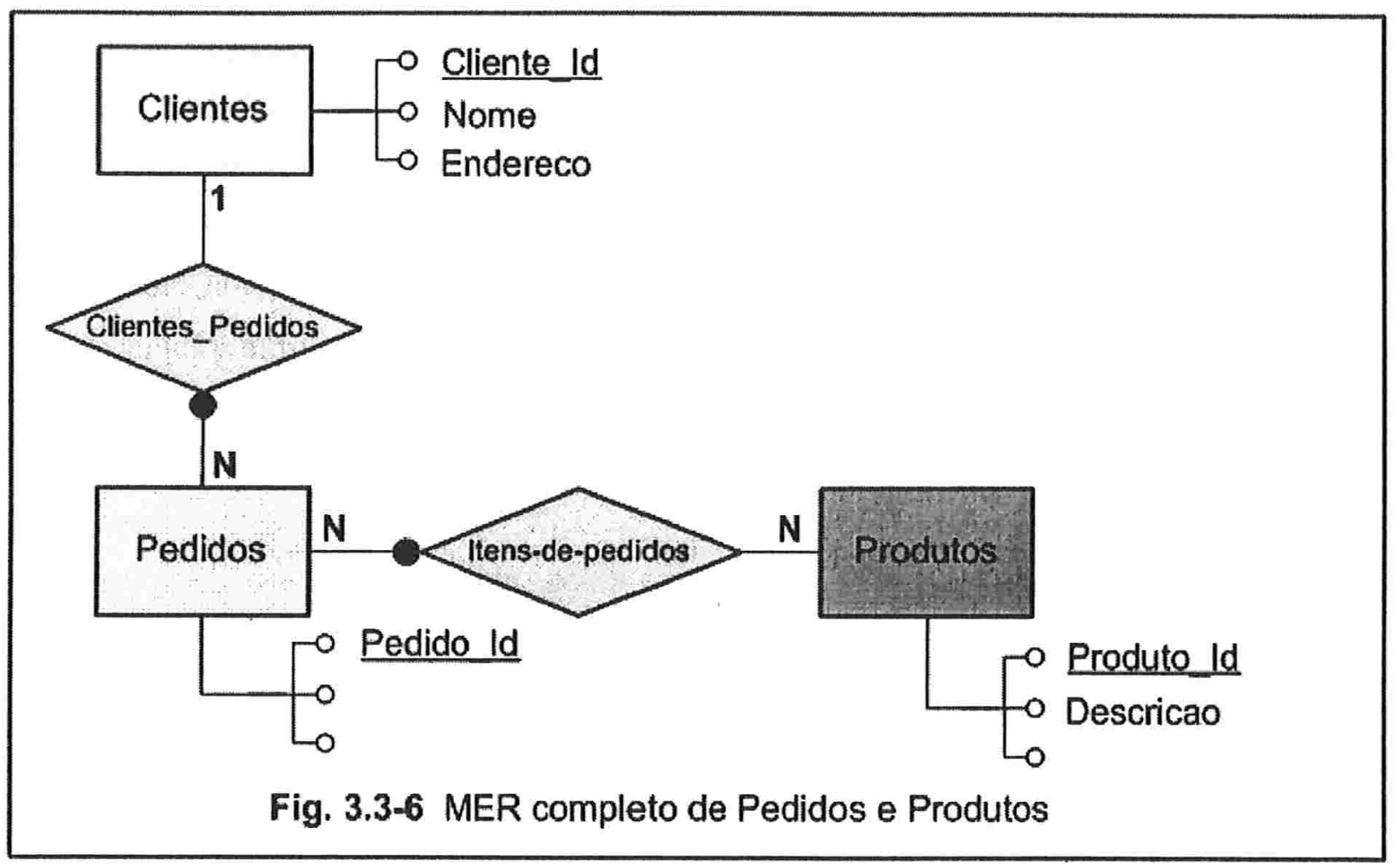

O comando em SQL para obter-se os pedidos de um cliente (supomos que seu Oid tenha sido atribuído à variável cid) poderia ser:

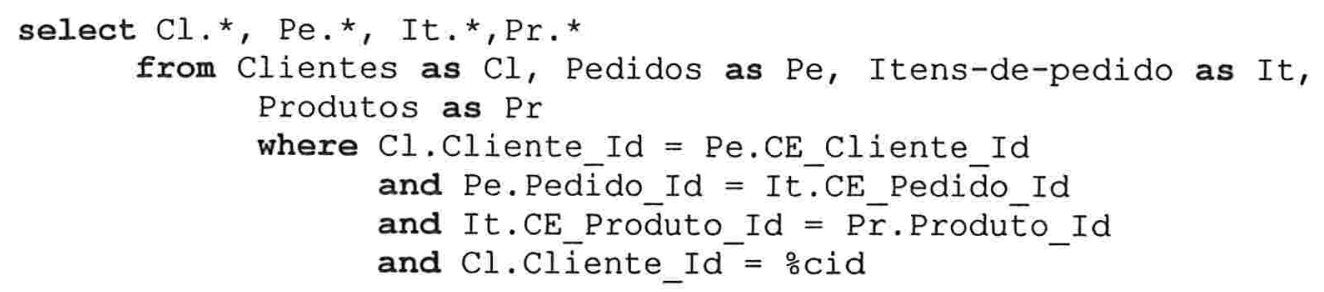




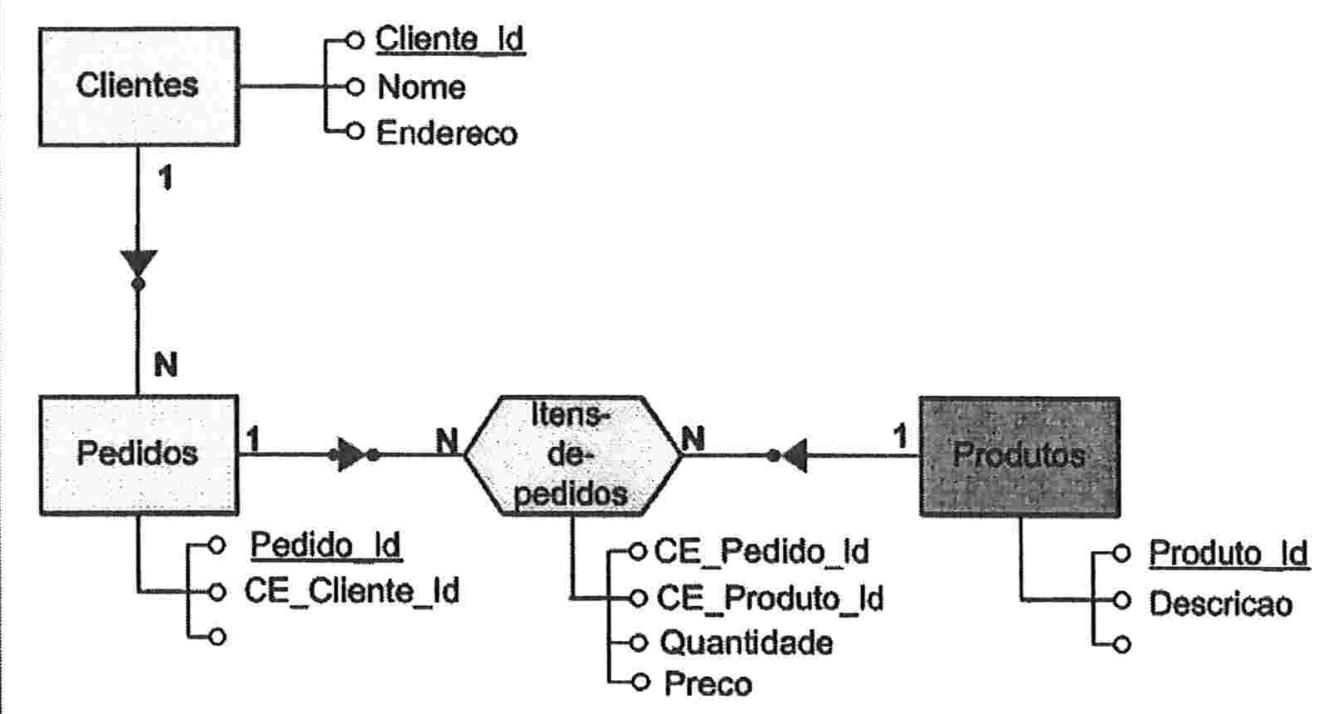

Fig. 3.3-7 Implementaçåo em BDR

Existem várias formas de implementações em $\mathrm{BDOO}$, dependendo de como se embutem as classes umas nas outras. Sugerimos uma forma como a da fig. 3.3-8, que faz o melhor aproveitamento da $\mathrm{OO}$, ou a da fig. 3.3-9 se fosse preciso também maior eficiência numa consulta do tipo "fornecer o histórico de pedidos de um certo cliente".

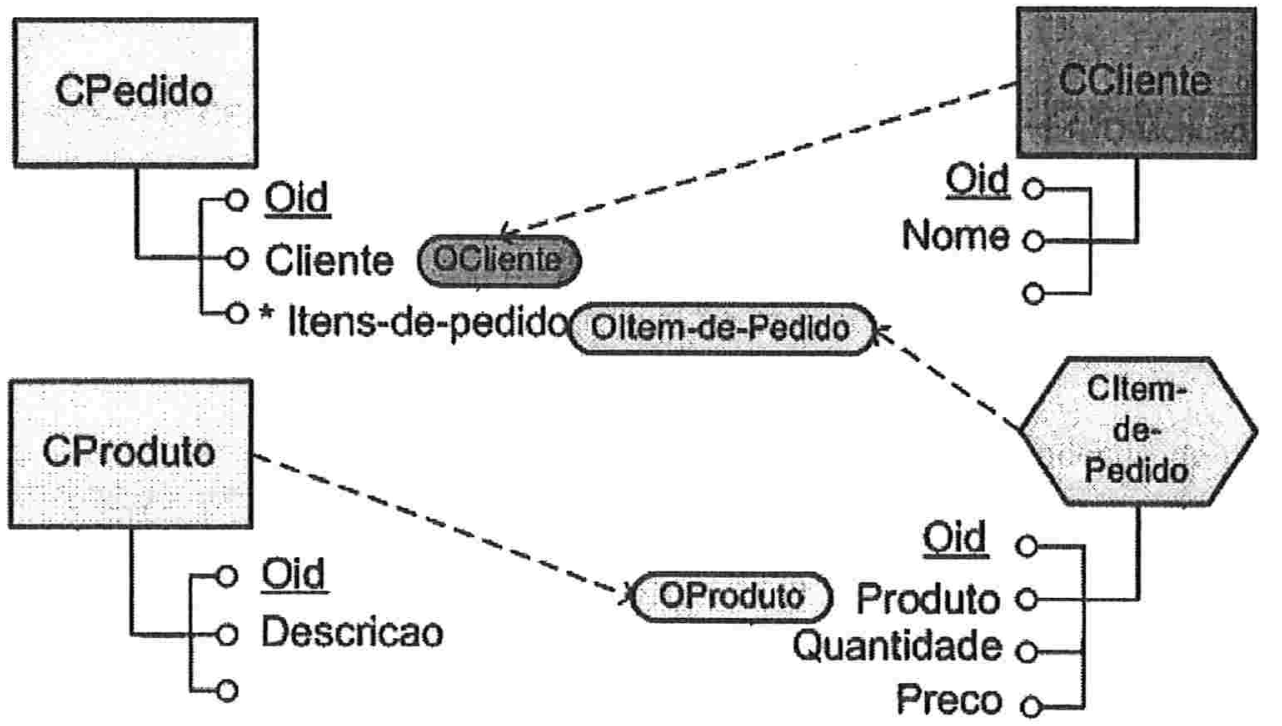

Fig. 3.3-8 Uma implementação em BDOO 


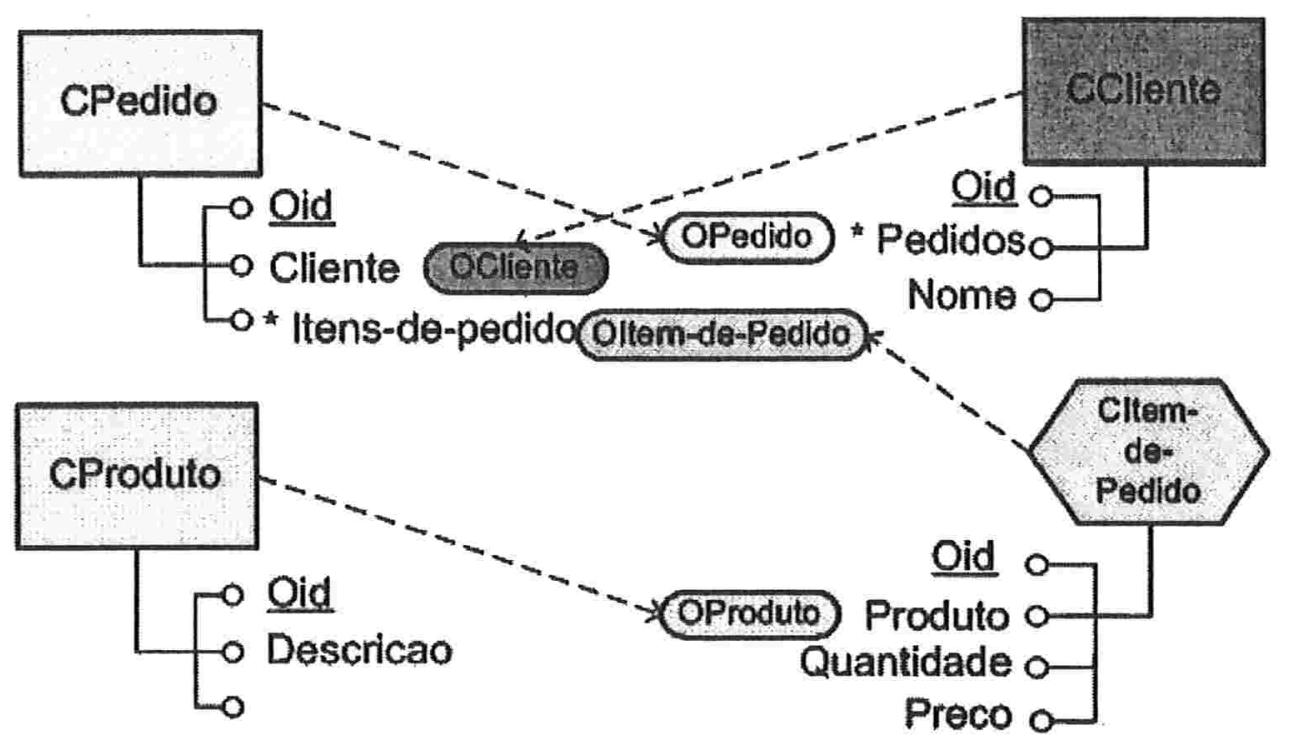

Fig. 3.3-9 Outra implementação em BDOO

Na fig. 3.3-9 temos uma redundância na representação do relacionamento entre clientes e pedidos análoga à da fig. 3.2-7. As figs. 3.3-10 e 3.3-11 mostram as visões estruturais da fig. 3.3-8 e 3.3-9 respectivamente.

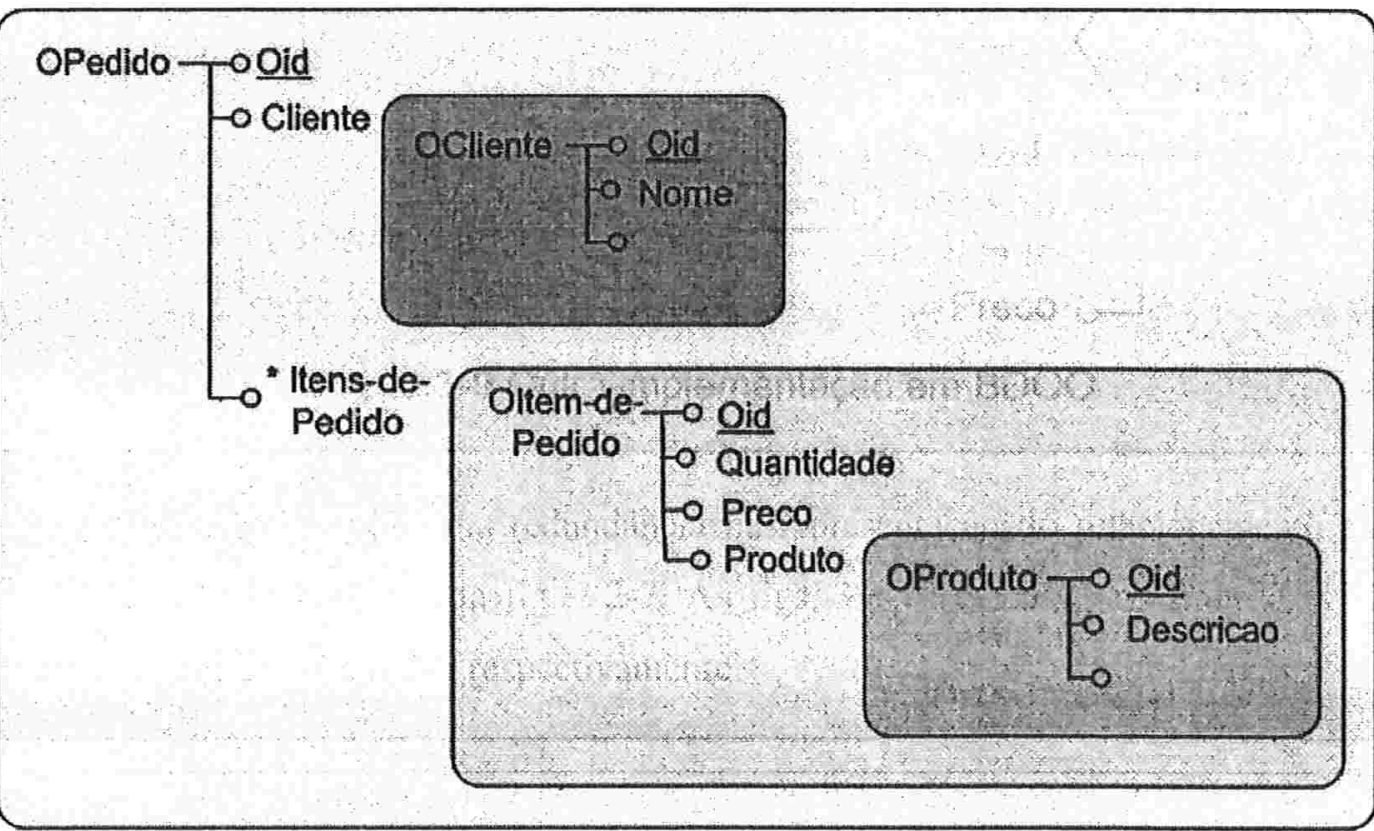

Fig. 3.3-10 Visão estrutural da Fig. 3.3-8 


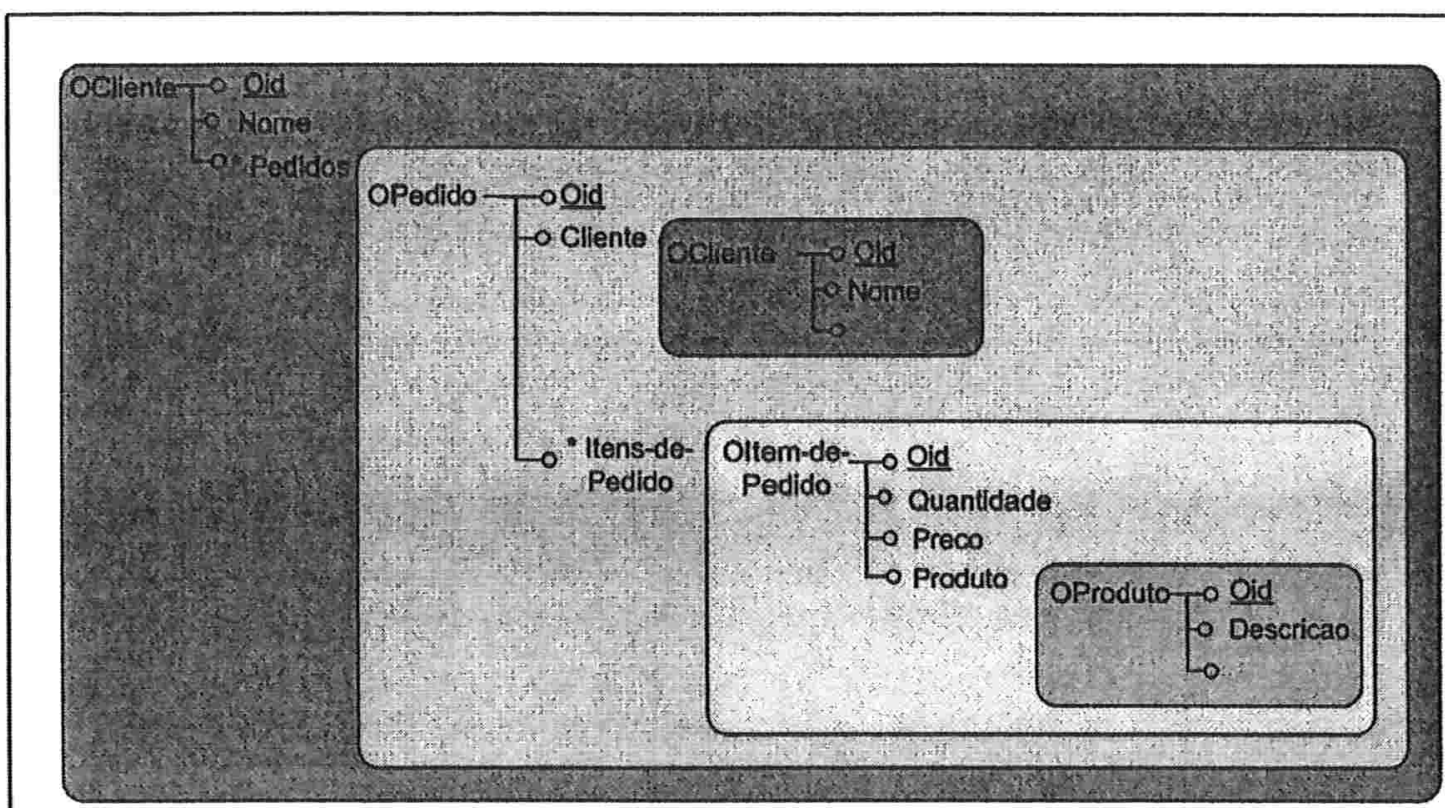

Fig. 3.3-11 Visão estrutural da Fig.3.3-9

O diagrama da fig. 3.3-9 pode ser declarado da seguinte maneira, em uma pseudolinguagem de OQL:

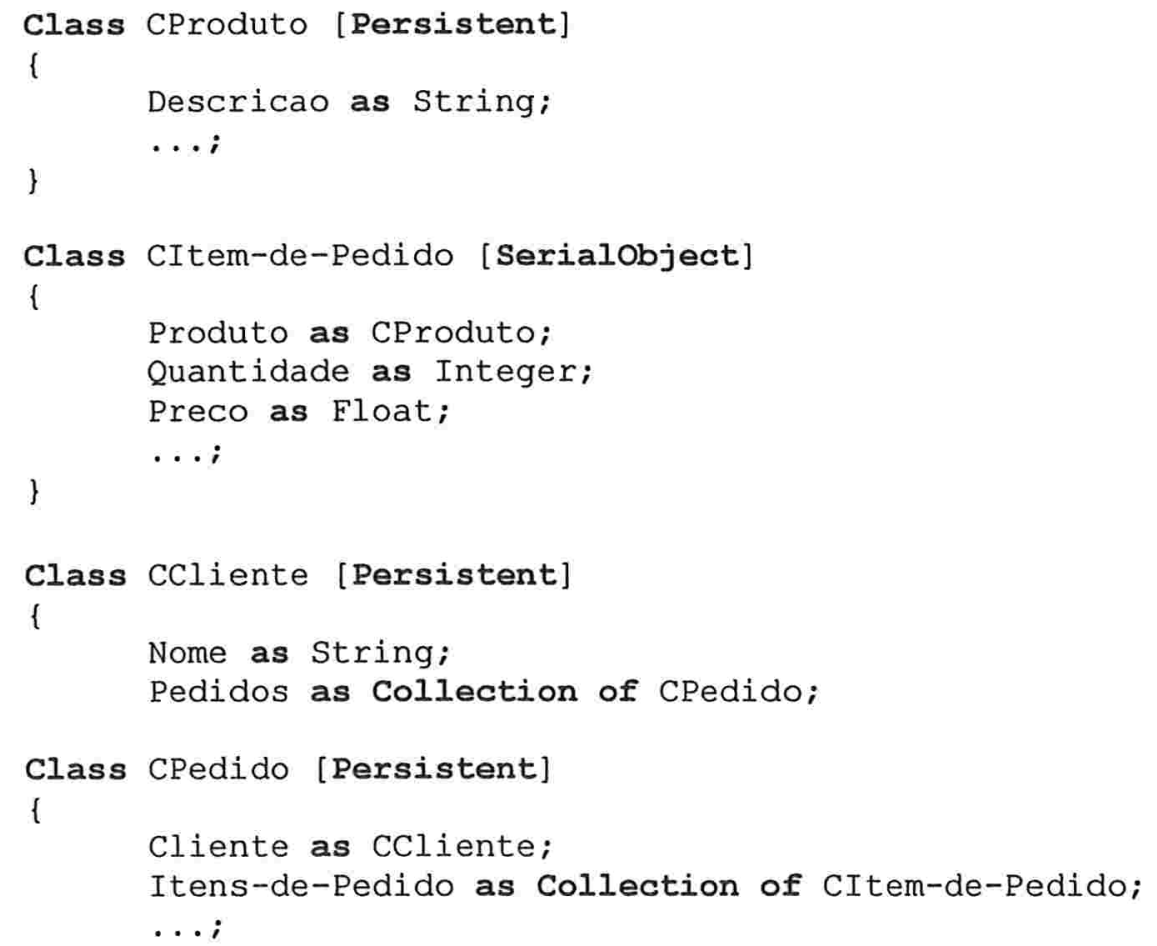


Vejamos como seria feita a inclusão de um pedido de um cliente cujo Oid é está armazenado em cid; vamos supor que foi implementado um sistema de telas em que são solicitados o Oid de cada produto do pedido, bem como sua quantidade e preço.

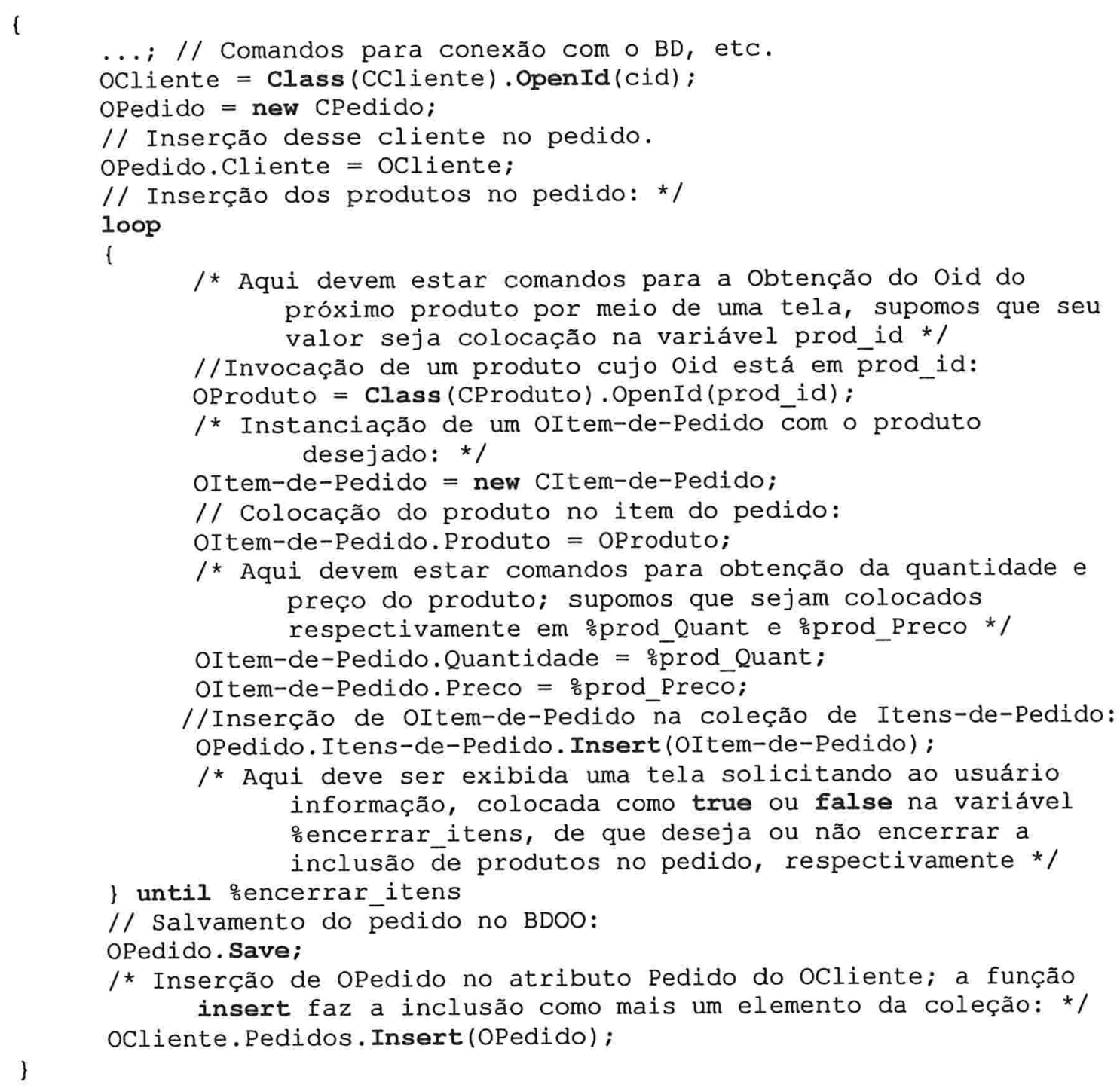

Note-se que, houve necessidade de implementar uma malha de repetição para varrer a coleção como na forma 3 da seção 3.2.

\subsection{Auto-relacionamento $N: N$}


O exemplo clássico de um auto-relacionamento é a composição de produtos nos vários materiais de que são compostos, como em sistemas de Materials Resource Planning (MRP). O seu modelo relacional conceitual está na fig. 3.4-1, onde "Compostode" e "Componente de" são os papéis de cada material em uma composição.

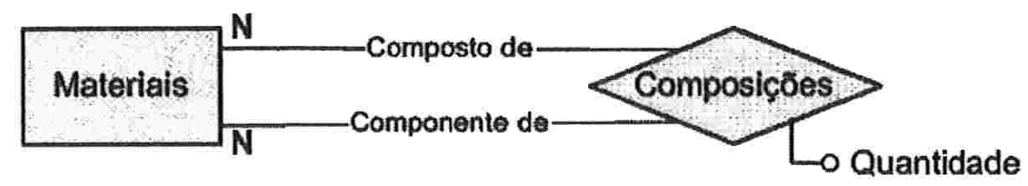

Fig. 3.4-1 Auto-relacionamento N:N

A implementação em um BDR é mostrada na fig. 3.4-2. É criada uma tabela auxiliar Composicoes, a qual contém duas chaves estrangeiras, CE_Componente-de_Id referente ao papel "Componente-de" e CE_Composto-de_Id referente a "Composto-de". Um material filho ("Componente-de") entra na composição de um material pai ("Composto-de"). Para cada material, todos os seus descendentes formam uma árvore de composições.

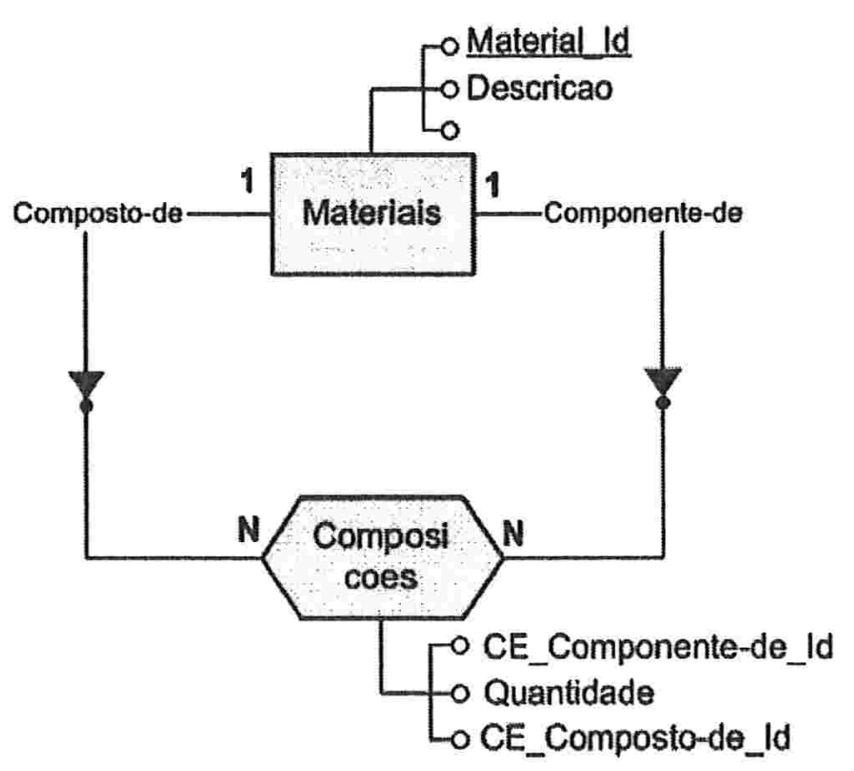

Fig. 3.4-2 Implementação em BDR 
Para obter uma lista de materiais de um certo produto final (a chamada "explosão de materiais"), é necessário fazer um programa recursivo para percorrer a estrutura de árvore daquele material. Quando trabalhamos na empresa Elebra Telecom em 1987, na linha de produção de um aparelho de radar havia mais de 12 mil itens de componentes em uma estrutura de árvore de até 7 níveis. O programa recursivo deve executar uma consulta em SQL em cada nó que é visitado, ou seja, deve haver mais de 12 mil consultas e acessos ao BD para listar a composição de todos os produtos.

Sugerimos neste caso uma implementação em BDOO como mostrada na fig. 3.43, que prioriza a explosão, e não a busca de que materiais contêm um dado material. Isto é, priorizamos a busca a partir de uma raiz de uma árvore de composições, para todos os seus descendentes. É criada uma classe auxiliar CComposto-de que contém um atributo Material do tipo CMaterial. Na classe CMaterial há um atributo que é uma coleção de objetos OComposto-de, indicando quais são os materiais que entram na composição de um objeto da classe CMaterial. A sua visão estrutural fica como fig. 3.4-4, para 2 níveis. Nesse tipo de visão, um dado material contém uma coleção de componentes, cada componente contém novamente uma coleção de materiais, e assim sucessivamente. A profundidade dessa visão estrutural depende do nível da árvore para cada material. No entanto, basta representar, digamos, 2 níveis para se ver o que deve ser feito (isto é, que atributos devem ser usados) recorrentemente no percurso de mais níveis, como na fig. 3.4-4.

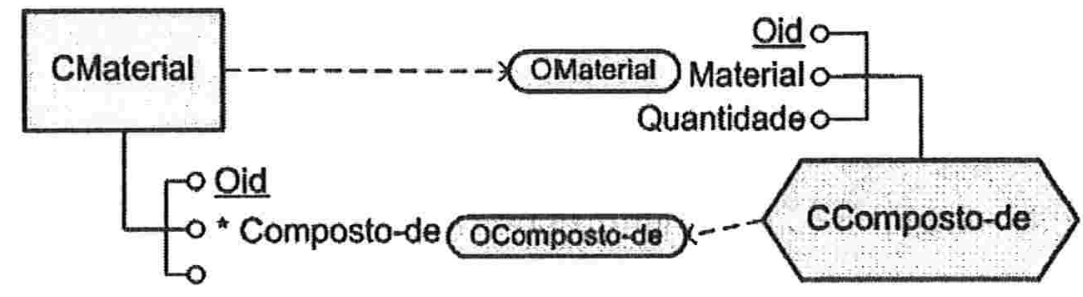

Fig. 3.4-3 Implementação em BDOO 


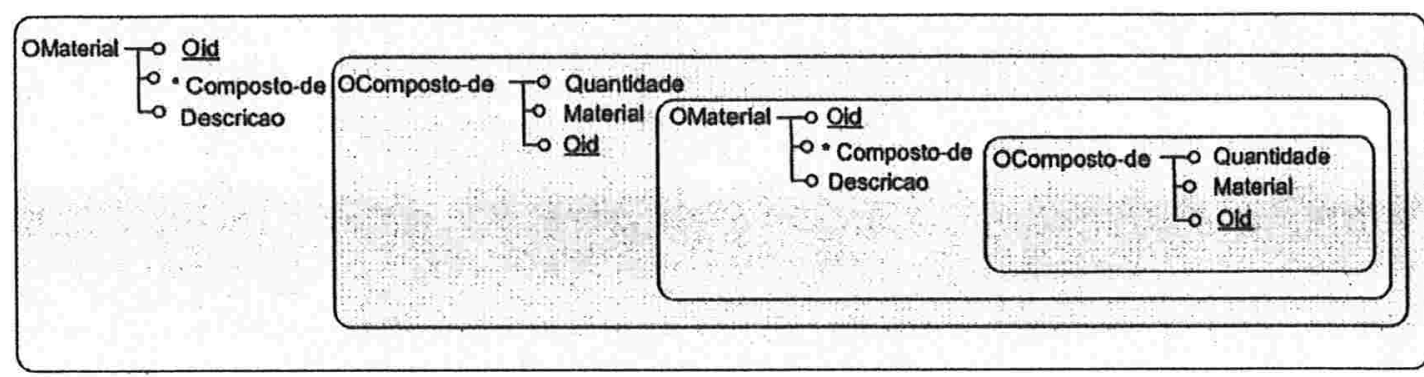

Flg. 3.4-4 Visäo estrutural em BDOO

Poder-se-ia pensar que cada coleção quebra totalmente a resolução de objetos, mas para o percurso até um determinado nível de profundidade esse não é o caso. Para isso, pode-se empregar no Caché a função GetAt(i) que especifica um objeto de uma coleção. Com dois níveis, a cláusula

OMaterial. Composto-de.GetAt (i-nivel1).

Material.Composto-de.Getat (i-nivel2). Material. Descricao

fornece a descrição de um material que é descendente no $2^{\circ}$ nível de um material dado. Obviamente, essa cláusula deve estar dentro de duas malhas de repetição, uma para variar a variável i-nivel1 e outra para i-nivel2.

Nessa solução, se for necessário saber quais materiais contêm em sua composição um determinado material $\mathrm{M}$, seria necessário varrer linearmente os objetos da classe CMaterial e, para cada objeto, verificar se na coleção Composto-de ocorre o material M. Para evitar isso, pode-se fazer uma implementação com redundâncias, como mostrado na fig. 3.4-5.

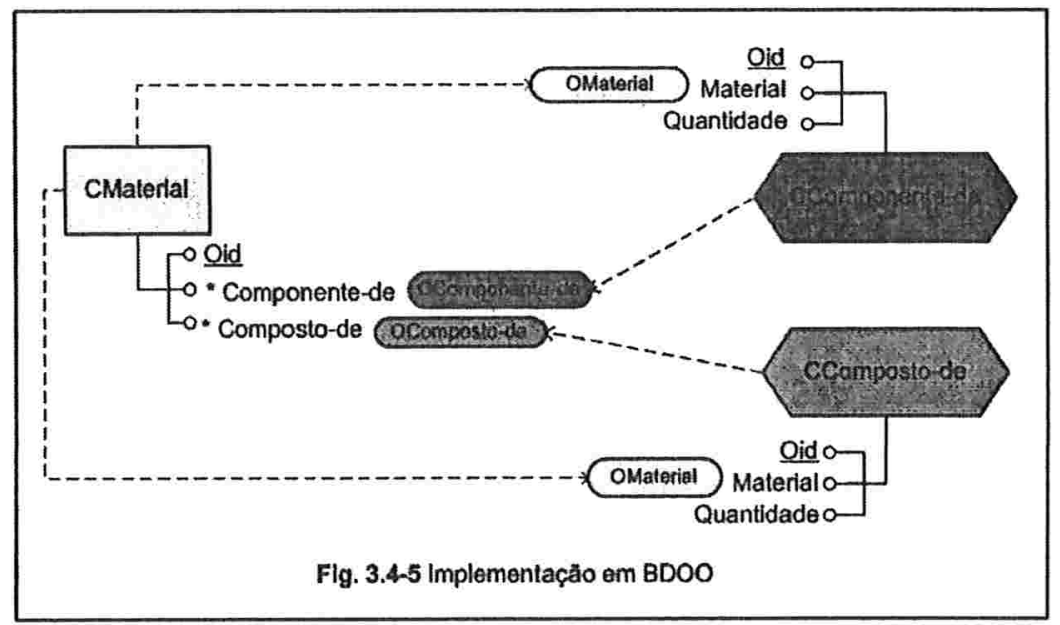




\subsection{Relacionamento com uma agregação}

Vejamos um exemplo de agregações do livro de Setzer [2005], mostrada na fig. 3.5-1. Materiais são requisitados, e várias requisições são agrupadas em vários pedidos de compra. A agregação tem uma característica típica, qual seja a da existência anterior de pares de um relacionamento (no caso, Itens-de-requisicoes), que são posteriormente relacionados com outro conjunto de entidades (Pedidos-de-Compra). No caso, os departamentos de uma empresa fazem requisições de materiais (que podem até ser fornecidos, se estiverem nos almoxarifados); o setor de compras agrupa posteriormente as requisições não satisfeitas para compor os pedidos de compra.

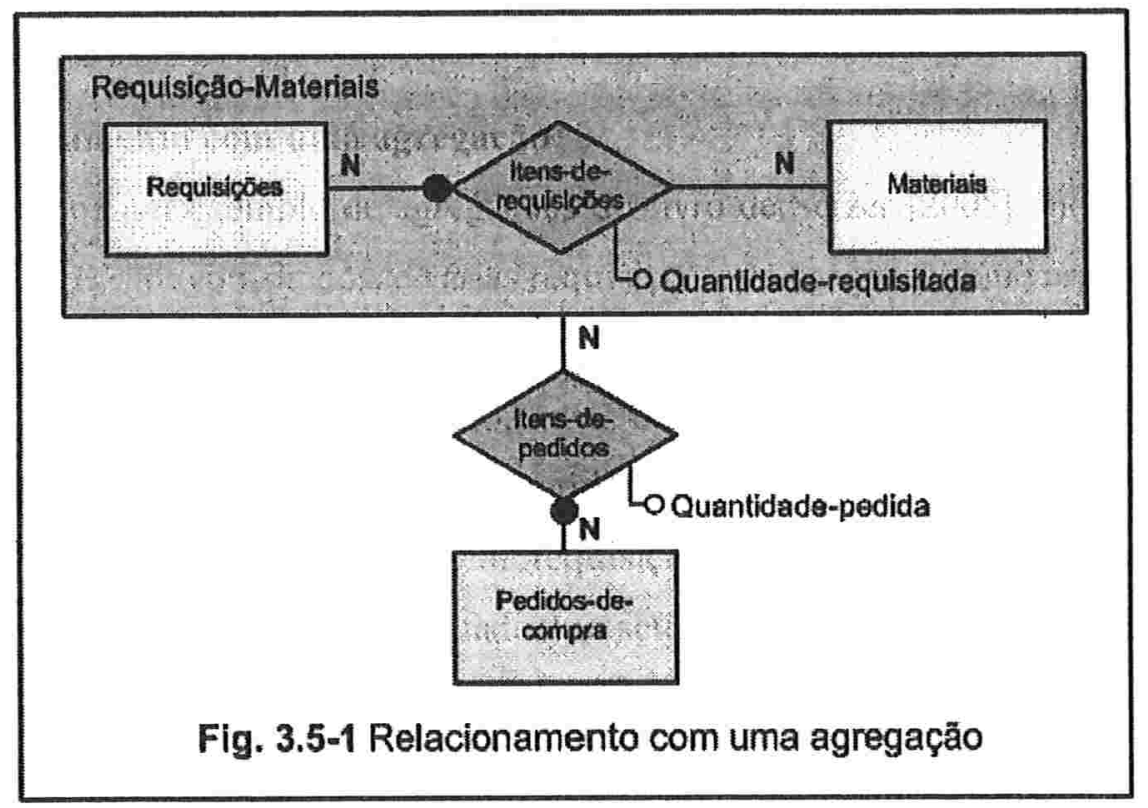

Duas implementações alternativas em BDR estão demonstradas nas fig. 3.5-2 e 3.5-3 [SET 05]. 


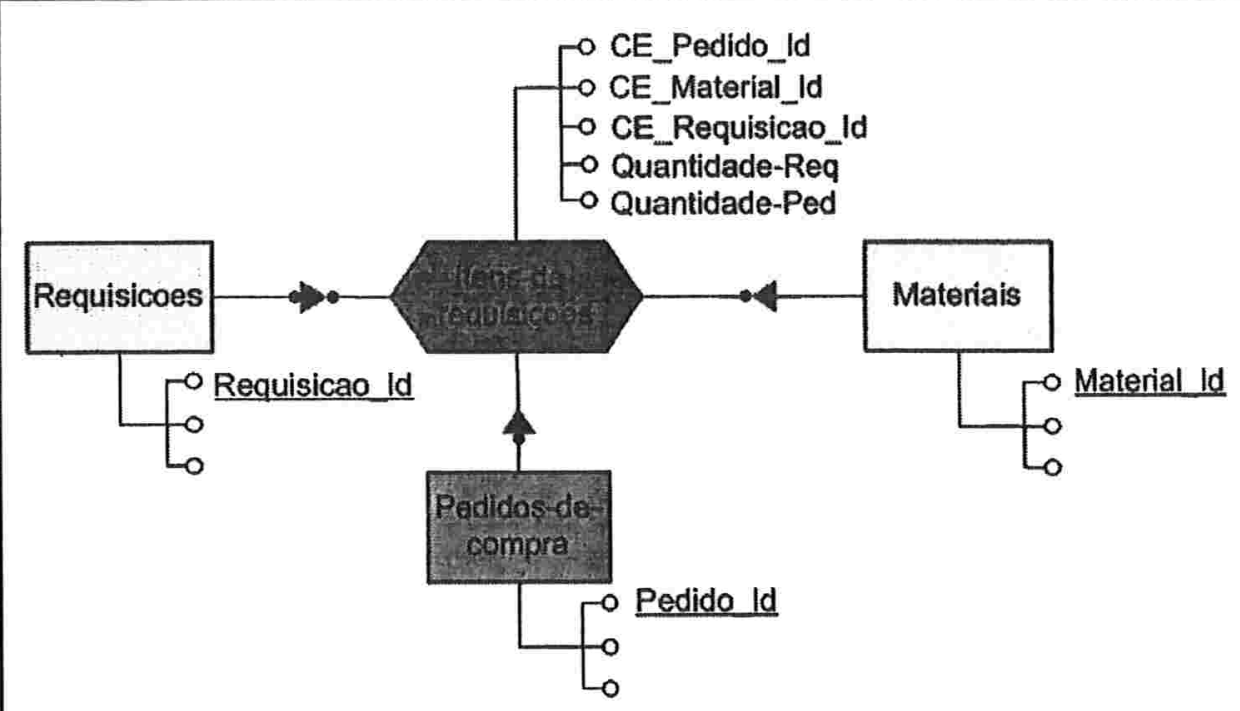

Fig. 3.5-2 Uma implementação de agregação em BDR

$\mathrm{Na}$ fig. 3.5-2, na tabela Itens-de-requisicoes foram colocadas 3 chaves estrangeiras que correspondem às chaves Material_Id, Requisicao_Id e Pedido_Id para fazer a junção das 4 tabelas. O valor de CE_Pedido_Id pode ser vazio, caso em que Quantidade-Ped também o é.

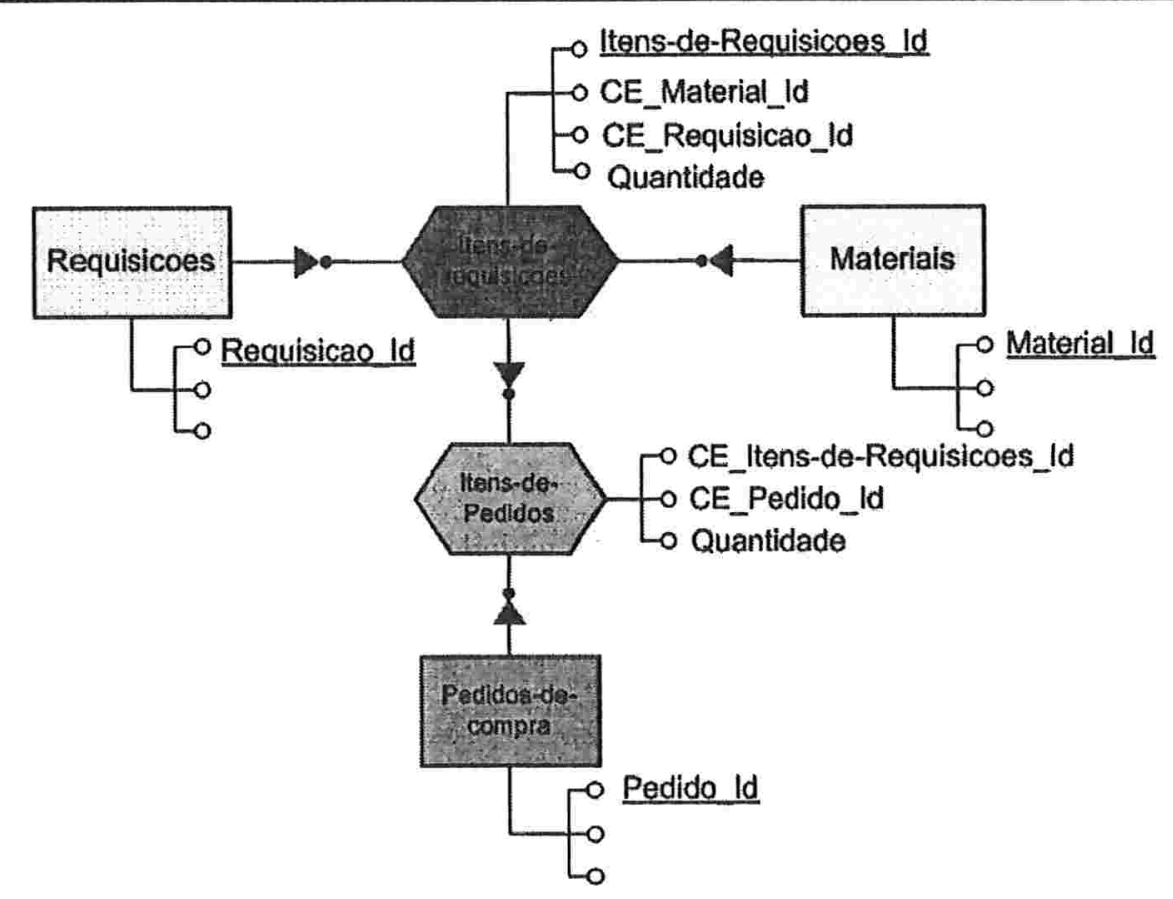

Flg. 3.5-3 Outra implementação de agregaçăo em BDR 
$\mathrm{Na}$ fig. 3.5-3, foi colocada uma tabela auxiliar Itens-de-pedidos, o que diferencia as duas alternativas. Com isso, obtém-se maior independência de dados, e os atributos da tabela Itens-de-pedidos não ficam vazios em casos de não haver ainda pedidos de compra emitidos para certos itens requisitados.

A implementação da fig. 3.5-2 em um BDOO está mostrada na fig. 3.5-4. Os objetos de CMaterial, CRequisicao e CItem-de-Requisicao foram implementados na forma de ligação N:N. Foi colocado um atributo Requisicao da classe CRequisicao em CItem-de-Requisicao (linha vermelha em negrito com traços longos). Com isso, um elemento de CItem-de-Requisicao pode conter dados de uma instância de CRequisicao e pode ser referenciado por uma instância de CPedido-de-Compra.

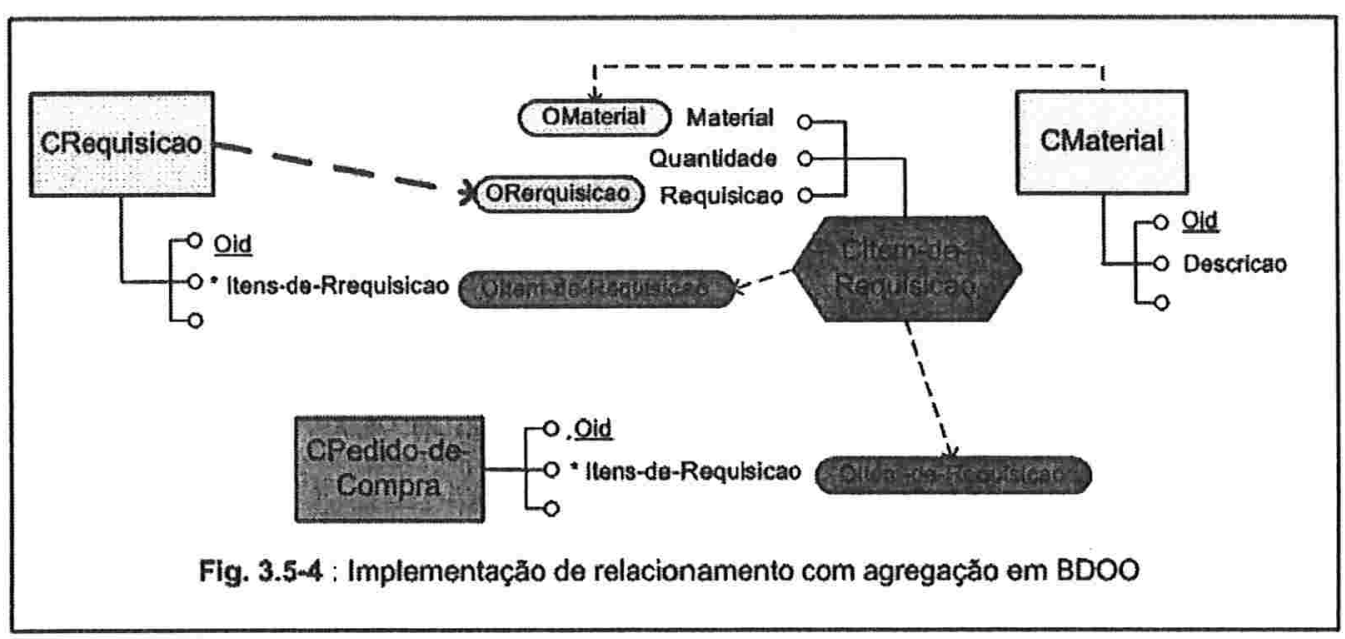

A visão estrutural desta figura está na fig. 3.5-5.

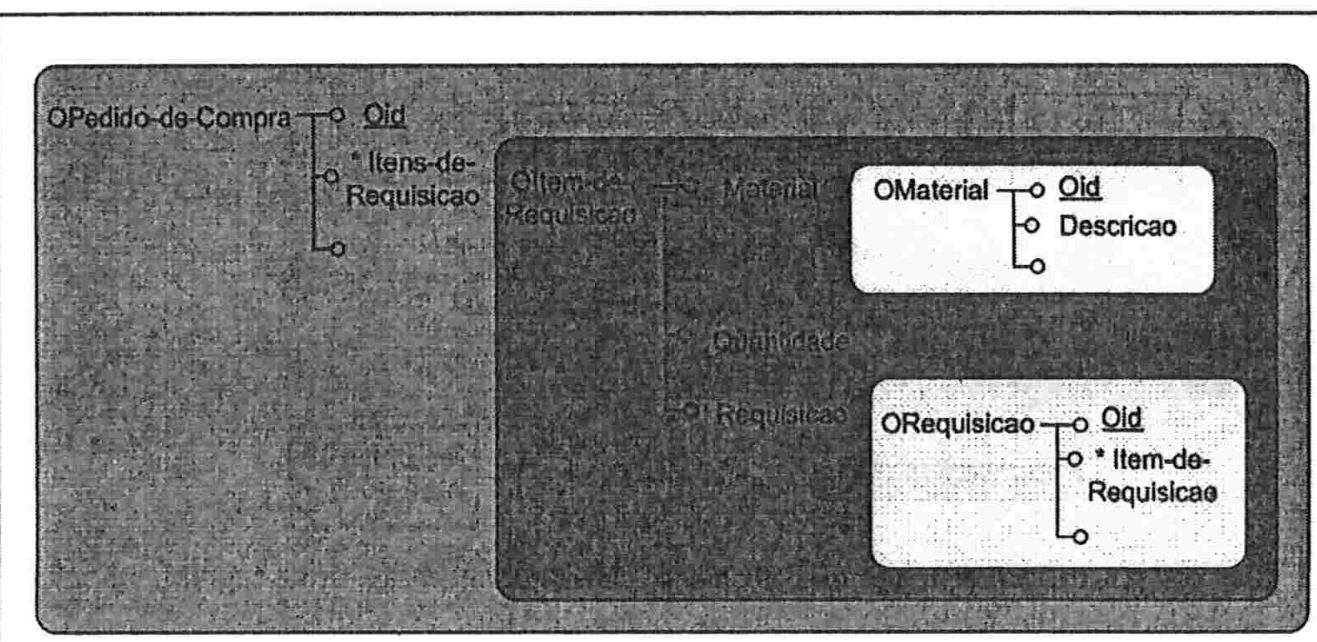

Fig. 3.5-5 Visäo estrutural de relacionamento com agregação em BDOO 
Uma alternativa da implementação da fig. 3.5-3 é mostrada na fig. 3.5-6 e sua visão estrutural na fig. 3.5-7.

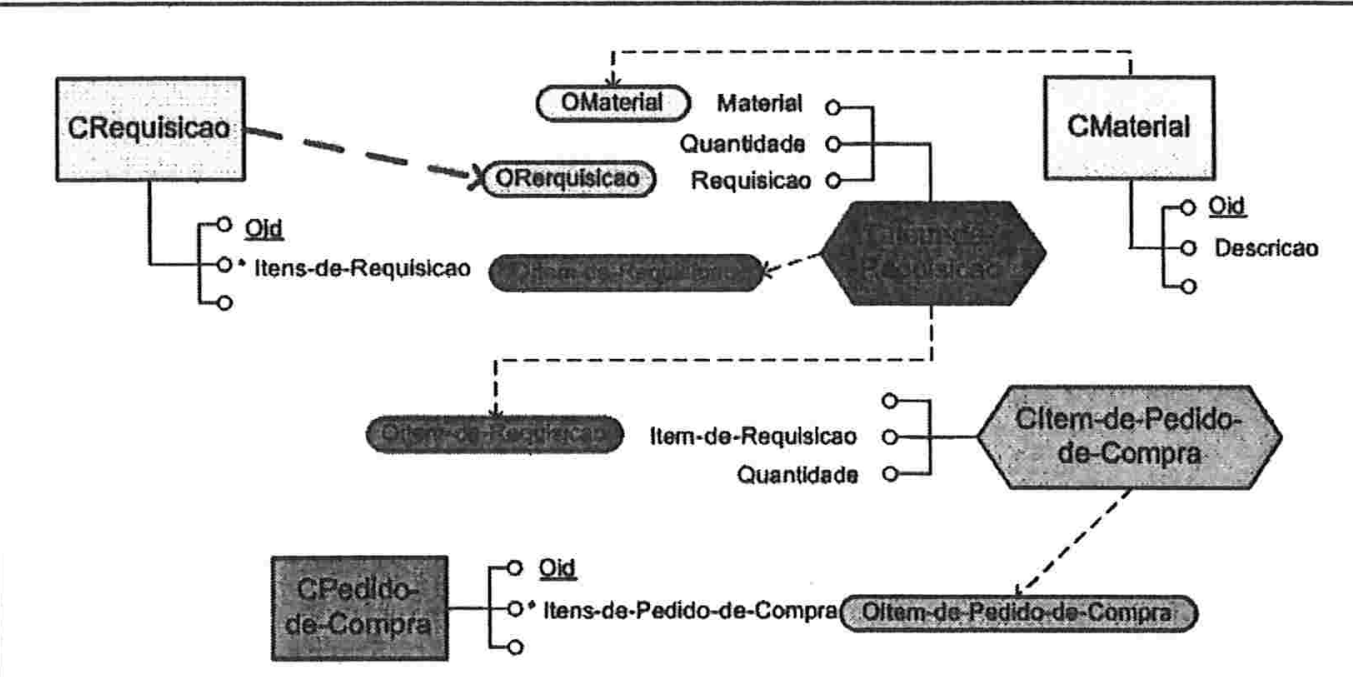

Fig. 3.5-6 Altemativa de implementaçāo de relacionamento com agregaçåo em BDOO

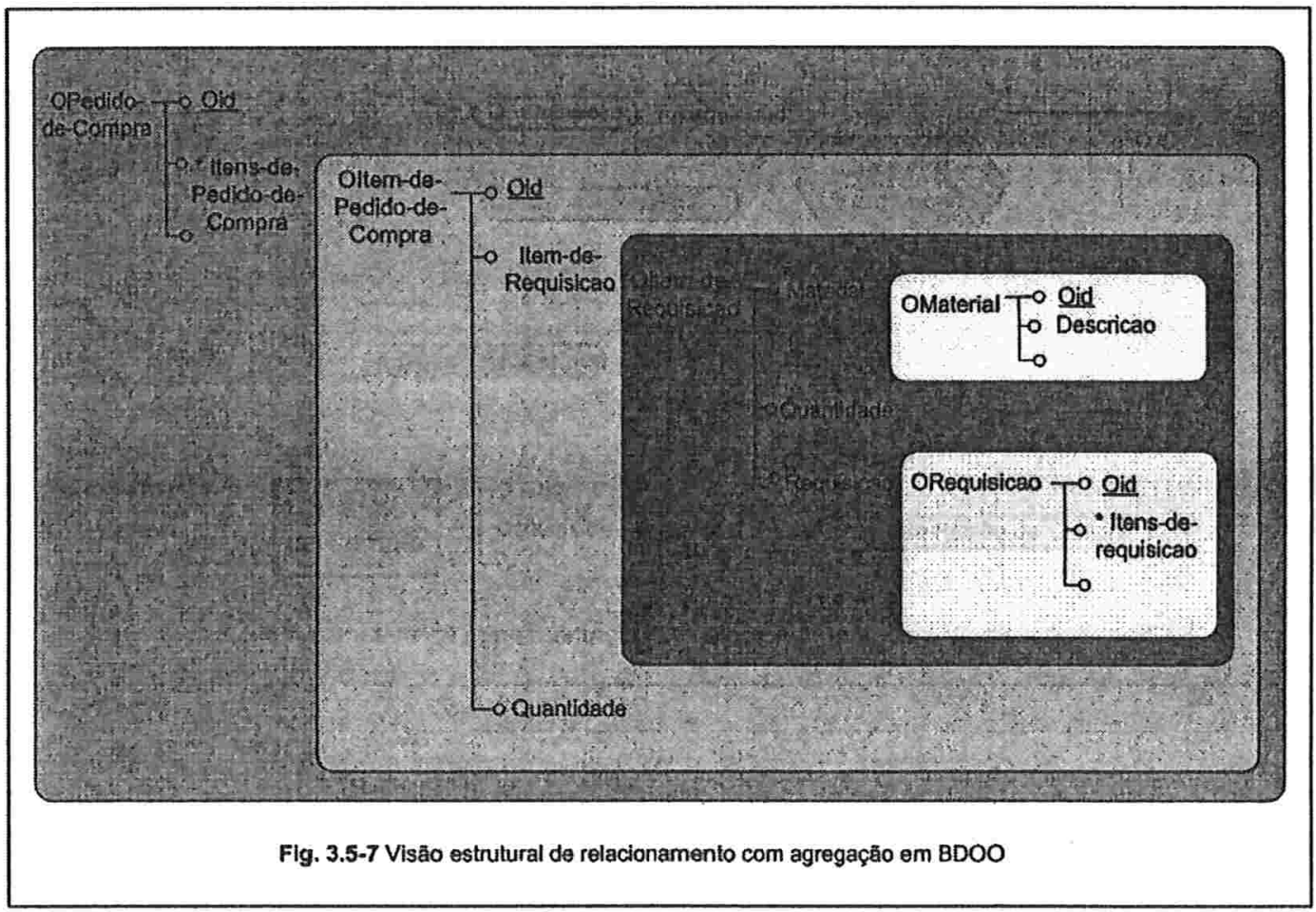

As declarações das classes e métodos da fig. 3.5-7, em nossa pseudo-linguagem, seriam:

Declaração de classes: 


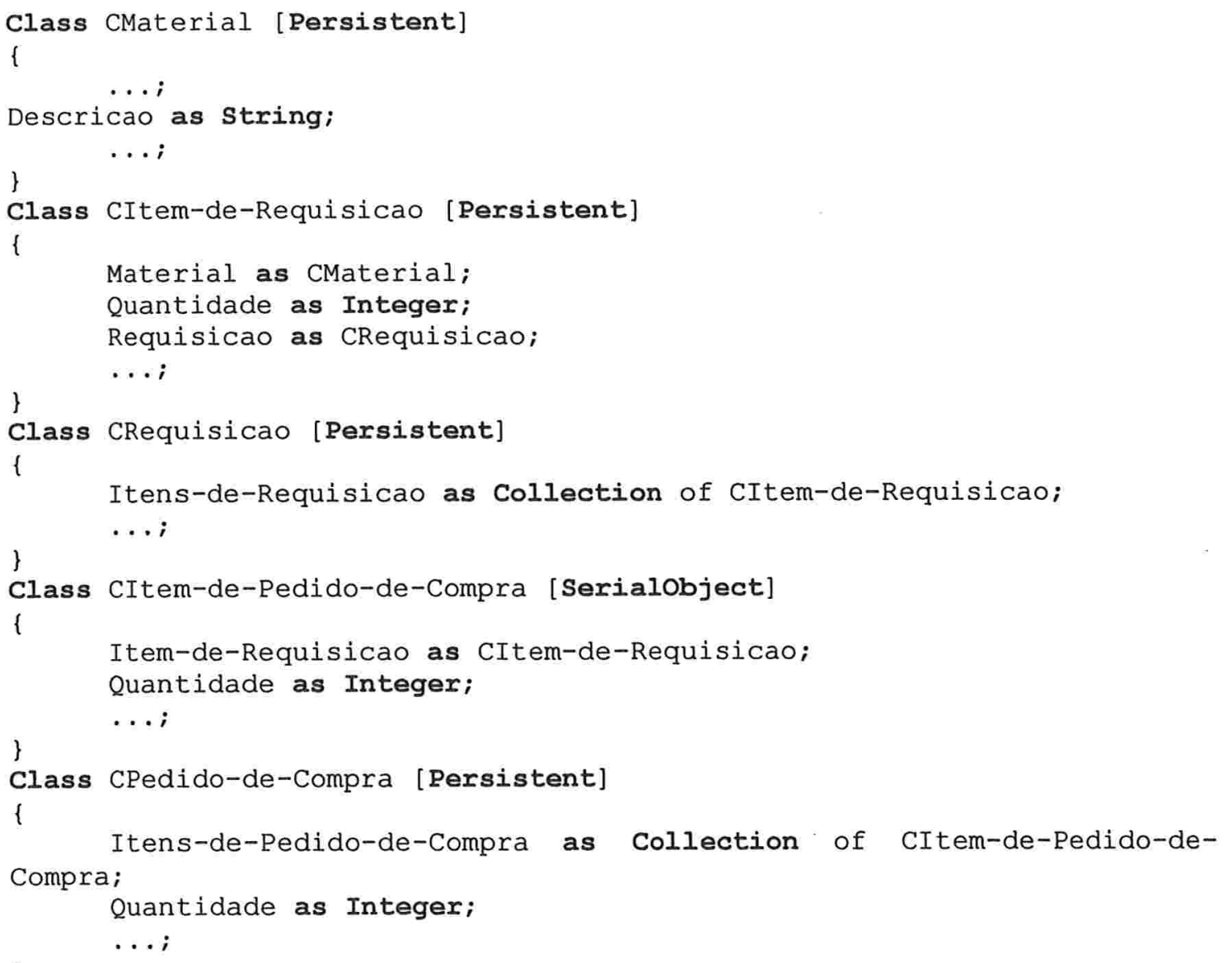

Método para inclusão de uma requisição $\operatorname{com} n$ itens de materiais:

...; // Comandos para conexão com o BD, etc.

ORequisicao= new CRequisicao;

loop

1

1* Aqui devem estar comandos para a Obtenção do Oid do próximo material por meio de uma tela; supomos que seu valor seja colocação na variável mat-Id */

OItem-de-Requisicao = new CItem-de-Requisicao;

OMaterial = Class (CMaterial). OpenId (\%mat-Id[i]);

OItem-de-Requisicao. Material = OMaterial;

/* Aqui devem estar comandos para obtenção da quantidade do material; supomos que seja colocado em mQuant. * / OItem-de-Requisicao.Quantidade = mQuant;

ORequisicao. Itens-de-Requisicao. Insert (OItem-de-Requisicao);

OItem-de-Requisicao. Requisicao = ORequisicao;

//salvamento de um item de requisição em BDOO. OItem-de-Requisicao.Save;

1 * Aqui deve ser exibida uma tela solicitando ao usuário informação, colocada na variável oncerrar itens, se deseja encerrar a inclusão de produtos no pedido */

\} until \%encerrar_itens; 
//salvamento da requisição no BDOO.

ORequisicao.Save;

)

Método para inclusão de um pedido de compra com os seus itens de requisição:

\{

OPedido-de-Compra $=$ new $\mathrm{CPedido-de-Compra;}$

loop

1

/* Aqui devem estar comandos para a Obtenção do Oid de OItem-de-Requisicao por meio de uma tela; supomos que seu valor seja colocação na variável req-Id */ OItem-de-Requisicao $=$ Class (CItem-de-Requisicao). OpenId (\%req-Id);

OItem-de-Pedido-de-Compra = new CItem-de-Pedido-de-Compra;

OItem-de-Pedido-de-Compra. Item-de-Requisicao $=$ OItem-de-Requisicao;

1* Aqui devem estar comandos para obtenção da quantidade do material; supomos que seja colocado em ঃpQuant.* / OItem-de-Pedido-de-Compra.Quantidade $=$ \%pQuant; OPedido-de-Compra.Itens-de-Pedido-de-Compra.Insert (OItem-de-Pedido-de-Compra);

1* Aqui deve ser exibida uma tela solicitando ao usuário informação, colocada na variável oncerrar_itens, se deseja encerrar a inclusão de requisições no pedido */

\} until oncerrar itens;

OPedido-de-Compra.Save;

\}

...;

\subsection{Generalização/especialização}

Em sistemas empresariais geralmente há dois tipos de cadastros, das pessoas físicas e das pessoas jurídicas. Isso é representado no MER por meio de uma especialização, como mostrado na fig. 3.6-1; o X no triângulo indica uma especialização exclusiva, isto é, se uma pessoa é do tipo "física" não pode ser do tipo "jurídica" e viceversa [SET 05]. 


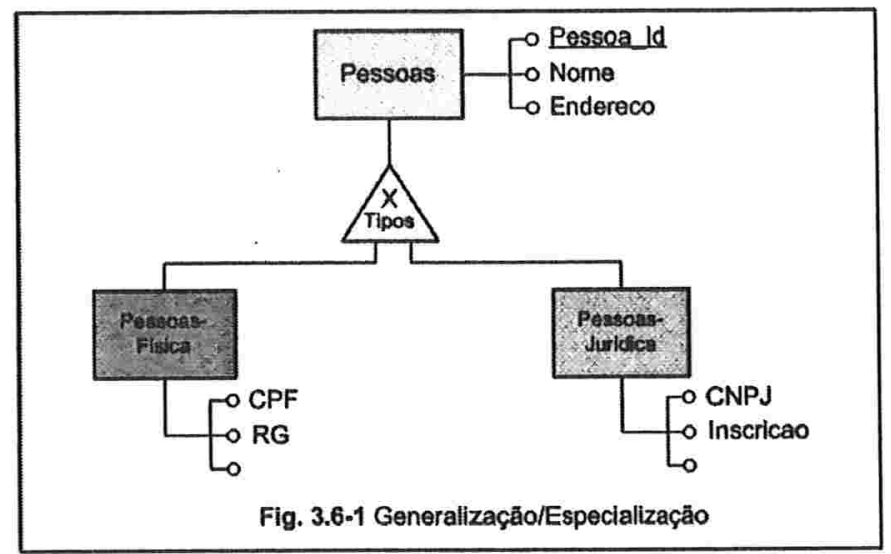

Uma possível implementação em um BDR está na fig. 3.6-2. Foi usada uma ligação generalizada [SET 05], e colocada uma chave estrangeira em cada uma das tabelas especializadas, permitindo fazer junções das mesmas com Pessoas, que contém os atributos comuns aos dois tipos especializados. A finalidade dessa implementação é obter melhor reaproveitamento de código e evitar redundância dos dados.

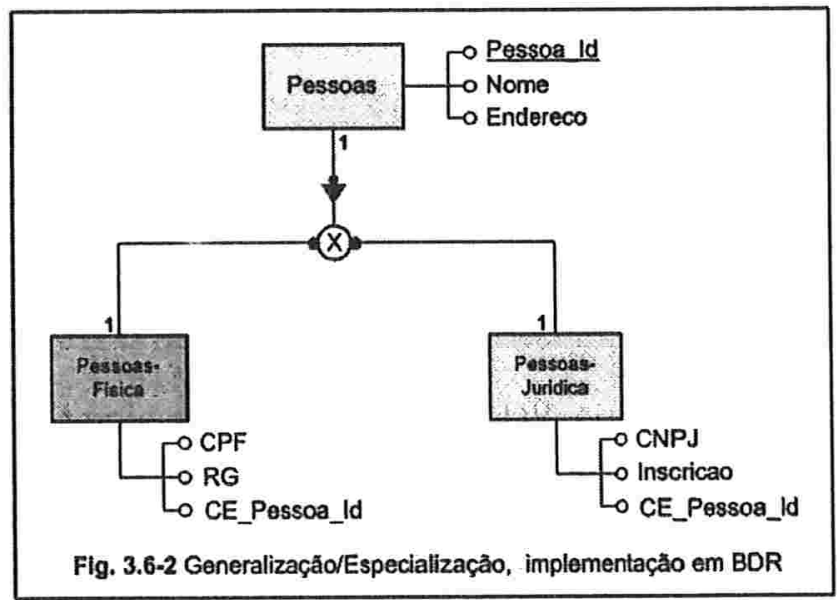

A implementação dessa estrutura em um BDOO é muito simples, pois usa o conceito de herança de classes. A fig. 3.6-3 mostra nossa representação de herança de classes para esse exemplo. Nas consultas, não haverá necessidade de especificar junções de tabelas; além disso, os métodos criados na classe CPessoa são naturalmente encapsulados e reaproveitados, o que não ocorre em um BDR. 


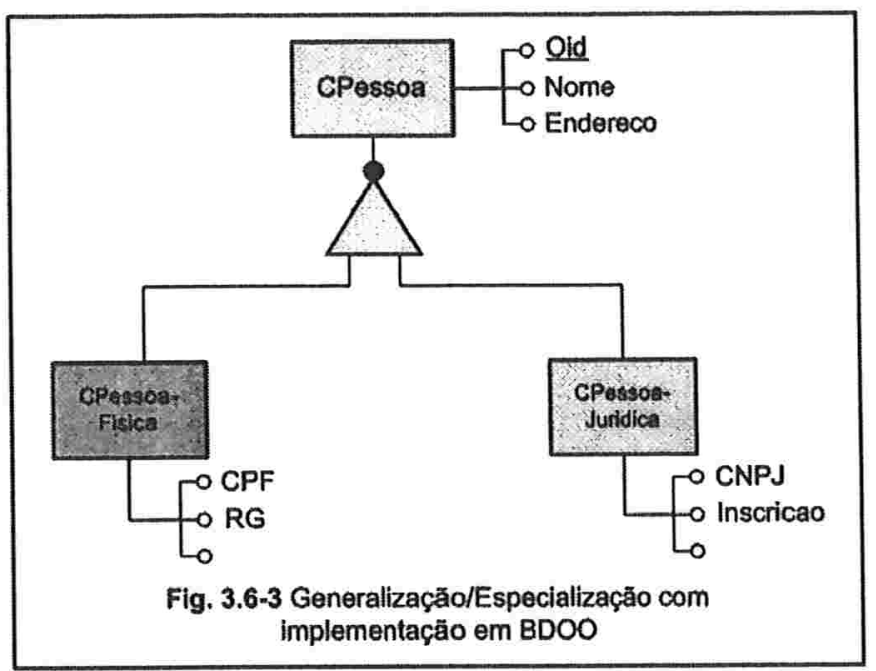

Seguem as declarações das classes com heranças:

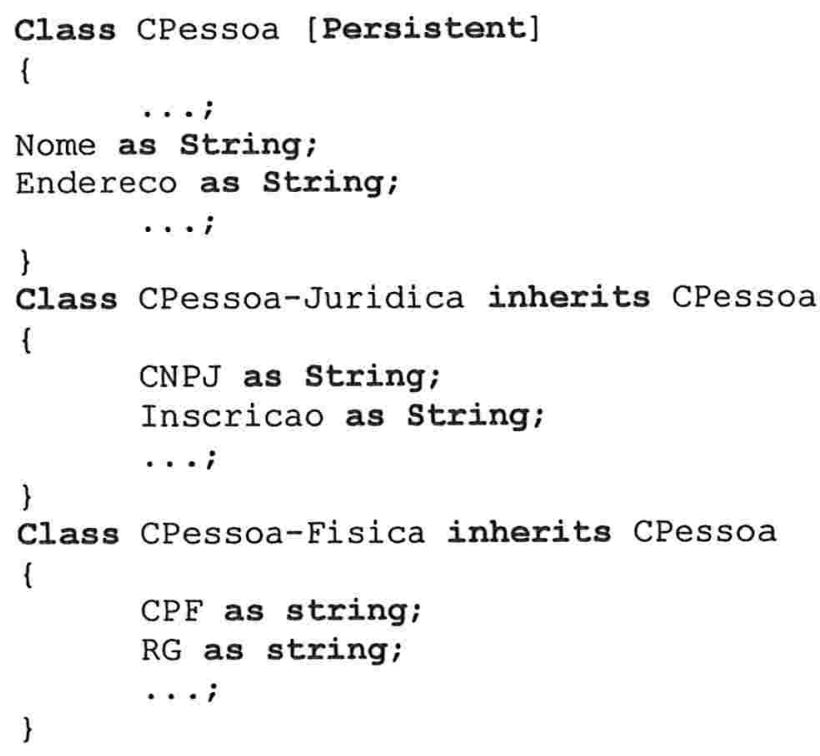




\section{Esquemas de conversão do MER para BDOO}

A partir dos exemplos acima, bem como das notações gráficas apresentadas, podem-se elaborar esquemas gerais abstratos para implementação de um MER em um BDOO.

\subsection{Esquema 1: Relacionamentos 1:1, 1:N e $\mathrm{N}: \mathrm{N}$}

Na fig. 4.1, o esquema 1, solução 1 , pode ser usado nos 3 casos de multiplicidades:

(a) 1:1. Basta tirar o asterisco do atributo $R$ de $C E 1$. Essa solução dá eficiência às consultas que não especificam valores de atributos de E2; CE1 torna-se o objetoraiz na visão estrutural. Se, ao contrário, forem dados valores para atributos de E2 e não para atributos de E1, deve-se inverter a figura, colocando o atributo $\mathrm{R}$ em CE2.

(b) $1: \mathrm{N}$, sendo a multiplicidade 1 no lado de E1. Esse esquema dá eficiência às consultas que não especificam valores de atributos de E2. Se, ao contrário, forem dados valores para atributos de E2 e não para atributos de E1, deve-se inverter a figura, colocando o atributo $\mathrm{R}$ em $\mathrm{CE} 2$, e retirando o asterisco, isto é, $\mathrm{R}$ deixa de ser uma coleção.

(c) $\mathbf{N}: \mathbf{N}$. Esse esquema dá eficiência às consultas que não especificam valores de atributos de E2. Se, ao contrário, forem dados valores para atributos de E2 e não para atributos de E1, deve-se inverter a figura, colocando em CE2 o atributo $\mathrm{R}$ como está, isto é, uma coleção.

No caso $\mathrm{N}: \mathrm{N}$, ainda há a solução 2 , na qual a busca é eficiente tanto especificando-se valores de atributos de E1 como de E2. No entanto, ela tem a desvantagem de conter redundâncias: cada par do relacionamento e seus atributos são representados duas vezes. Essa solução pode também ser usada nos casos de relacionamentos 1:1 e 1:N, quando se deseja eficiência nas consultas em que se especificam valores de atributos dos dois conjuntos de entidades.

Note-se que os GBDOOs Caché e FastObjects permitem que se declare uma coleção como sendo um índice. No entanto, obviamente um atributo que é uma classe não pode ser indexado; o que se indexa é alguns dos atributos da classe. 


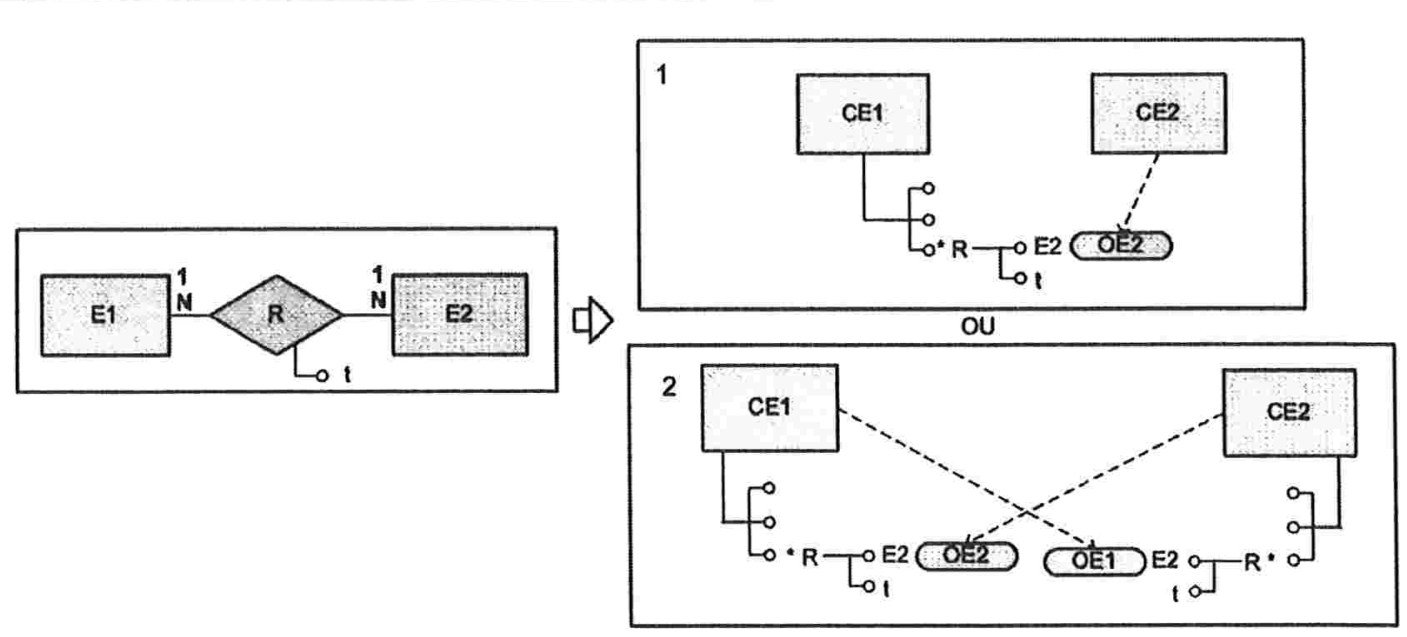

Fig. 4.1 Esquema 1: Relacionamentos 1:1, 1:N e N:N

\subsection{Esquema 2: auto-relacionamento N:N}

$\mathrm{Na}$ fig. 4.2, mostramos uma possível implementação, que visa possibilitar buscas eficientes tanto iniciadas pelo papel P1, usando-se o atributo R-P1, quanto pelo papel P2, usando-se o atributo R-P2. Isso permite um percurso eficiente tanto partindo de algum elemento $e$ de $\mathrm{E}$ para os elementos relacionados por P1, quanto por P2. No exemplo da fig. 3.4-5, isso é o mesmo que buscar, em um caso, tanto os componentes de um material $e$ quanto os materiais em que $e$ entra como componente. Os atributos t em CR-P1 e CRP2 implementam o atributo $t$ (no caso das composições, poderia ser a quantidade que uma peça entra na outra).

Note-se que essa implementação tem redundâncias: dados um par $\left(\mathrm{e}_{1}, \mathrm{e}_{2}\right) \in \mathrm{R}$; envolvendo dois elementos $e_{1}$ e $e_{2}$ de $\mathrm{E}$, onde $\mathrm{e}_{1}$ faz o papel de P1 e $\mathrm{e}_{2}$ o de P2, o atributo R-P1 da representação de $e_{1}$ em CE deve conter o objeto que representa $e_{2}$, e o atributo RP2 de $e_{2}$ deve conter o objeto $e_{1}$, isto é, há duas representações para o mesmo par do relacionamento. Além disso, cada valor do atributo $\mathrm{t}$ do par deve também ser representado duas vezes, uma em CE1 e outra em CE2.

Note-se ainda que, se o percurso dá-se sempre a partir de um dos papéis do relacionamento, por exemplo, P1 (como no caso de se querer sempre os componentes de uma peça $p$ e nunca as peças em que $p$ entra), não é necessário implementar R-P2 e CRP2, eliminando-se a redundância citada. Essa solução também pode ser empregada se há muito mais consultas por P1 do que por P2. 


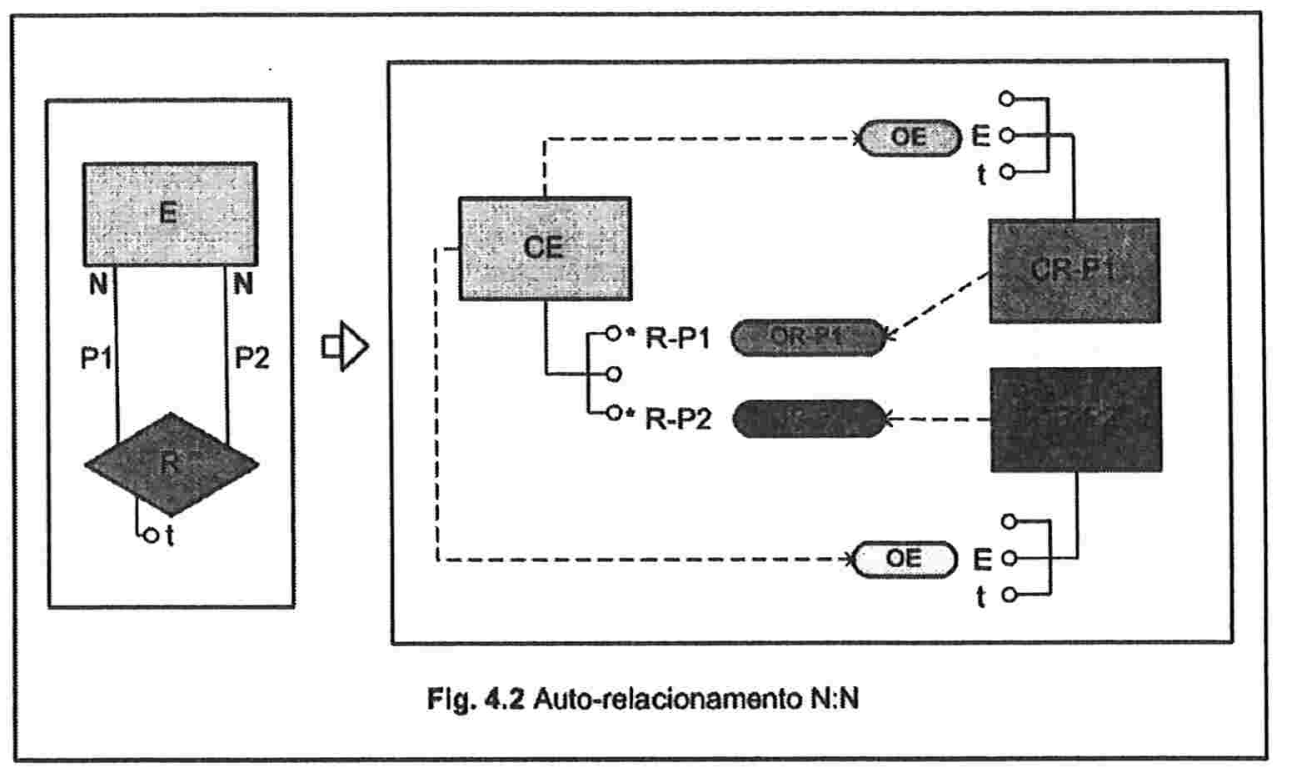

\subsection{Esquema 3: Relacionamento com uma agregação}

A fig. 4.3-1 mostra uma implementaçãde relacionamento de uma agregação entre E1, E2 e R1 (Usamos aqui uma notação gráfica alternativa para agregação, apresentada em [SET 05]); a agregação é relacionada com E3 por meio de R2. Na implementação em BDOO, foram colocados dois atributos E1 e E2 em CR1 para que o OR1 contenha as informações dos OE1 e OE2. Na CR2 foi colocado o atributo R1 que assume valores de objetos de OR1. A sua visão estrutural está na fig. 4.3-2. Um exemplo desta implementação está na fig. 3.5-6. A solução tem a desvantagem de introduzir redundâncias na representação das ligações. 

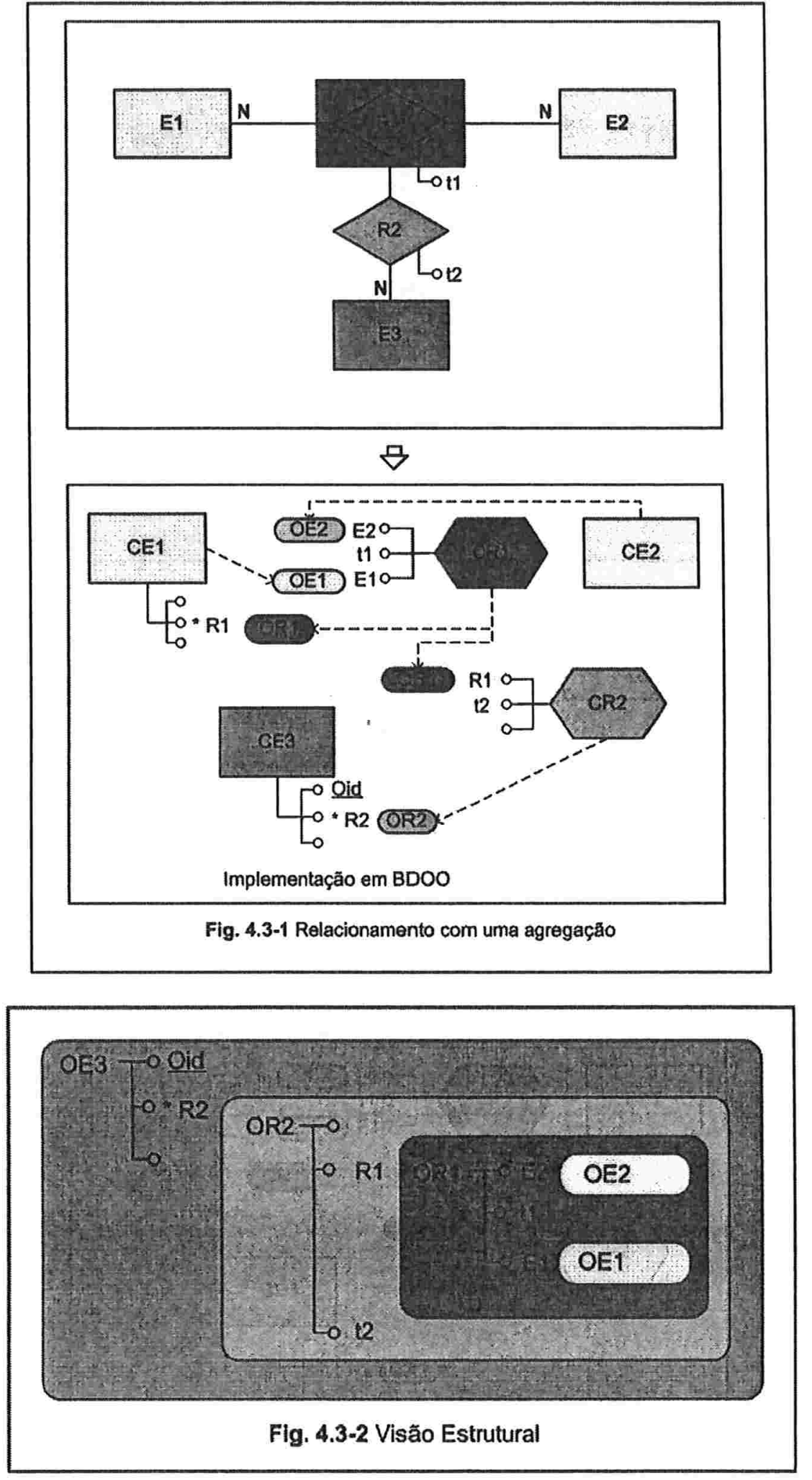


\subsection{Esquema 4: Generalização/especialização}

$\mathrm{Na}$ fig. 4.4 mostramos a implementação em BDOO da estrutura de generalização/especialização. A solução para este caso, como indicamos em 3.6, emprega a herança da OO. As classes CE1 até CEn herdam os atributos e métodos da classe CE. A letra $e$ indica o critério (atributo) para a distinção entre as várias especializações.

Se a especialização é exclusiva (deve ser indicada no MER por um $\mathbf{x}$ dentro do triângulo), a herança deve ser simples; se ela é inclusiva, (indicada por um o), deve ser múltipla; nesse ultimo caso, o triangulo deve ter um $m$.

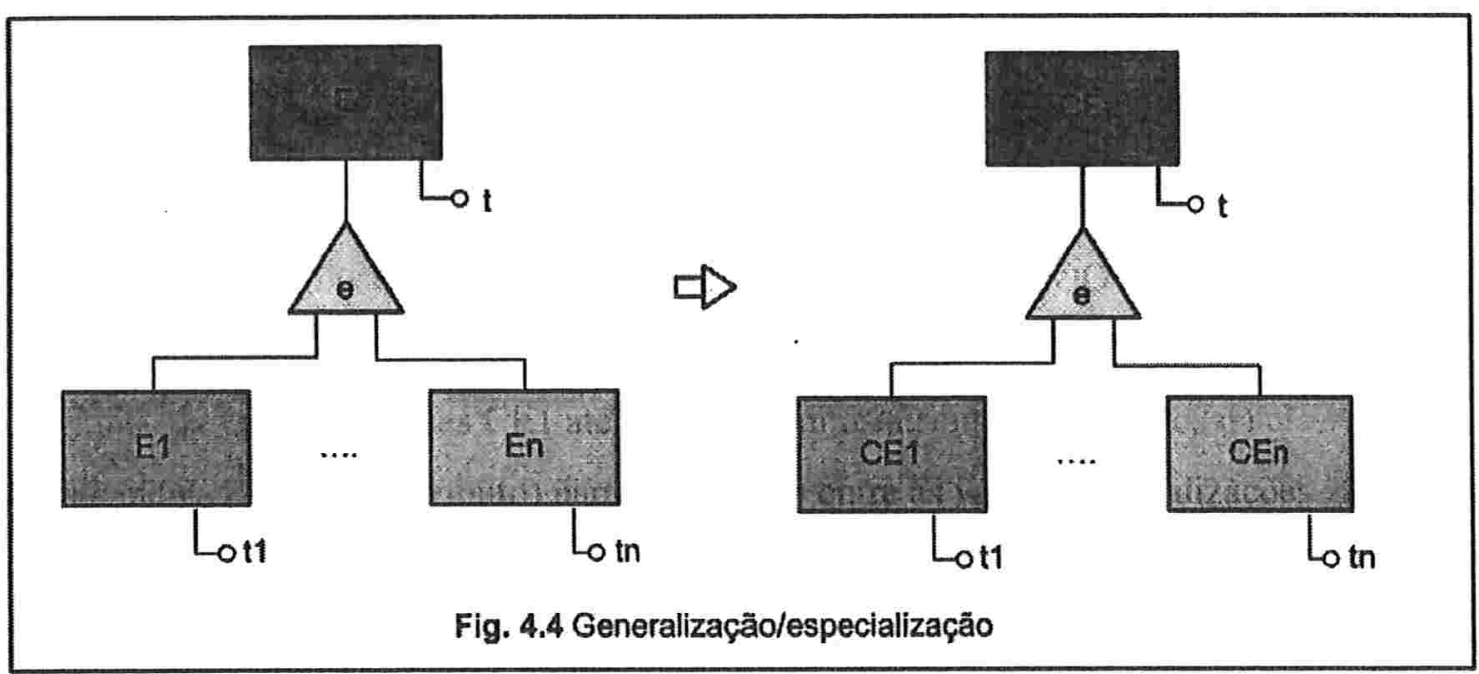




\section{Estudo de caso: o MER de um sistema e sua implementação em BDR e BDOO}

Neste capitulo, vamos mostrar como aplicamos de nossas idéias no desenvolvimento de um sistema administrativo comercial, ilustrando assim como a visão estrutural pode ajudar na implementação de um sistema com BDOO, e como ela é superior a uma implementação em BDR.

Esse sistema foi desenvolvido em 2005 para a empresa importadora e distribuidora Zimex Comercial Ltda, de São Paulo. Antes de conhecer os BDOOs, fizemos várias implementações de sistemas de aplicação semelhante, para empresas distribuidoras, usando as linguagens ASP e o GBDR MySQL. Ao receber do Prof. Setzer a sugestão do tema desta dissertação, qual seja, uma comparação entre BDR e BDOO, e obtendo de E. Nassu a sugestão de examinar o GBDOO Caché, fizemos a próxima implementação daquele sistema, para a Zimex, usando esse gerenciador, esperando com isso obter subsídios práticos para o presente trabalho. Para isso, empregamos as LOOs Java, CSP, ObjectScript e o BDOO Caché. A decisão de partir para algo novo, apesar dos riscos nisso envolvidos, revelou ter sido excelente.

A fig. 5-1 mostra o MER para esse sistema, apenas no que diz respeito aos conjuntos de entidades e de relacionamentos, isto é, sem os atributos. Por uma questão de espaço, separamos as especializações na fig. 5-2. A fig. 5-3 mostra o BDR correspondente à fig. 5-1 e na fig. 5-4 a implementação das especializações no BDR nas quais incluímos as chaves e alguns atributos, As implementações correspondentes em BDOO estão nas figs. 5-5 e 5-6. A fig. 5-7 é a implementação da especialização com as heranças e as 5-8 e 5-9 mostram todas as visões estruturais desse BDOO empregadas no mencionado desenvolvimento.

A questão de como o sistema funciona não é o tema deste trabalho. Portanto não vamos explicar os elementos do MER um por um. Podemos, no entanto, garantir que o sistema é bem completo, controlando o estoque, os clientes, vendedores, compras, vendas, emissões de notas fiscais, despacho de material, contas a receber e a pagar. Ele gera caixa, fluxo de caixa e apuração de resultados periódicos.

A fig. 5-3 mostra a implementação do MER para um BDR e as figs. 5-4 e 5-5 são as implementações de especializações e generalização das entidades. As figs. 5-6 e 5-7 
são as implementações em BDOO. A fig. 5-8 é a visão estrutural da fig. 5-6 e a fig. 5-9 da fig. 5-7.

As figs. 5-4 e 5-5, ER em especialização e generalização, servem como ER tanto para BDR e quanto para BDOO. Elas são bem estruturadas visualmente. Mas a fig. 5-3, implementação de ER em BDR, é o mais usado hoje, não traz uma visão estruturada dos dados. Mas. Então a comparação é focalizada entre a fig. 5-3 com as fig. 5-6 e 5-7. As figs. 5-8 e 5-9 são as figuras auxiliares das fig. 5-6 e 5-7, a fim de monstrar conceitualmente que elas são estruturadas. Do ponto de vista de engenharia de software, essas visões estruturais tornaram as visões das estruturas de dados usadas em todas as aplicações do sistema muito simples, evitando muitos possíveis erros durante o desenvolvimento. 


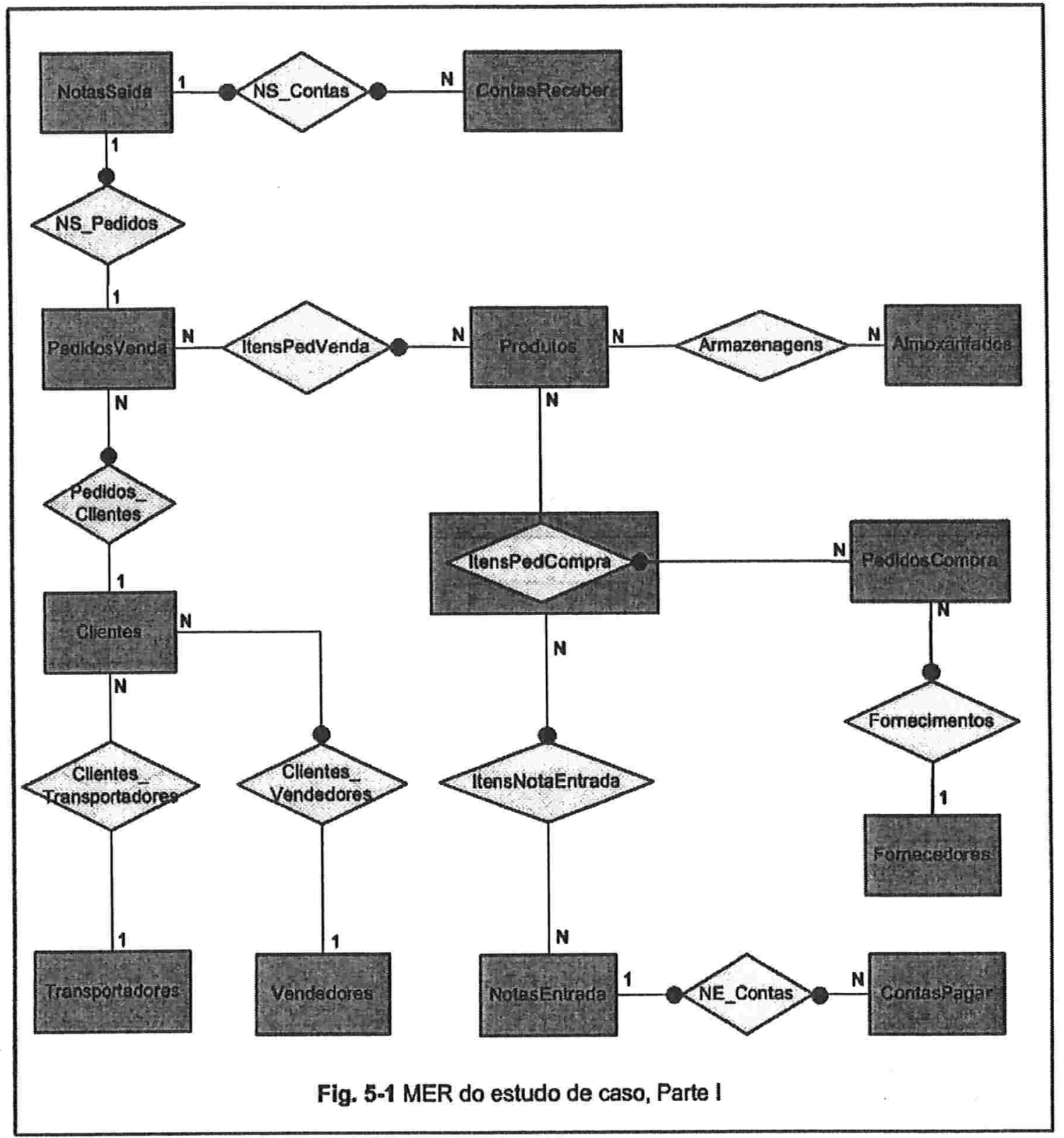




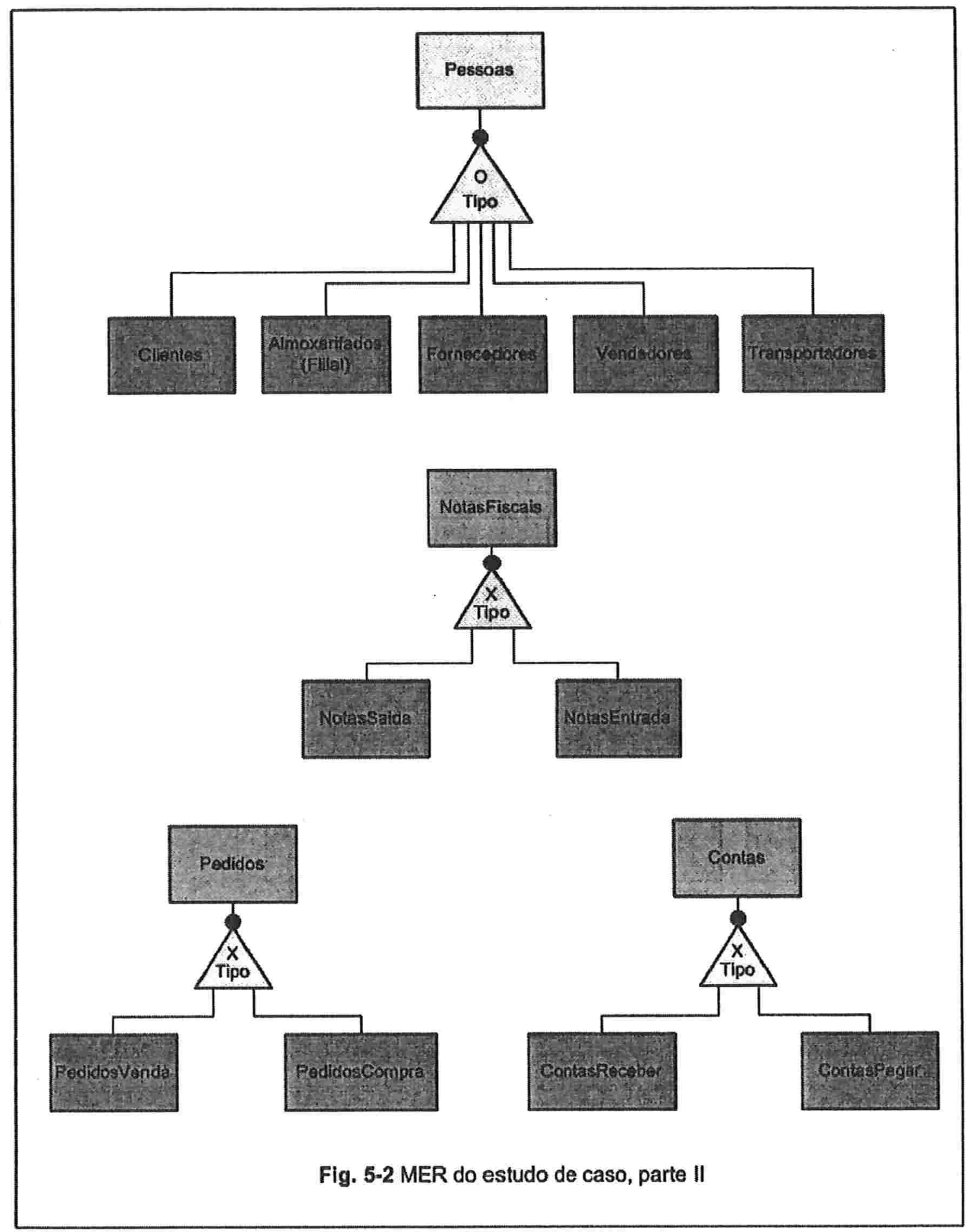




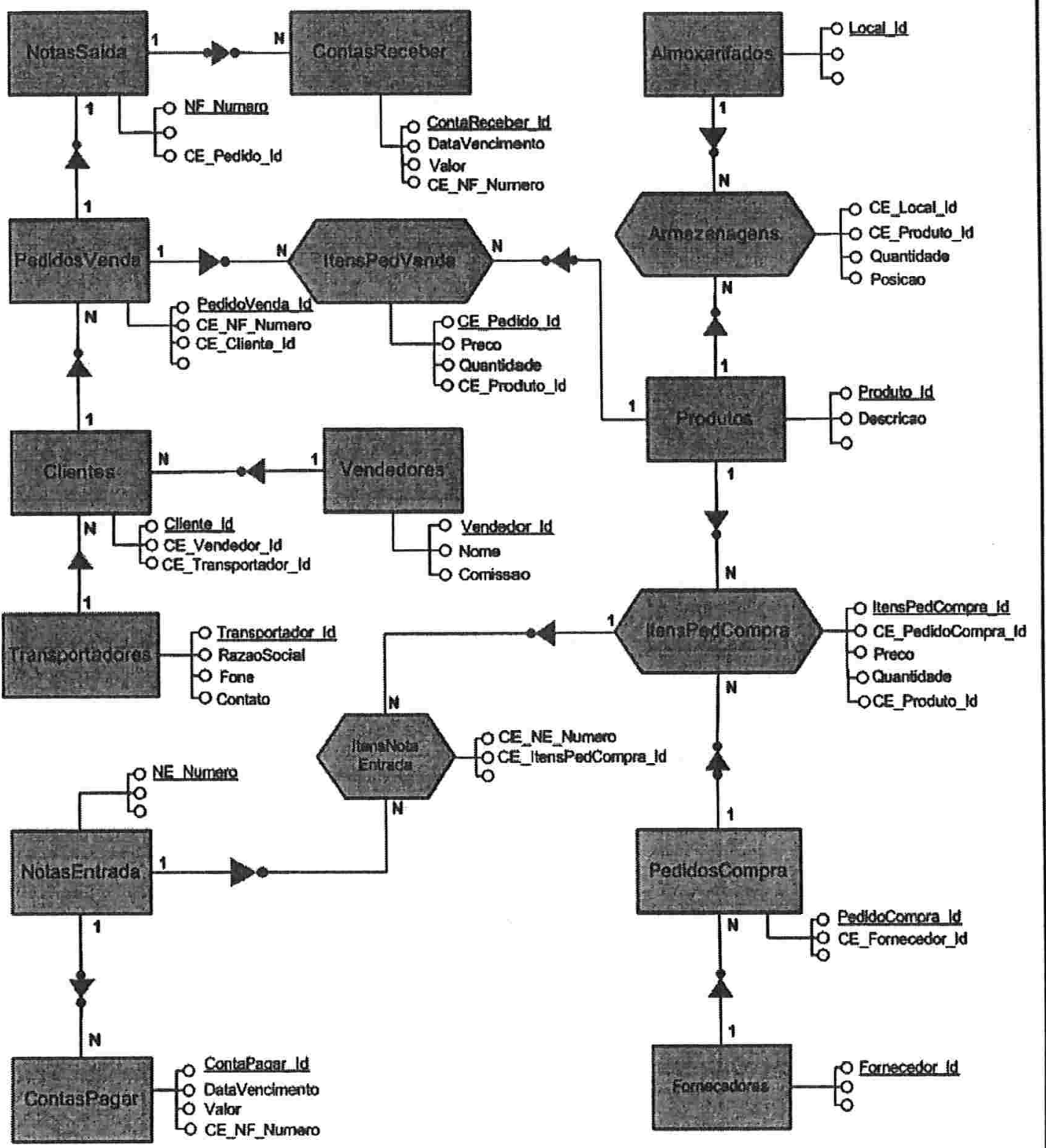

Fig. 5-3 Implementaçäo em BDR Parte I 


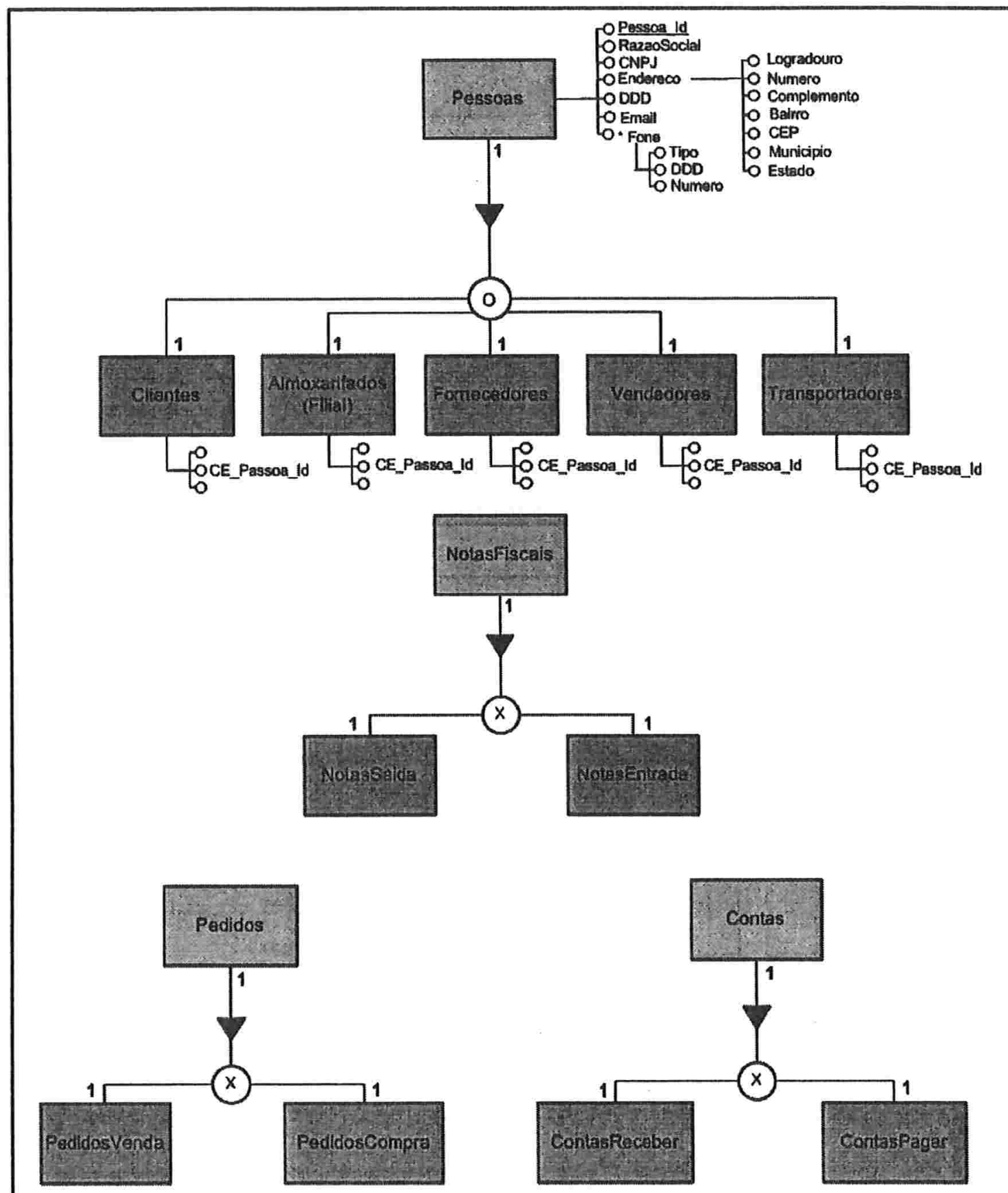

Fig. 5-4 Implementação de especialização/generalização em BDR 


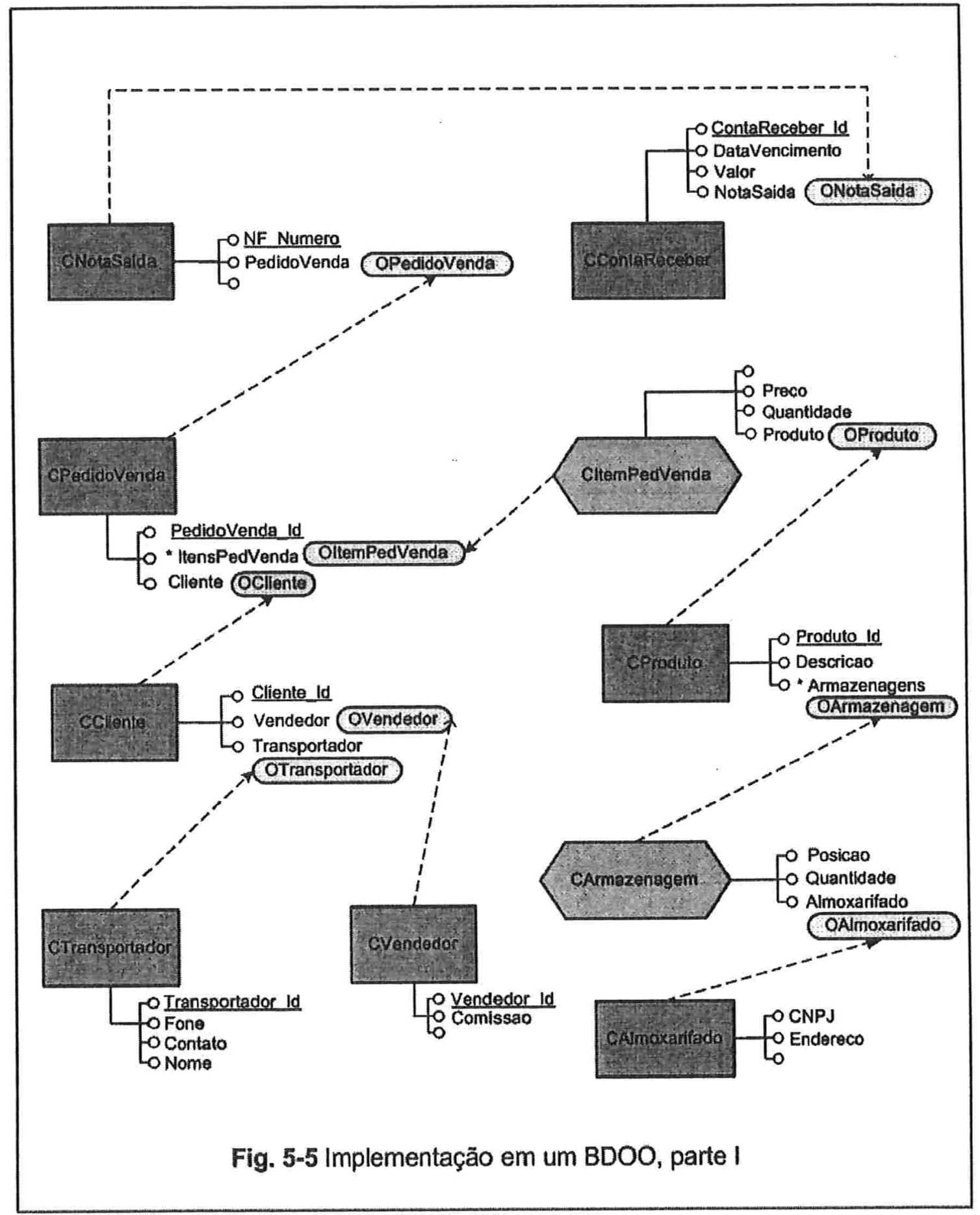




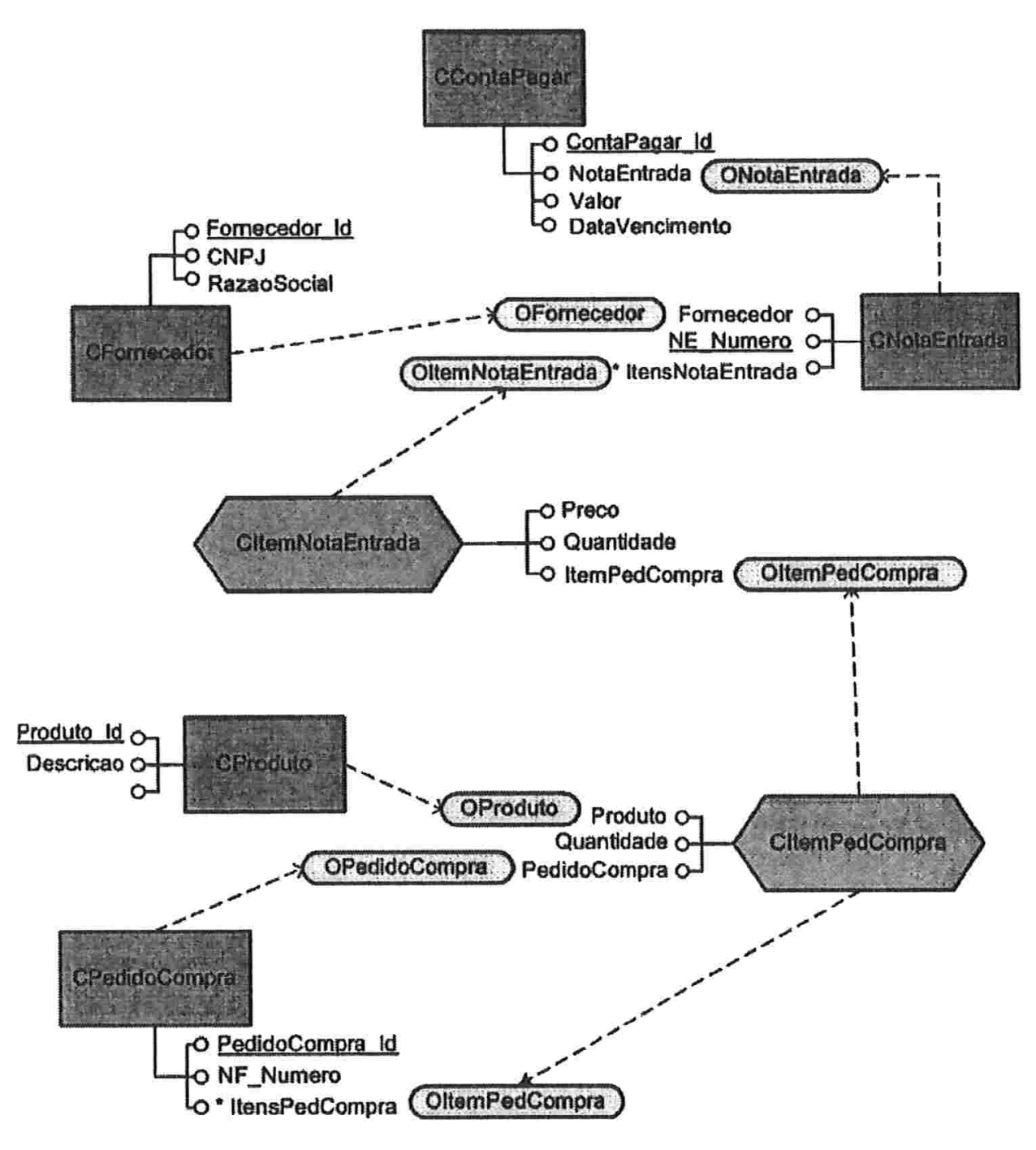

Fig. 5-6 Implementação em um BDOO, parte II 


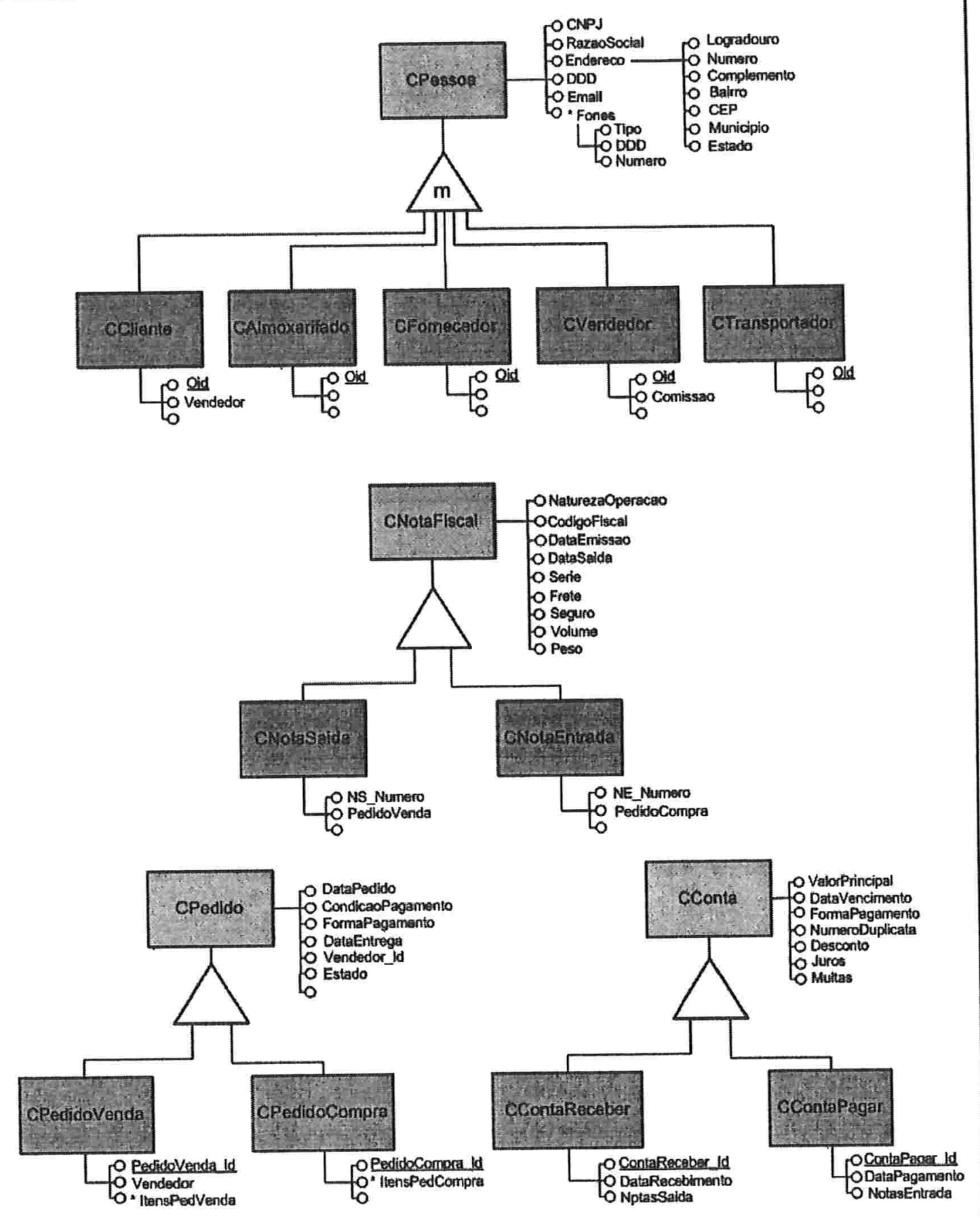

Fig. 5-7 : Implementação das especializações/generalizações em um BDOO 


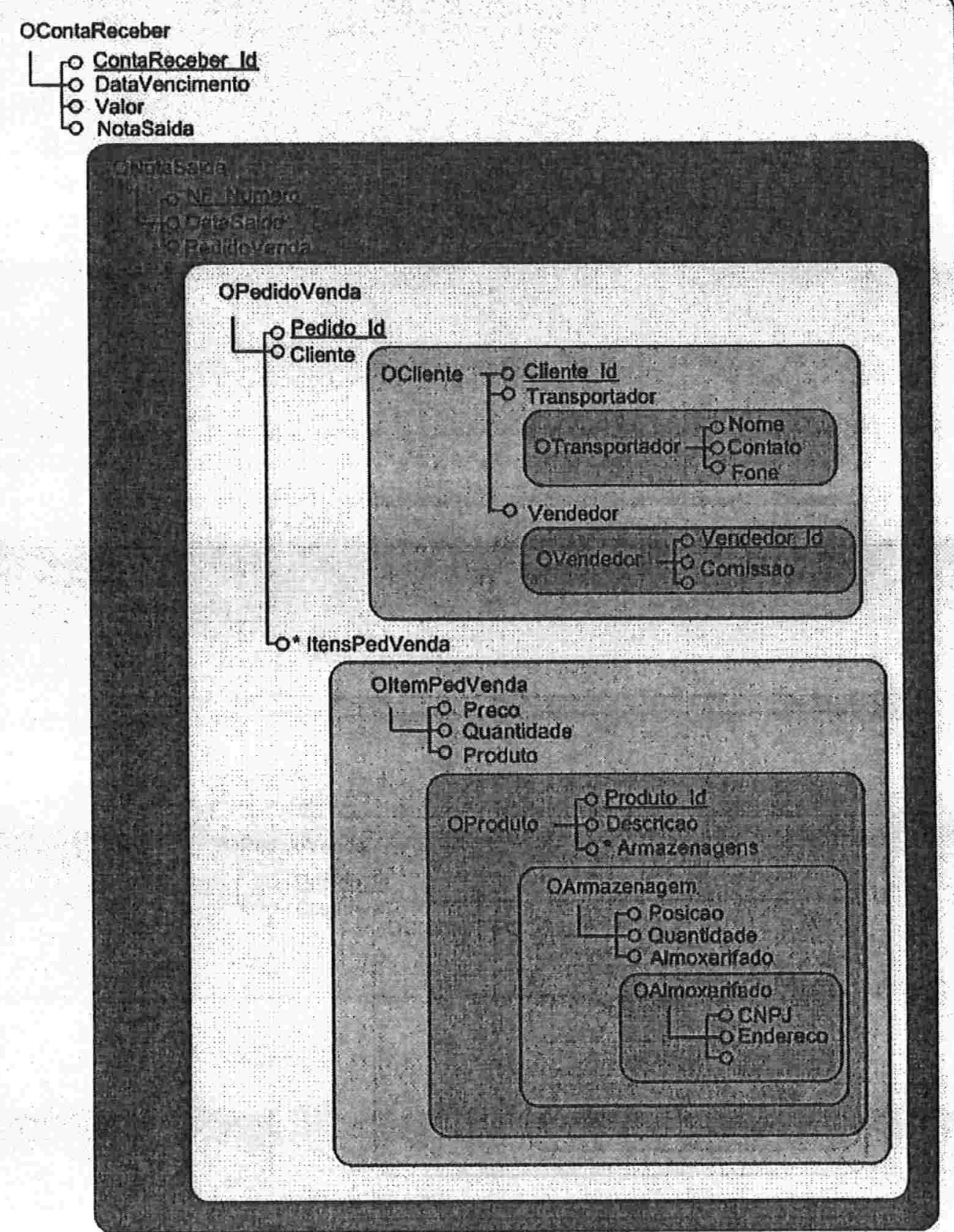

Fig. 5-8 Visão estrutural I 


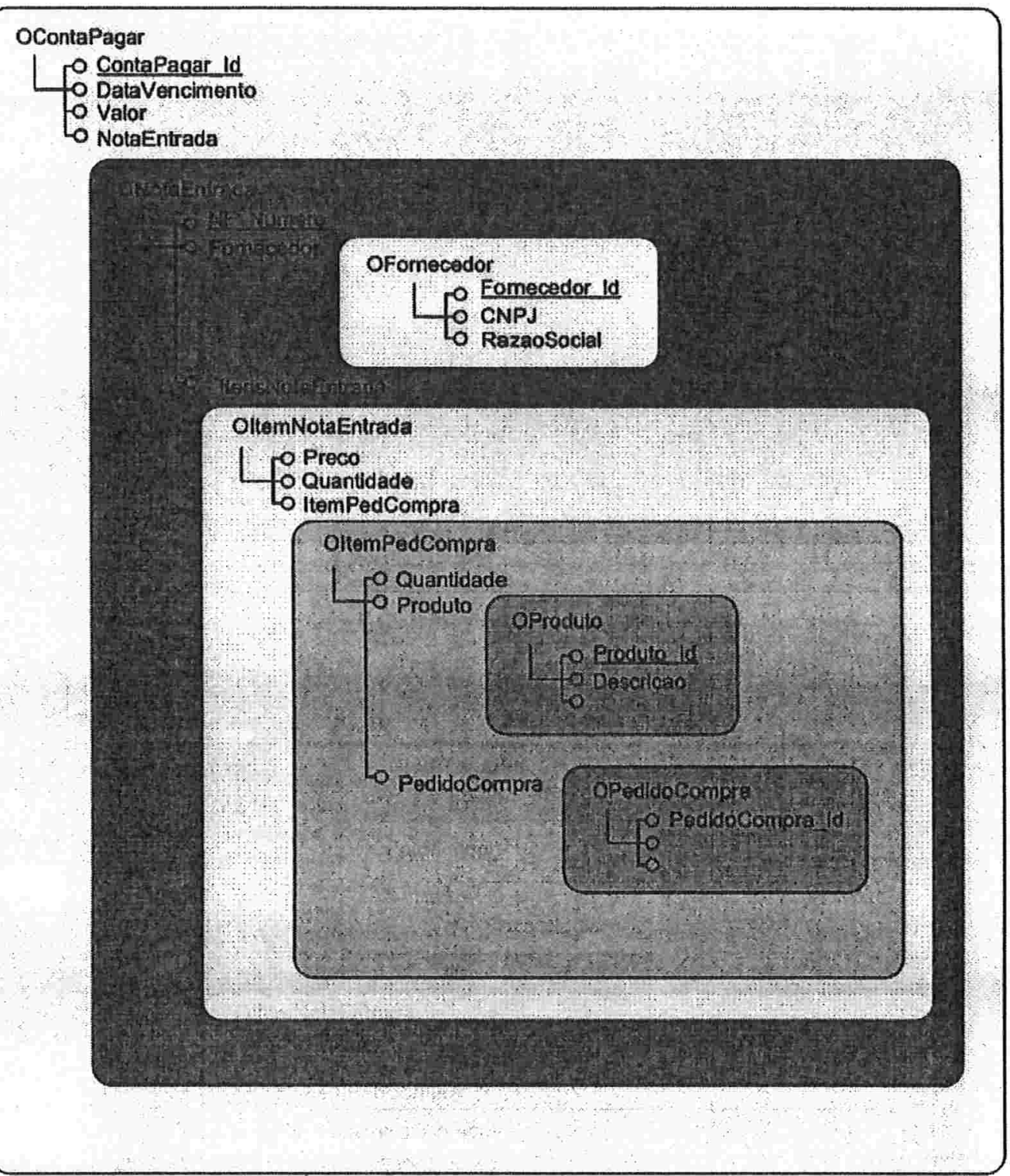

Fig. 5-9 Visão estrutural II

A primeira versão desse sistema, com uso de uma linguagem estruturada (ASP e VB) e BDR MySQL, ficou com mais que 500 programas e mais de 100.000 linhas de código Levou 6 meses para ser desenvolvida e causou muito re-trabalhos no primeiro ano de uso. Uma grande parte do sistema teve que ser refeita, pois devido às inúmeras alterações, passou a ser impossível de ser modificada. 
A nova versão, com BDOO Caché e linguagens OO, principalmente Caché Server Page (CSP), ObjectScript do Caché e JavaScript, ficou com apenas 175 programas e cerca de 20.000 linhas de código. Levou 3 meses para ser desenvolvida e depois de 2 meses do sistema implantado, não precisou mais de re-trabalho. Os trabalhos de manutenção revelaram-se extremamente simples. Em geral, em qualquer problema que surgia, bastava um exame superficial nas figuras da visão estrutural para logo descobrirse a sua causa.

O melhor de tudo é que o sistema inteiro não tem mais junções de tabelas e chaves estrangeiras que, em nossa experiência, são grandes fontes de erros. 


\section{Análise de sistemas e de requisitos de software voltada para BDOO}

Em [LIN 05] é apresentado um método original para análise de requisitos de software, baseado no MER. Nesse método, começa-se construído o MER inicial de uma aplicação, apenas com os atributos mais característicos. Em seguida, passam-se a detalhar os atributos de todas as entidades e relacionamentos, ao mesmo tempo em que se desenham protótipos de telas e relatórios. Com o MER completo, e definitivo, contendo todos os atributos, mais as telas e relatórios definitivos passa-se, baseado nesses elementos, à análise e descrição dos requisitos de software. Em [LIN 05] é apresentado um formulário especial para a descrição de cada requisito.

Esse método pode ser completado para a implementação em um BDOO. Como vimos, há várias possibilidades de implementar uma estrutura do MER, como por exemplo um relacionamento $\mathrm{N}: \mathrm{N}$. Assim, propomos que se completem as fases descritas daquele método, e em seguida projetem-se as estruturas do BDOO, pois nessa fase ter-seá uma boa noção de como serão todas as consultas, podendo-se escolher a solução mais adequada e eficiente dentre todas as estruturas possíveis. Em seguida, desenham-se as visões estruturais, para auxiliar a programação.

É importante neste ponto chamar a atenção para o fato de não se dever ficar obcecado com as estruturas puramente orientadas a objetos. De fato, em alguns casos, é possível que uma implementação usando as estruturas de um BDR normalizado seja mais eficiente; pode-se até pensar em usar algumas não-normalizações, que são permitidas pelos BDOO (empregando-se atributos tipo coleção, eventualmente declarados como índices). Um exemplo típico foi visto no caso de auto-relacionamentos $\mathrm{N}: \mathrm{N}$ (V. 3.4 e 4.2). Se é importante percorrer uma estrutura de composições de materiais tanto partindo-se dos produtos finais como dos componentes, a melhor solução pode ser a relacional, como na fig. 3.4-2, pois aí não há redundâncias. Todos os GBDOOs implementam busca eficiente de índices, por meio de B-árvores. Assim, declarando-se naquela figura CE_Composto_de_Id e CE_Componente_de_Id como índices em um BDOO, usando a implementação de um BDR, consegue-se o percurso eficiente nas estruturas nos dois sentidos. 


\section{Conclusões}

Neste trabalho introduzimos uma notação gráfica para o projeto de BDOO. Comparando com outras notações, como a UML, vê-se que a nossa é mais rica e clara. Por exemplo, distinguimos, seguindo [SET 05], as classes que implementam relacionamentos do MER (usando hexágonos). Os retângulos arredondados, representando atributos que são objetos de classes também facilitam a compreensão dos diagramas; essa notação inexiste na UML. O uso de triângulos unindo todas as subclasses de uma classe igualmente parece ser mais claro do que as setas vazias da UML. Finalmente, nossa grande contribuição para a representação gráfica foram as visões estruturais, que se mostraram de uma utilidade enorme na programação.

Os exemplos de esqueletos de programas podem servir de padrões para a programação, tendo evidentemente de ser adaptados para cada LOO.

Os esquemas de conversão do MER para o modelo de BDOO, que introduzimos, podem ser usados como um catálogo mostrando as várias possibilidades e levando o implementador a pensar sobre elas e escolher a mais conveniente. Esperamos também que as nomenclaturas introduzidas neste trabalho (como por exemplo, escrever os nomes de classes começando com $\mathrm{C}$ e seus os objetos com os mesmos nomes, mas começando com 0) possam servir para facilitar a programação e a documentação dos programas. Essa distinção desvia do padrão bastante difundido de se usar os mesmos nomes para classes e objetos, isto é, fazendo uma confusão entre uma estrutura e os objetos instanciados que a seguem.

O estudo de caso é um exemplo completo baseado em um caso real de desenvolvimento que, esperamos, seja útil para ilustrar nosso método.

Neste trabalho, abordamos principalmente a modelagem e a implementação de BDOOs e demonstramos a sua viabilidade e superioridade. Infelizmente, os BDOOs ainda não são muito aceitos no mundo. Nos principais livros sobre $\mathrm{BD}$, não há boas recomendações sobre eles. O livro de Ramakrishnan faz uma comparação entre BDOR e BDOO e apresenta as seguintes criticas ao BDOO [RAG 02, p. 770]:

a) Cada GBDOO é integrado a uma determinada LOO como, por exemplo, C++, Java ou Smalltalk. 
b) Cada transação de atualização de um GBDOO bloqueia o BD como um todo. Isso pode dar origem a uma fila de acesso e uma lentidão no acesso pelos outros usuários.

c) A linguagem OQL não tem tanta eficiência como a SQL, especialmente a SQL 1999, que ganhou interfaces com muito mais linguagens de programação, que trabalham com ela como embeded SQL.

Com nossa experiência sobre GBDOOs, podemos rebater essas criticas da seguinte maneira:

Para o ponto (a): o BDOO foi criado inicialmente com a idéia de adicionar persistência aos objetos de uma LOO. Mas esses objetos são da particular linguagem de programação. Assim, os GBDOOs iniciais foram feitos tendo em vista uma determinada linguagem. Com a evolução, os produtores lançaram GBDOOs com diversas versões, cada versão para uma linguagem. Mas hoje, já existem GBDOOs para várias linguagens, desde que sejam orientadas a objetos, como é o caso do Caché da Intersystems. Fundamentalmente, os primeiros GBDOOs armazenavam objetos criados pelas LOO já existentes. No Caché, os objetos já são dele próprio, porque ele possui um ambiente de declaração de classes, ou seja, não trabalha com objetos das outras linguagens. Para empregá-las, foram criados componentes de conexão e manipulação, desenvolvidos pela própria Intersystems, a fim de produzir a comunicação com os objetos do Caché.

Para o ponto (b): Essa crítica reflete provavelmente os GBDOOs disponíveis ao autor desse capítulo (25) daquele livro naquela época, isto é, FastObjects e GemStone. No primeiro caso, as atualizações de dados dos objetos armazenados no BD são feitas diretamente nos objetos armazenados no repositório. No segundo, é feita uma cópia do banco de dados que o usuário vai manipular (essa operação é denominada de faulting). Depois de fazer a alterações no seu BD, o usuário solicita o armazenamento do BD (para obter persistência; essa operação denominada é de flushing); nesse momento, o GemStone produz um faulting para todos os usuários que estão com esse BD aberto. Para gerenciar os possíveis conflitos, os programadores precisam colocar todas as instruções de atualização dentro de uma sessão tipo Transaction. Infelizmente, numa dessas sessões o nível de bloqueio chega a ser o do BD inteiro, como no GemStone, o que produz filas de espera dos outros usuários. Já o Caché não tem essa característica, pois bloqueia 
apenas cada objeto envolvido em uma transação de alteração de dados, como se passa com o bloqueio de cada linha das tabelas dos BDRs mais modernos.

Para o ponto (c): Realmente a OQL de alguns GBDOOs não tem tantas funções de manipulação de dados como SQL. Mas a OQL, no princípio, foi criada para manipular os objetos, e essa manipulação é diferente da de tabelas de um GBDR. Projetando-se as nossas visões estruturais de modo a que reflitam fielmente as aplicações, estamos convictos de que a eficiência dos GBDOOs será maior do que as dos GBDRs, pois nestes há necessidade de se fazerem freqüentes junções de tabelas. Por exemplo, na fig. 5-9 a invocação de um objeto OContaPagar faz com que os objetos nele contidos, tais como ONotaEntrada, OPedidoCompra, OFornecedor e OProduto dos itens do pedido fiquem todos disponíveis em tempo $\mathbf{T}(1)$.

Assim, essas críticas são baseadas nos primeiros GBDOOs e não nos mais recentes. Os critérios de avaliação não são imparciais e, aparentemente, não partiram do ponto de vista de um desenvolvedor e sim de um pesquisador. Especialmente, não foi avaliado como junções de tabelas prejudicam o trabalhos de programação e de implementações, pois hoje em dia, a menos de transações envolvendo um número enorme de dados (da ordem de milhões), o importante é reduzir o tempo de desenvolvimento dos sistemas. Pensamos ter demonstrado neste trabalho que as visões estruturais permitidas pelos GBDOOs produzem uma redução nesse tempo.

Como dissemos na introdução, este trabalho centrou-se na eficiência de desenvolvimento, não tendo entrado em considerações quanto à eficiência de processamento, principalmente em relação a GBDs relacionais. No entanto, podemos considerar que não há nenhuma razão para que um GBDOO seja menos eficiente, em processamento, do que um GBDR, para BDs implementados no primeiro caso como um BDR, já que o primeiro pode conter índices implementados como o segundo. Por outro lado, o uso de orientação a objetos deveria acelerar consultas que usam junções.

Quisemos, além disso, mostrar neste trabalho que a visão orientada a objetos é uma visão completa dos dados envolvidos em cada transação. A visão relacional é sempre picada em várias partes: as tabelas envolvidas e, eventualmente, algumas tuplas: Somente quando há atributos multivalorados em uma classe (uma coleção), recaímos em 
uma visão semelhante à relacional. No entanto, mostramos que nesse caso há uma solução padronizada envolvendo o percurso dos elementos da coleção.

Esperamos que este trabalho tenha contribuído para mostrar aos desenvolvedores de software que há grandes vantagens no uso de BDOOs, que aos poucos substituam, por estes, o uso que fazem dos BDRs e BDORs. 


\section{Apêndice \\ O GBDOO Caché}

O GBDOO Caché foi criado pela empresa americana Intersystems. Há 3 décadas, ela fornece ao mercado software de grande porte, tais como linguagens de programação, GBDs e ambientes de desenvolvimento. Os seus maiores clientes são hospitais americanos.

O Caché foi lançado em 1997. É um BDOO de alto desempenho, independente de linguagem e com um ambiente de desenvolvimento que permite uma alta eficiência e escala de produção. Atualmente há mais de 4 milhões de usuários em 88 países no mundo. Detalhes sobre a empresa criadora e o BDOO Caché encontram-se no site http://www.intersystems.com.

Naquele site encontra-se também uma versão gratuita do Caché. A versão é limitada a monousuário e armazena até 36 mil objetos em cada classe. Encontram-se também documentações completas e atualizadas, tais como de instalação, introdução, manuais para cada linguagem, arquitetura do Caché, gerenciamento da instalação, etc.

As linguagens tais como CSP, ObjectScript e Basic (uma linguagem especial do Caché, não confundir com a linguagem Basic tradicional) são fáceis de apreender e trabalhar. Um wizard para desenvolver páginas da Internet com CSP usando o BDOO Caché permite construir rápida de uma página contendo as funções de inclusão, busca e manutenção dos dados de uma classe do $\mathrm{BD}$, a partir dos seus atributos que não são objetos.

A versão atual do Caché é a 5.2 (versão para Windows XP ou 2000). Para carregá-la, faça download dos dois pacotes de arquivos CachePCKit (Servidor do Caché, $241 \mathrm{MB}$ ) e CacheClient (65MB), aos quais se tem acesso imediato dentro da página citada acima. Instale o CachePCKit primeiro, escolhendo a linguagem de exibição de títulos e rótulos, e em seguida no mesmo diretório, o CacheClient (o padrão é C:/CacheSys). Aparecerá na barra de tarefas do Windows um cubo mágico azul. Acionando o botão direito do mouse sobre esse cubo aparecem várias opções. Uma delas é a studio que, acionada, ativa o ambiente de desenvolvimento. Na primeira vez que se entra no studio, o Caché pede o nome do usuário e a senha. Preenchendo o usuário com "Admin" e a senha "SYS", o studio abrirá a tela abaixo, que é o principal ambiente de 
trabalho do Caché, onde se podem criar classes com os seus atributos e métodos, e também programas em CSP (note-se o cubo mágico no ícone mais à esquerda, na barra de tarefas).

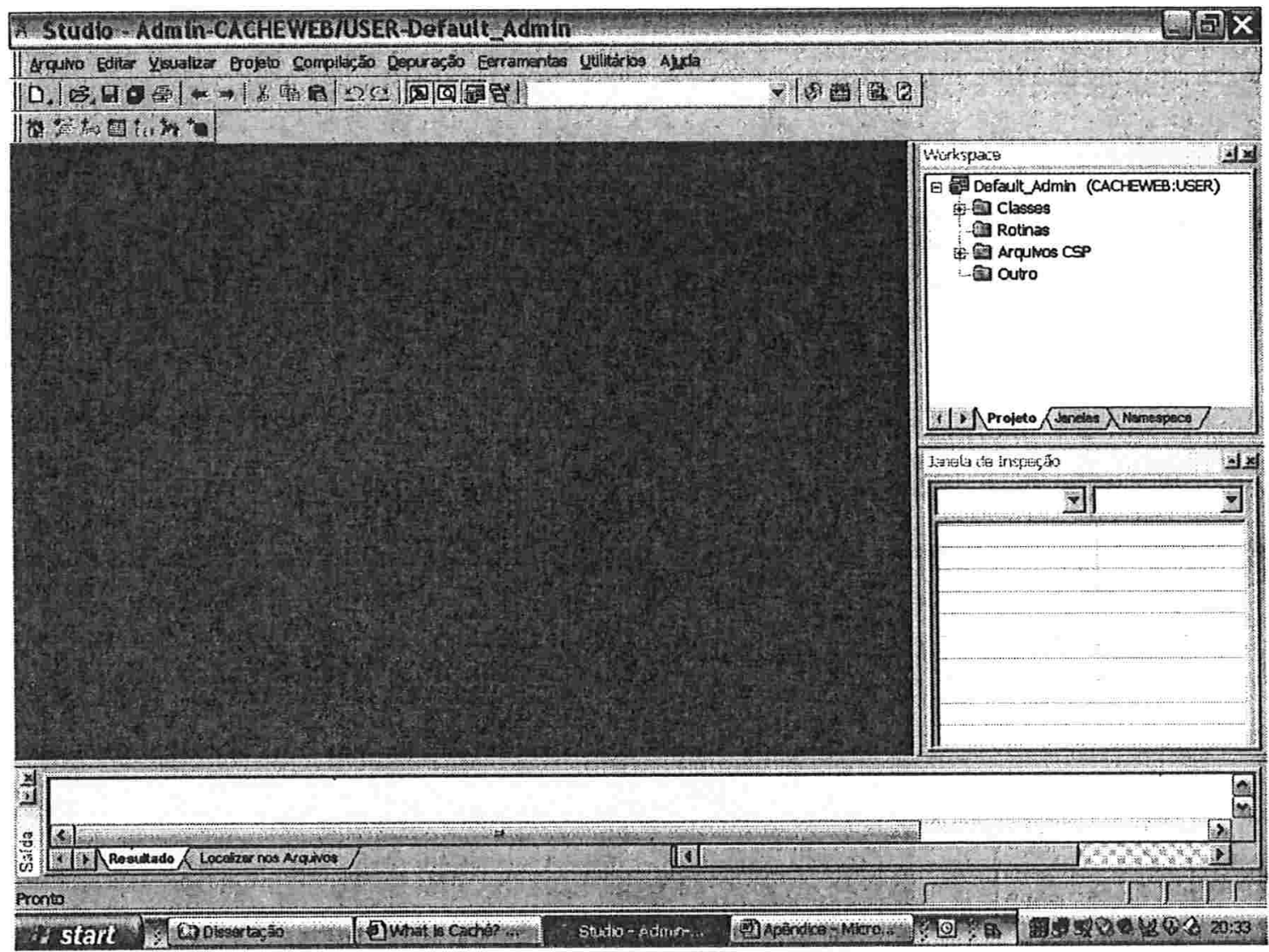

Vamos criar algumas classes como exemplo. Com o botão direito do mouse ative a área de trabalho "Classes" e em seguida selecione "Criar nova classe". Aparece uma janela com o assistente de criação de uma nova classe. Aparecem duas caixas; a primeira com um "Nome de pacote" (um pacote - é um agrupamento de classes, o que permite organizar projetos, cada um com seu grupo de classes), pré-definido como "Teste". Vamos deixar esse nome como está. Na segunda caixa, "Nome da Classe" vamos digitar "CVendedor" e acionar "Next". Na página que aparece, selecione "Persistent" e "Next". Não preencha nada nesta nova página e acione "Finish". A classe está criada como uma classe vazia. Vamos agora criar atributos para esta classe, chamados no Caché de "Propriedades". 
Acione na faixa das ferramentas (que na figura acima está na $4^{\mathrm{a}}$ linha) o ícone com uma casinha (com indicação Nova propriedade). Será aberto um assistente de nova propriedade. Vamos dar a esse novo atributo o nome Nome, preenchendo o campo Nome, que é obrigatório. Acione em seguida Next. Selecione o tipo \%String (que é o tipo padrão) e acione Next. Na nova página do assistente, seleciona "Obrigatória" (significando que o valor do atributo não pode ser vazio) e acione "Next". Aparecerão os parâmetros dessa propriedade. Vamos manter do jeito que está e terminar com Finish, encerrando a definição desse primeiro atributo daquela classe.

Vamos criar outra propriedade, de nome "Comissao" como tipo "Float" com os procedimentos análogos aos anteriores; do mesmo modo, podem ser criados outros atributros.

Depois de definidos todos os atributos de uma classe, ela deve ser compilada, acionando-se o $3^{\circ}$ ícone da esquerda na $3^{\mathrm{a}}$ linha da figura acima (o $4^{\circ}$ ícone provoca a compilação de todas as classes).

Em seguida, criamos outra classe chamada "CCliente": Os procedimentos de criar essa classe e suas propriedades são as mesmas.

Vamos mostrar como criar uma propriedade do tipo classe, como "Vendedor" do tipo "CVendedor". Para isso, criamos a propriedade "Vendedor"; na hora de selecionar o tipo, acione o button "Procurar...". O studio abrirá uma janelinha chamada "Seleção de Tipo". No final da caixa de seleção há um grupo de tipo "Persistent". Abra esse grupo e em seguida o subgrupo "Teste", aparecendo o tipo já compilado "CVendedor" (se este não tiver sido compilado, não vai aparecer no subgrupo. Selecione-o e acione OK. Na caixa de entrada a primeira linha mostra "Um valor único do tipo de" seguido da caixa com o texto "CVendedor". Se quiséssemos uma coleção de valores (atributo multivalorado), usaríamos o button Procurar na $2^{\text {a }}$ linha). Acionar "Finish". A tela do studio fica como a figura seguinte. Note a exibição do grupo Teste contendo as classes CCliente e CVendedor. 


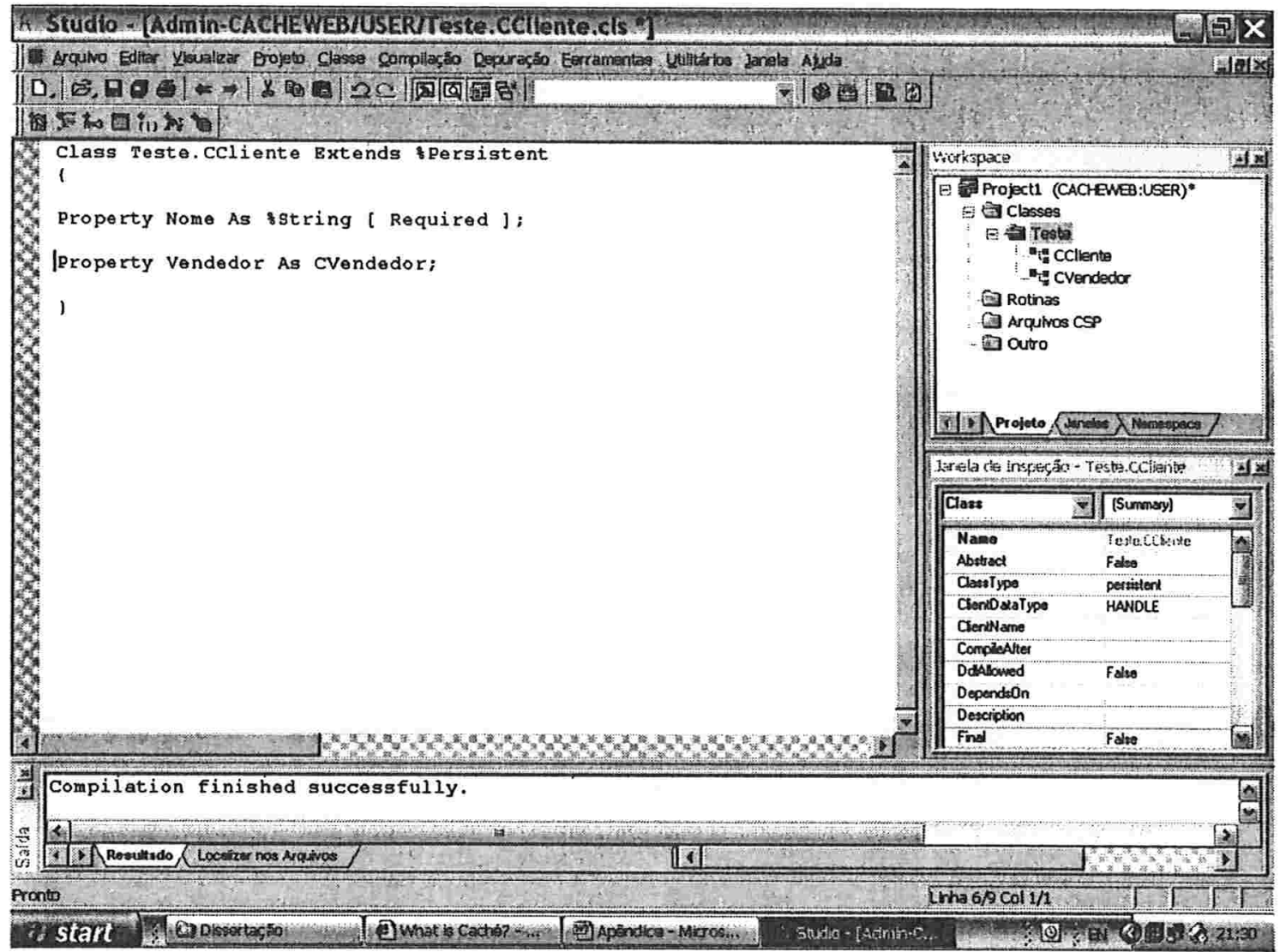

Compile também esta classe CVendedor, bastando para isso acionar o ícone de compilação (o melhor é definir primeiro todas as classes e compilá-las em conjunto, pois assim não se esquece de compilar alguma).

Para cada linguagem o Caché tem documentações e manuais de desenvolvimento, muito bem explicados com exemplos. 


\section{Bibliografia}

[ATK 89] Atkinson, M. et al. The Object-Oriented Database System Manifesto. Proceedings of the First International Conference on Deductive and Object Oriented Databases, Kyoto, Japan. Jan/1989.

[BAN 92] Bancilhon, E. Understanding Object-Oriented Database Systems. O2 Technology Technical Report No. 5, 1992.

[BER 91] Bertino, E. e L. Martino. Object-Oriented Database Management Systems: Concepts and Issues. IEEE Computer, Apr. 1991, pp 206-221

[BRE 89] Bretl, R. et al. The GemStone Data Management System. Gemstone, USA, 1989.

[BUT 91] Butterworth, P.et al. The GemStone Object Database management System. Communications of the ACM, 34(10),pp.64-77USA, out/1991,

[CAC 04] Intersystems Caché Database Online Documentation. Intersystems Corp., 2004. Disponível em www.intersystems.com.

[CHE 76] Chen, P. The Entity-Relationship Model-Toward a Unified View of Data, ACM Transactions on Database Systems, 1(1), mar/1976, pp. 9-36

[COD 70] Codd, E. A Relational Model of Data for Large Shared Data Banks. Comunications of the ACM, 13(6), Jun 1970, pp. 377-387.

[COD 79] Codd, E. Extending the Database Relational Model to Capture More Meaning, ACM Transactions on Database Systems, 4(4) Dec. 1979, pp. 397-434.

[COR 01] Cormen, T., C. Leiserson, R. Rivest e C. Stein. Algoritmos 2a. Ed. S.Paulo, 2001.

[ELM 94] Elmasri, R. e S. Navathe. Fundamentals of Database Systems, 2a. Ed. Benjamming/Cummings, 1994.

[FON 05] Fastobjects.NET Technical Documentation. Fastobjects, Germany, 2005 Disponível em www.fastobjects.com

[HUG 91] Hughes, J. Object-Oriented Databases. Prentice Hall, 1991.

[KHO 93] Koshafian, S. Object Oriented Databases. Ed. John Wiley \& Sons, 362 pp. 1993.

[KIM 90] Kim, W. Introduction to Object-Oriented Databases. Cambridge: MIT Press, 1990.

[KIR 03] Kirsten, W. Object-Oriented Application Development. Frankfurt 2nd ed. Springer, 2003

[LIN 05] Linares Fo., . Análise de Requisitos de Software Baseada em Modelagem Conceitual de Dados e Protótipos. Dissertação de Mestrado. São Paulo: Instituto de Pesquisas Tecnológicas, 2005. 
[MCC 04] McConnell, S. Code Complete. 2nd edition. Seattle: Microsoft, 2004.

[NAS 97] Nassu, E.A. e V.W. Setzer. Bancos de Dados Orientados a Objetos. São Paulo: E. Blücher, 1997.

[PAG 95] Page J. What Every Programmer Should Know About Object-Oriented Design, Dorset House Publishing, USA, 1995.

[POS 02] The PostgreSQL Development Group. PostgreSQL 8.0 Beta5 Documentation. 2004 - www.postgre.com

[RAM 02] Ramakrishnan, R. e J. Gehrke, Database Management Systems. 3rd ed. Medison, USA: McGraw Hill, 2002.

[SET 05] Setzer V.W. e F. Soares. Banco de Dados; o que são, melhore seu conhecimento, construa os seus. São Paulo: E. Blücher, 2005.

[SIL 90] Silva D. Programação por Objetos: Conceitos, Linguagens e uma Experiência, Dissertação de Mestrado, IME-USP, 1990.

[TAK 90] Takahashi, T., Liesenberg, H. e Xavier,D. Programação Orientada a Objetos, , São Paulo: II Escola de Computação, jul/1990. 